NISTIR 7548

\title{
Selected Impacts of Documentary Standards Supported by NIST 2008 Edition
}



NISTIR 7548

\title{
Selected Impacts of Documentary Standards Supported by NIST 2008 Edition
}

\author{
Erik Puskar \\ Standards Coordination and Conformity Group \\ Standards Services Division \\ Technology Services
}

\begin{abstract}
National Institute of Standards and Technology
Gaithersburg, MD 20899
\end{abstract}

January 2009

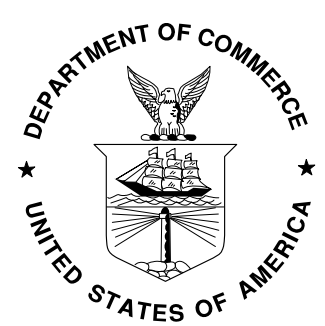

U.S. DEPARTMENT OF COMMERCE

Carlos M. Gutierrez, Secretary

NATIONAL INSTITUTE OF STANDARDS AND TECHNOLOGY

Patrick Gallagher, Acting Deputy Director 



\section{Table of Contents}

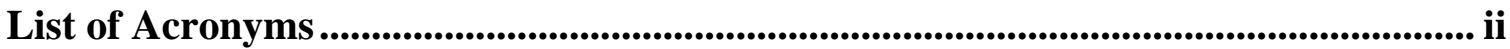

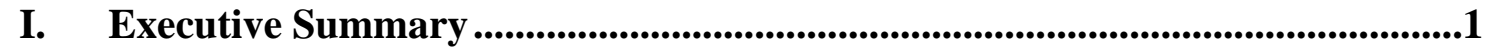

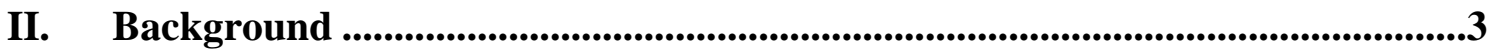

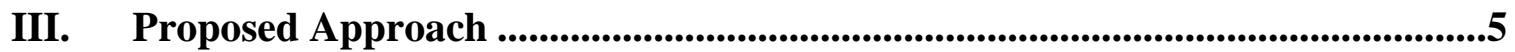

IV. Report Methodology ...........................................................................................8

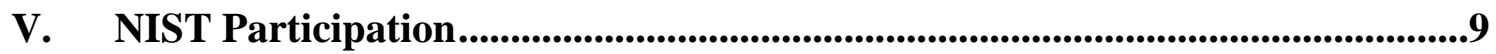

VI. Findings...................................................................................................................11

VII. Reported Outcomes ...........................................................................................14

VIII. 16 CFR Part 1633 Standard for the Flammability (Open Flame) of Mattress

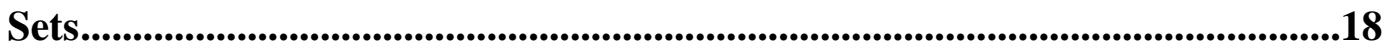

IX. Development of Radiation Detector Standards for Homeland Security

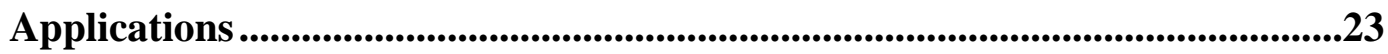

X. Materials Declaration Standards to Support Environmental Regs .................29

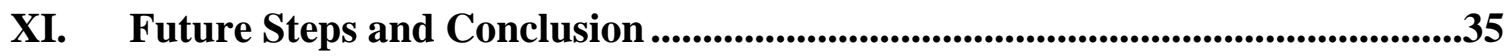

Table of Figures:

Figure 1 NIST Technology Services Created an Approach to Evaluating Stds.......1

Figure 2 NIST Involvement in Standards Development .............................................3

Figure 3 Strategic Assessment Development Process ...................................................5

Figure 4 Breakdown of Standards Participation by Org. Type ..............................14

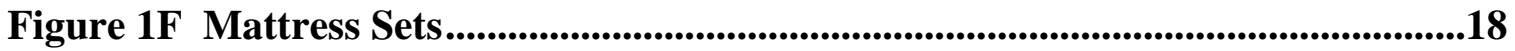

Figure 2F Burning Bed at One and a Half Minutes .................................................21

Figure 1R NIST Technical Leadership Contributes..........................................................24

Figure 2R Cargo Screening Equipment Installed at an Airport .................................25

Figure 3R Handheld Radiation Detectors ..............................................................27

Figure 1M NIST has Positive Impact on Standards Development................................30

Figure 2M IPC 1752 Tool Screen Shot Showing Class 1 \& 2 Declarations.................33

List of Tables:

Table 1 NIST Participation in Standards Committees by OU .................................10

Table 2 Sample Overview of Impacts Derived from NIST ......................................11

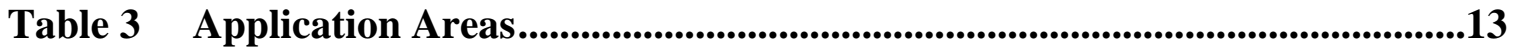

Table 4 Description of Intermediate Outcome Metrics.............................................14

Table 5 Canvassing Results..........................................................................................................37

Table 1R IEEE's Radiation Detection Standards..............................................................26 


\section{List of Acronyms}

ACI American Concrete Institute

ANSI

American National Standards Institute

ASHRAE

American Society of Heating, Refrigerating and Air-Conditioning

Engineers

ASME American Society for Mechanical Engineers

ASTM

ASTM International, formerly American Society for Testing \& Materials

CIE International Commission on Illumination

CIPM International Committee for Weights and Measures

CISPR The International Special Committee on Radio Interference

CLSI The Clinical and Laboratory Standards Institute

DHS Department of Homeland Security

DNDO Domestic Nuclear Detection Office

DOE Department of Energy

FIPS Federal Information Processing Standard

GRaDER Graduated Rad/Nuc Detector Evaluation and Reporting Program

HITSP Health Information Technology Standards Panel

HL7 Health Level 7

HIS Homeland Security Instrumentation

IEC International Electrotechnical Commission

IEEE Institute of Electronic and Electrical and Electronics Engineers

IESNA Illuminating Engineering Society of North America

IETF Internet Engineering Task Force

IFSTA International Fire Service Training Association

ILO International Labour Organization

INCITS International Committee for Information Technology Standards

iNEMI The International Electronics Manufacturing Initiative

IPC formerly Institute of Interconnecting and Packaging Electronic Circuits

IT Information Technology

ISO International Organization for Standardization 
ITU International Telecommunication Union

JTC1 ISO Joint Technical Committee 1 (Information Technology Standards)

NEMA National Electronics Manufacturers Association

NFPA National Fire Protection Association

NIJ National Institute of Justice

NIST National Institute of Standards and Technology

NVLAP National Voluntary Laboratory Accreditation Program

OAG Open Applications Group

OASIS Organization for the Advancement of Structured Information Standards.

OIML International Organization for Legal Metrology

OMG Object Management Group

RM Radioactivity Measurements

SAE SAE International, formerly Society of Automotive Engineers

SCP Standards Committee Participation Database

SI International System of Units

SSL Solid State Lighting

STEP Standard for the Exchange of Product Model Data

TIA Telecommunications Industry Association

UL Underwriters Laboratories Inc.

VESA Video Electronics Standards Association

W3C World Wide Web Consortium 


\section{Executive Summary}

This report is intended to reflect NIST's success in meeting its mission, executive guidance, and legislative requirements for developing standards and reporting on the effect of those standards on the manufacturing and service sectors. The survey and study also support a NIST strategic priority to foster more efficient transactions in the domestic and global marketplace through development and use of effective standards by manufacturing and service sectors.

Figure 1 offers an overview of the reasons why evaluating NIST involvement in standards development makes sense and summarizes the approach towards identifying benefits accrued from NIST involvement in standards development.

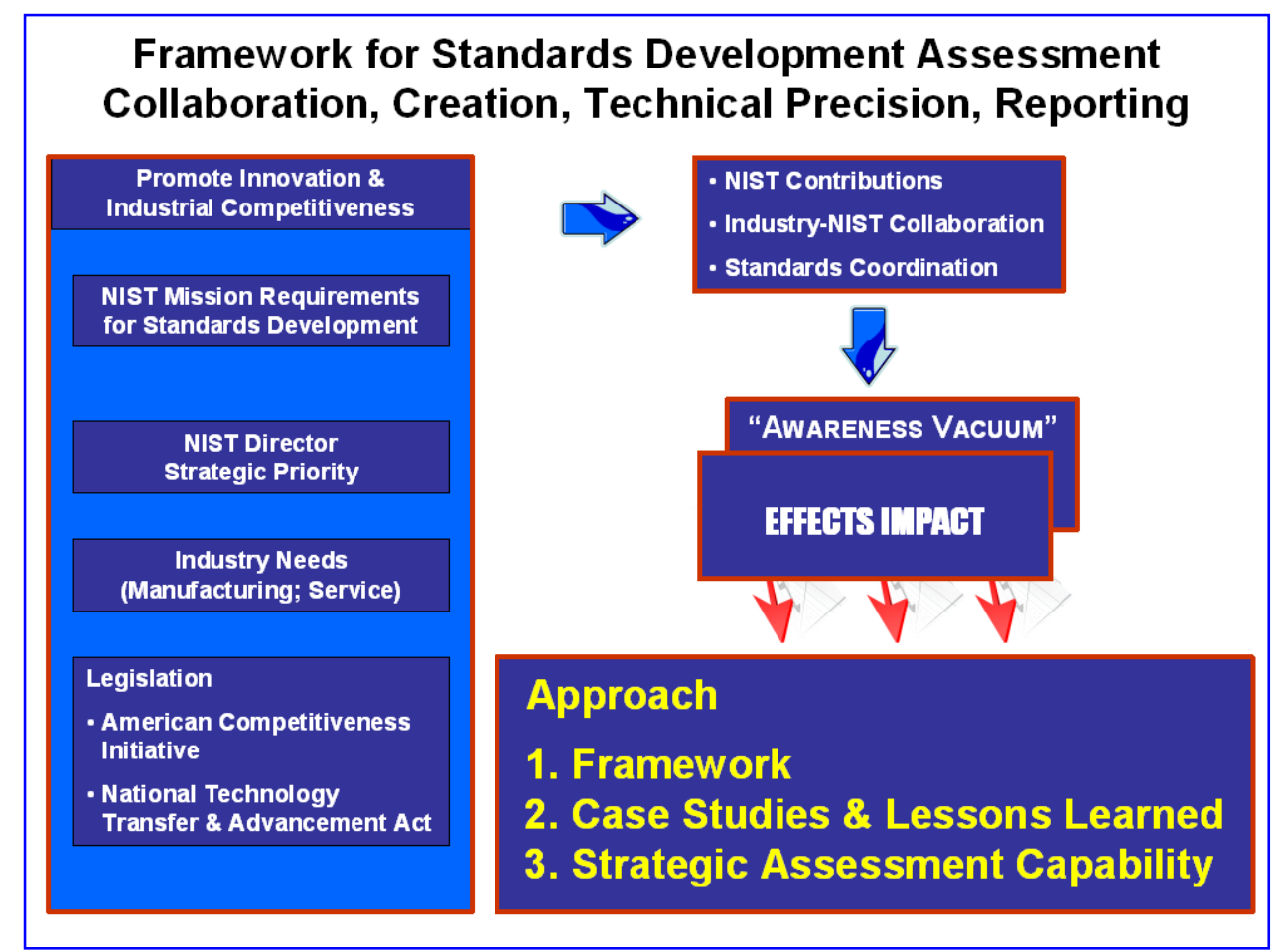

Figure 1: NIST Technology Services Created An Approach to Evaluating Standards Development Impact Based on Policy And NIST Actions

Technology Services canvassed a number of NIST operating units that were involved in recent standards development, obtaining results from 53 of 78 projects. The responses offered some interesting observations and led to a number of implications for NIST involvement in standards development.

The benefits from NIST involvement included producing standards faster than would have been the case without NIST; creating specific improvements to products and services; and developing broader standards. Figure 2 offers highlights of the results. Some specific implications are: 
- On average, for every full-time-equivalent of NIST staff working on one of the high impact standards, almost 12 times that amount of non-NIST staff (primarily industry) were supporting the project. This suggests that NIST leverages valuable industry labor, and is indicative of the lower bound estimate of the social benefits of standards development activities.

- NIST participation led to standards produced 1.65 years earlier on average. It is a gross indicator of the transaction time savings that NIST involvement in a voluntary standards development effort affords industry.

- Standards in many cases would have been narrower without NIST involvement. This is a gross indicator of an increase in the number of newly available products or services enabled by the standard in question. Combined with time saving due to NIST's participation, the increase in scope scales up the economic benefits that flow from NIST's participation in voluntary standards development efforts. ${ }^{1}$

- Of 53 projects, $62 \%$ had involvement from industry groups or consortia in developing the standard. This percentage indicates strong industry support and, ultimately, significant economic impact.

- Forty-two (42) percent of respondents stated that the standard resulted in having a product or service available, or available at a lower cost, or more broadly, or in different qualities, or earlier that would not be in the absence of the standard. In addition, many of the other respondents, who did not specifically claim new products or services, did claim broader societal benefits, such as: trade facilitation, increased homeland security, interoperability benefits, etc.

- A large majority (85 percent) of the projects resulted in professional publications, including journal articles, conference proceedings and presentations, NIST publications, magazine articles and other reports. These publications are a noneconomic indicator of the secondary output of NIST's engagement.

- Of those 23 projects which reported claims that the standard has had an impact on actual products and services, there is a higher ratio of non-NIST participants to NIST staff (15.3 v 11.8). This indicates a higher rate of external (likely industry) participation.

Taken together, it is clear that many of these NIST standards projects leveraged the work of non-NIST participants to develop high impact standards which were developed faster and resulted in product and service improvements and general benefits to the country. If we look at the subsets, industry involvement is, as expected, associated with a larger percentage of new or improved products/services. No attempt has been made yet to put an economic value on the resulting goods and services or the faster development time. 


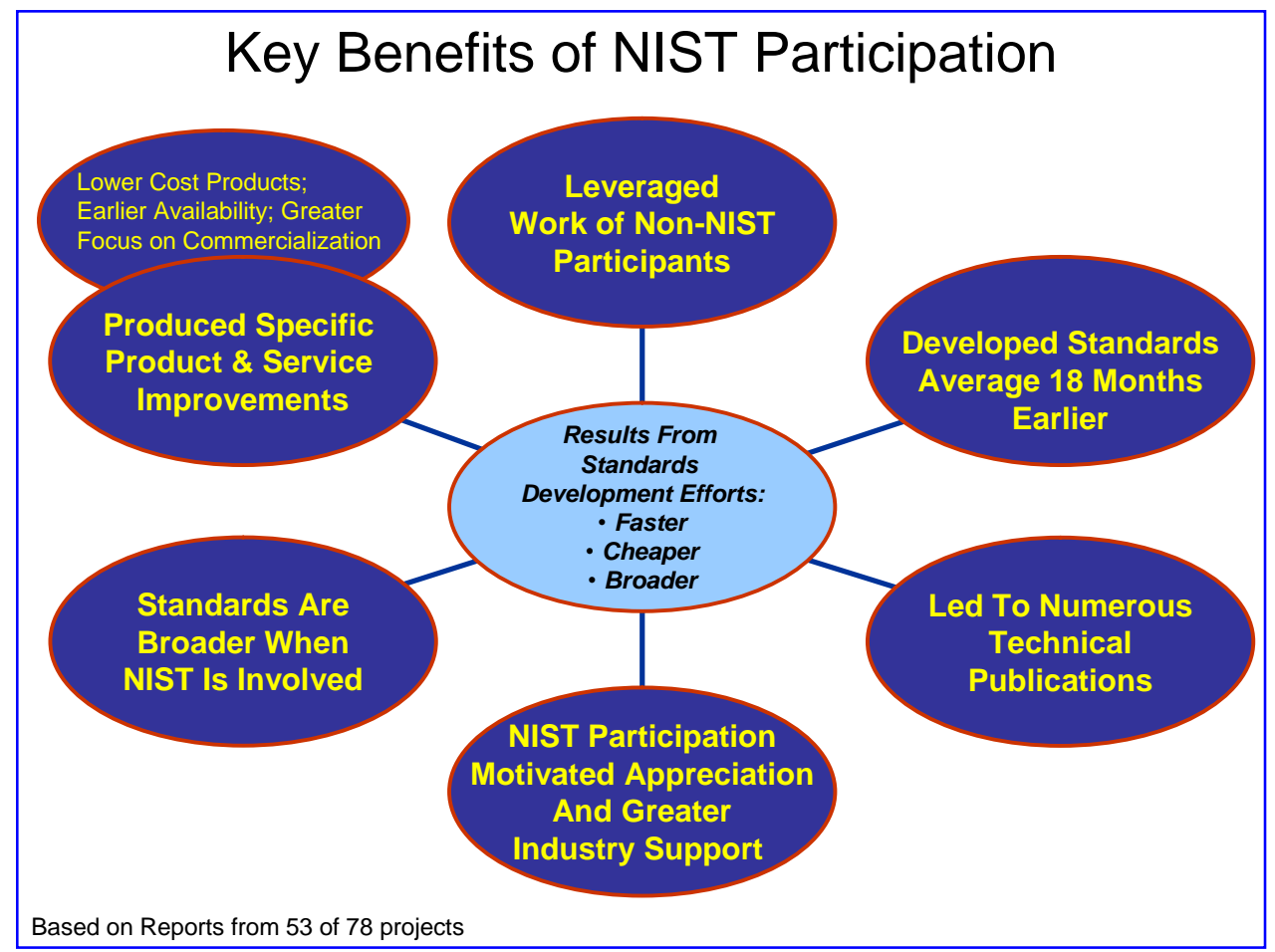

Figure 2: NIST Involvement In Standards Development Generates A Range of Benefits for Industry

NIST involvement in voluntary standards development efforts need not result in new products or services to generate significant economic impacts. The only basic requirement is that NIST bring valuable resources to a process that contributes value to the marketplace of producers and consumers. Where new products and services are available, additional benefit streams will have been induced. Where NIST contributes uniquely to the flow of those benefits, the returns to the investment of NIST's resources will be higher yet. ${ }^{2}$

\section{Background}

The mission of the National Institute of Standards and Technology (NIST) is to promote U.S. innovation and industrial competitiveness. One of NIST's core competencies is the development and use of standards. During late 2007, Technology Services (TS) canvassed other NIST Operating Units (OUs) to answer the question: How well is NIST doing in this area? The OUs were specifically asked about instances where NIST has played an active role in the development or implementation of documentary standards that:

(1) have been broadly adopted, or

(2) have produced, or are expected to produce, significant economic or societal benefits. 
This study reports on the results of the survey. ${ }^{1}$ The report is intended to reflect NIST's success in meeting its mission, executive guidance, and legislative requirements for developing standards and reporting on the effect of those standards on the manufacturing and service sectors. The survey and study also support one of the NIST Director's strategic priorities: to foster more efficient transactions in the domestic and global marketplace through development and use of effective standards by manufacturing and service sectors.

NIST has a long tradition of standards development. The Administration's American Competitiveness Initiative of 2006, for example, highlights NIST's role in supporting the development of standards used by the public and private sectors. NIST participation includes:

- carrying out research that provides the technical underpinning for standards;

- participating in standards development activities in a broad range of technical areas;

- providing technical information related to standards;

- participating extensively in international industrial consortia; and

- in some cases, providing calibrations and standard reference materials (SRMs) called for in the standards.

Congress has given NIST additional standards-related responsibilities in several specific areas of current national interest, including: IT security, biometrics and voting. In particular, under the National Technology Transfer and Advancement Act (NTTAA) of 1996, Congress has charged NIST to coordinate standards activities among Federal agencies and with State and local governments for the purpose of promoting participation in private sector voluntary standards activities and making greater use of available voluntary standards rather than relying or depending on developing in-house standards.

Our objective is to have a capability that provides 1) a comprehensive picture of NIST's documentary standards development activities and 2) the ability to assess their impact. There are many choices of standards venues with which to participate. NIST's participation is broad, but selective. Our ultimate goal is to be able to provide advice to the stakeholder community inside and outside NIST on the best use of the resources dedicated to documentary standards development.

One of NIST's strategic priorities is to develop and encourage the use of effective standards by the manufacturing and service sectors. There is ample evidence that standards foster, and indeed are integral to, economic growth and development, and that the role of standards-related activities is increasingly important to international competitiveness in technology-based markets. Conceptually, we understand the role of all these infratechnologies in the design, development, production, and marketing of products and services. ${ }^{3}$ NIST has an important role in supporting the development, diffusion, and impact of physical standards and measurement technologies.

\footnotetext{
${ }^{1}$ This is a follow-up study to NISTIR 7398 "Selected Impacts of Documentary Standards Supported by NIST" and part of a broader Technology Services (TS) effort to assess the impact of documentary standards on global competitiveness and innovation.
} 
There are grounds for asserting that documentary standards are an important factor in reducing risks and transactions costs in product and service markets. Recent studies, as well, indicate that documentary standards are correlated with indicators of economic growth at the macroeconomic level. ${ }^{4}$ However, public and private organizations in the United States and globally lack a well-developed understanding of the role, nature and impact of documentary standards. ${ }^{5}$ This unawareness complicates NIST's ability to inform its own leadership and other stakeholders of the best ways to manage this critical responsibility.

Several people supported the work reflected in this report, with special credit to David Leech $^{6}$ for work on success stories and impact analysis guidance, and Joanne Henson, ${ }^{7}$ who assisted with the early data analysis.

\section{Proposed Approach}

This report highlights NIST's effort to fill this "awareness vacuum" by providing a strategic assessment of the role and impact of NIST's documentary standards efforts. The initial canvassing study identified 55 high impact standards projects and described some of their characteristics ${ }^{8}$ Figure 3 describes the three stages of Technology Services' proposed approach. ${ }^{9}$

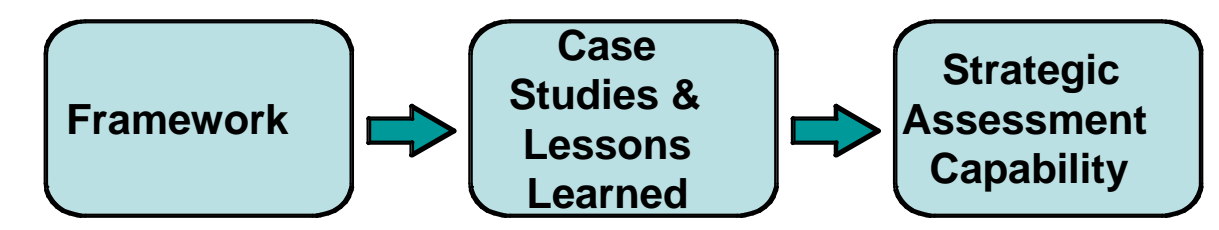

Figure 3. Strategic Assessment Development Process

Technology Services' canvassing efforts are part of the first stage of this process. The near-term goal is to describe NIST's documentary standards activities and to begin the iterative process of constructing a conceptual framework for talking about, communicating, and exploring the nature and impact of these efforts. This includes questions such as the following:

- What "kinds" of documentary standards can we distinguish in the information we have gathered?

- What is the extent of NIST"s participation in the various "kinds" of documentary standards development efforts?

- What other types of organizations are involved in the development of 
documentary standards?

- What is the extent of other organizations' involvement?

- Over and above the formal distinctions between types of standards activities, do NIST's activities cluster along dimensions that might make them distinguishable in terms of high, medium, and low potential impact?

- Are they distinguishable in terms of underlying technologies, or industries served, or in terms of their national or international scope?

- What are the obvious, near-term consequences (outcomes) of these efforts?

As a conceptual framework for NIST's documentary standards activity begins to emerge, it will be compared with, and possibly integrated with, other more general, frameworks that that have been developed to describe NIST's overall role in the nation's (indeed, the world's) technical measurement and economic systems. ${ }^{10}$ Integrating NIST's documentary standards activities into these more general frameworks is important in the transition to the second, case studies \& lessons learned, step in our approach.

In the case studies \& lessons learned step we will ask a different set of questions than asked in the first step. How do we understand the impact of NIST's documentary standards development activity? The two obvious answers - technical impact and economic impact - are related, but it is often harder to discern economic impact. During the second step of the proposed process, the relationships among the components (variables) of our emerging framework are hypothesized and associated with outcomes. Case studies are designed to test these associations. ${ }^{11}$

The broad outlines of this phase are already in view, thanks to the past and ongoing efforts of NIST's economic assessment community. A host of retrospective and prospective case-based economic impact assessments have been conducted. ${ }^{12}$ On the basis of these and related efforts, we can formulate a conservative model for understanding the social benefits of NIST's interaction with voluntary standards organizations. A company invests resources in voluntary standards development activities (often in the form of in-kind labor time contributions) up to the point where the expected value of additional resources invested (for example, another hour of in-kind labor time) equals the present discounted value (or present value) of the additional expected benefits (from the additional investment) to the company. Investment up to the point where the marginal benefit for the company equals its marginal cost will maximize the net present value of its investment. ${ }^{13}$ The present value of the company's investments will thus be a lower bound on the expected present value of the company's benefits from those investments. Moreover, the sum of the discounted individual company benefits would be a lower bound estimate of the expected social benefits of the voluntary standards development process because some of the benefits will spill over to other companies and to consumers. It is reasonable to postulate that these social benefits will be higher where NIST provides specialized cost-effective resources to the voluntary standards development process.

Candidate impact studies are already emerging from the canvassing process ( 78 high impact standards identified) as participants describe 1) their level of involvement, 2) the 
identity of private and other public sector participants and their level of involvement, 3) the outputs from these activities, and 4) an estimate of any change in scope or timing of the documentary standards activity due to NIST's involvement. In the future as case study impact assessments are selected and performed, a thorough understanding of the nature of NIST's activities will begin to emerge and our understanding of how, and under what circumstances, significant economic impacts come to fruition. Accumulations of these case-based explanations are valuable as internal "lessons learned." They are also valuable as a potent means of communicating NIST's role to stakeholders about NIST's important contributions to the nation's national innovation system.

Over time, as we accumulate knowledge of high impact activities and those of lesser impact, and we clarify the circumstances in which these outcomes transpire, we will move into step three of our strategic assessment development process. We will begin to:

- formulate, test, and periodically verify the types of activities NIST does best;

- offer advice about where documentary standards resources should be focused for greatest impact; and

- identify NIST's optimal role in these activities.

We will begin to answer the following types of questions:

- What can be done to create more effective and efficient standards development processes?

- Where is NIST concentrating its efforts today?

- Where should NIST be concentrating for the future?

- On what basis is such a strategy established? Is the nature of documentary standards development changing?

- Is the pace of these developments changing?

- Is NIST facilitating strategic change?

- Are these changes productive?

In time, we envision that our efforts at developing, testing, and improving strategic assessment criteria will evolve into an ongoing "indicators" approach that will allow managers to "take the pulse" of ongoing documentary standards activities. For example, it could turn out that when NIST personnel from multiple operating units are engaged in creating a cluster of related standards, those standards tend to have greater impact individually and collectively. Or, it could be that when the ratio of industry participants to NIST participants is exceptionally high, the resulting standards tend to have high impact. To the extent that such factors can be confidently demonstrated to "lead" the emergence of high impact documentary standards activities, they could be construed as "leading indicators" of effective standards activities and, more importantly, serve as guidelines for future activities.

In summary, Technology Services has launched a long-term effort to assess the extent, nature, and outcomes of NIST's involvement in documentary standards development activities. The initial and on-going canvassing activities (this paper) are part of a threestep approach to thoroughly understand NIST's role in these activities and the impact. 
The long-term goal is to develop an assessment capability and integrate it into NIST's planning, evaluation, and resource allocation cycle. The ultimate objective is to improve the standards development process to help promote U.S. innovation and industrial competitiveness.

\section{Report Methodology}

The data in Table 1 were used to direct the search for specific standards development activities where NIST's participation might have produced significant, positive impacts. Emphasis was placed on identifying standards efforts that were fairly recent and that resulted in (or were expected to result in) either broad adoption of the standard or significant economic or social impact. The intent was to limit the collection of information to a handful of successful documentary standards efforts and to use this information as a basis for choosing activities to be the subject of future retrospective case studies.

The results from the first canvassing study (NISTIR 7398) were sent to all NIST OU's in late 2007 requesting updates to the initial set of 55 projects or additions to the original list. In addition, the following "potential impact" questions were included:

\section{Participation}

1. Estimate the number of hours (of NIST personnel) dedicated to the development of a given standard.

2. Estimate the multiple of total NIST hours that non-NIST participants dedicated to the development of this documentary standard.

3. Were any industry consortia involved in the development of this standard?

\section{Output}

4. In the absence of NIST's participation in the development of this documentary standard, would the scope of the resulting standard be broader, narrower, or about the same? Is there any evidence you could cite to support this claim?

5. Did NIST personnel publish any professional papers as a result of their participation in the development of this documentary standard?

$\underline{\text { Effect }}$

6. If everything about this documentary standard development effort remained the same except for NIST participation, estimate when the standard would have been published.

7. What products or services are available, or available at a lower cost, or available more broadly, or available in different qualities, or available earlier that would not be available in the absence of this standard?

After reviewing the results, more in-depth information was sought on three projects where the impact rationale was well articulated and plausible and where it was judged that a short "success story" would be relatively easy to develop. The success stories are 
also referred to as "descriptive case studies" which examine what happened, describe the context in which it happened, explore how and why, and. consider what would have happened otherwise. Thus case study can be particularly useful in the exploratory phases of a program such as this effort by Technology Services. ${ }^{14}$ We contacted pertinent staff and stakeholders to gather additional information or clarify results by asking follow-up questions and discussing results. The success stories help to fill the "awareness vacuum" by providing a more detailed look at the need for a new standard, the research that was required, NIST's specific role and contributions, and the resulting success, including a description of the impact. These are presented in section VI.

\section{NIST Participation}

In understanding NIST's commitment to the development of high quality standards, it is useful to know where and how many NIST staff members participate in the activities of key standards development organizations (SDOs). Staff participate on committees where their technical competence matches committee needs and where they can ensure that US. national interests are represented. NIST's commitment of resources to the development of documentary standards is substantial. The Standards Committee Participation (SCP) database, which attempts to capture all NIST participation in the committees of SDOs and consortia, shows over 400 NIST staff members involved in the development of documentary standards. Table 1 displays the number of NIST staff members, organized by NIST OU, participating in the standards activities of the listed SDOs as of August 2008. 


\section{Table 1. NIST Participation in Standards Committees by OU}

\begin{tabular}{|c|c|c|c|c|}
\hline $\mathbf{O U}$ & $\begin{array}{l}\text { No. of Staff } \\
\text { Members }\end{array}$ & $\begin{array}{l}\text { Committee } \\
\text { Memberships }\end{array}$ & \begin{tabular}{|l} 
No. SDOs \\
\end{tabular} & $\begin{array}{l}\text { Top SDO's (\# } \\
\text { membership) }\end{array}$ \\
\hline $\begin{array}{l}\text { Office of the } \\
\text { Director }\end{array}$ & 7 & 10 & 5 & $\begin{array}{l}\text { HPS (4) } \\
\text { ASTM (3) } \\
\text { ANSI (1) }\end{array}$ \\
\hline $\begin{array}{l}\text { Technology } \\
\text { Services }\end{array}$ & 32 & 195 & 21 & $\begin{array}{l}\text { OIML (51) } \\
\text { ASTM (43) } \\
\text { ANSI (25) }\end{array}$ \\
\hline $\begin{array}{l}\text { Technology } \\
\text { Innovation } \\
\text { Program }\end{array}$ & 2 & 2 & 2 & $\begin{array}{l}\text { ASTM(1) } \\
\text { OLA (1) }\end{array}$ \\
\hline $\begin{array}{l}\text { Center for Neutron } \\
\text { Research }\end{array}$ & 4 & 13 & 3 & $\begin{array}{l}\text { ANS (8) } \\
\text { ISO (4) }\end{array}$ \\
\hline $\begin{array}{l}\text { Center for } \\
\text { Nanoscale Science } \\
\text { and Technology }\end{array}$ & 2 & 7 & 4 & $\begin{array}{l}\text { ISO (3) } \\
\text { ASME (2) }\end{array}$ \\
\hline $\begin{array}{l}\text { Electronics and } \\
\text { Electrical } \\
\text { Engineering } \\
\text { Laboratory }\end{array}$ & 47 & 145 & 19 & 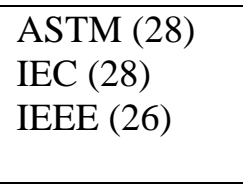 \\
\hline $\begin{array}{l}\text { Manufacturing } \\
\text { Engineering } \\
\text { Laboratory }\end{array}$ & 52 & 185 & 28 & $\begin{array}{l}\text { ASME (43) } \\
\text { ISO (26) } \\
\text { ASA (16) }\end{array}$ \\
\hline $\begin{array}{l}\text { Chemical Science } \\
\text { and Technology } \\
\text { Laboratory }\end{array}$ & 65 & 189 & 30 & $\begin{array}{l}\text { ASTM (89) } \\
\text { CIPM (15) } \\
\text { ISO (15) }\end{array}$ \\
\hline $\begin{array}{l}\text { Physics } \\
\text { Laboratory }\end{array}$ & 45 & 201 & 26 & $\begin{array}{l}\text { ASTM (48) } \\
\text { IEEE (28) } \\
\text { CIPM (23) } \\
\text { CIE (23) }\end{array}$ \\
\hline $\begin{array}{l}\text { Materials Science } \\
\text { and Engineering } \\
\text { Laboratory }\end{array}$ & 33 & 128 & 10 & $\begin{array}{l}\text { ASTM (87) } \\
\text { ISO (17) } \\
\text { ADA (13) }\end{array}$ \\
\hline $\begin{array}{l}\text { Building and Fire } \\
\text { Research } \\
\text { Laboratory }\end{array}$ & 49 & 177 & 18 & $\begin{array}{l}\text { ASTM (79) } \\
\text { NFPA (23) } \\
\text { ACI (22) }\end{array}$ \\
\hline $\begin{array}{l}\text { Information } \\
\text { Technology } \\
\text { Laboratory }\end{array}$ & 66 & 146 & 25 & $\begin{array}{l}\text { INCITS (35) } \\
\text { IETF (22) } \\
\text { NIST (14) }\end{array}$ \\
\hline Totals & 404 & 1398 & & \\
\hline
\end{tabular}

\footnotetext{
${ }^{2}$ ANSI is not an SDO, but coordinates the development and use of voluntary consensus standards in the United States and represents the needs and views of U.S. stakeholders in standardization forums around the globe. NIST staff chair or participate in a broad range of ANSI policy committee activities. In addition, some of the activities counted as "ANSI" activities reflect NIST staff participation in ANSI-accredited standards committees, which are administered by other SDOs.
} 
NIST provides technical leadership in standards development in a number of technology areas. NIST also works closely with industry to translate NIST research results into appropriate standards. A common theme of the standards efforts documented in Table 3 was NIST support for testing and other conformity assessment activities associated with the standards. Other NIST contributions included: conducting research that formed the basis of the standard; working cooperatively with industry to establish appropriate requirements; and developing applicable software.

\section{Findings}

The results of the canvassing identified 78 documentary standards efforts that are considered to have significant impact, or that are widely used and adopted. This is an increase of 23 projects (or 42\%) from the first canvassing study published in early 2007 . Table 2 contains a sample from each OU to illustrate the wide variety and the broad scope of the impacts and the resulting public benefits. It is important to note that the impact/benefits noted in the table were self-reported by the participants. In only a few cases were the impacts/benefits based on quantitative data or previous study results. The complete results are presented in Table 5, which due to its length is included at the end of the report.

\section{Table 2. Sample Overview of Impacts Derived from NIST -Supported Standards Efforts}

\begin{tabular}{|c|c|c|c|c|}
\hline $\mathrm{Lab}$ & Title & Description \& NIST Roles & Impact & SDO \\
\hline BFRL & Sustainable Building & $\begin{array}{l}\text { In developing its Building for } \\
\text { Environmental and Economic Sustainability } \\
\text { (BEES) tool, NIST applied standards for life } \\
\text { cycle assessment, life cycle costing, } \\
\text { multiattribute decision analysis, and } \\
\text { building element classification. Once BEES } \\
\text { was published, NIST wrote initial draft of } \\
\text { biobased product sustainability assessment } \\
\text { standard. }\end{array}$ & $\begin{array}{l}\text { - More than } 24,000 \text { users rely } \\
\text { on BEES software for } \\
\text { building products. } \\
\text { - BEES also being applied to } \\
\text { biobased products as } \\
\text { required by federal } \\
\text { regulation implementing } \\
\text { Section } 9002 \text { of the } 2002 \\
\text { Farm Bill }\end{array}$ & $\begin{array}{l}\text { ASTM SP } \\
\text { D7075 } \\
\text { (Evaluating } \\
\text { and Reporting } \\
\text { Environmental } \\
\text { Performance of } \\
\text { Biobased } \\
\text { Products), } \\
\text { ISO }\end{array}$ \\
\hline CSTL & $\begin{array}{l}\text { Alternative } \\
\text { Refrigerants }\end{array}$ & $\begin{array}{l}\text { NIST engaged in research that would allow } \\
\text { industry to make the switch to alternative } \\
\text { refrigerants in a timely and economic } \\
\text { fashion to meet the timetable imposed by the } \\
\text { Montreal Protocol of } 1987 \text { to develop } \\
\text { alternatives to CFCs. NIST researchers } \\
\text { developed the REFPROP database which } \\
\text { contains precompetitive properties data so } \\
\text { that industry could design their own } \\
\text { proprietary CFC alternatives. ISO has } \\
\text { incorporated this into their standard. }\end{array}$ & $\begin{array}{l}\text { - A comparison of industry } \\
\text { benefits with the funding } \\
\text { stream of NIST's research } \\
\text { program estimated a social } \\
\text { rate of return of at least } \\
433 \% \text { and a BC ratio of } 4 \text { to } \\
1 \text { (1998 study). }\end{array}$ & ISO (2004) \\
\hline
\end{tabular}




\begin{tabular}{|c|c|c|c|c|}
\hline EEEL & $\begin{array}{l}\text { Restriction of Certain } \\
\text { Hazardous Substances } \\
\text { in Electronic Products } \\
\text { (ROHS) }\end{array}$ & $\begin{array}{l}\text { NIST was instrumental in facilitating the } \\
\text { development of a Materials Declaration } \\
\text { Management standard (consisting of UML } \\
\text { model, XML schema and } 2 \text { interactive PDF } \\
\text { forms) necessary for U.S. companies to } \\
\text { show compliance with an EU directive, } \\
\text { which bans electrical products exceeding the } \\
\text { specified threshold amounts for } 6 \text { hazardous } \\
\text { substances used in electronics. }\end{array}$ & $\begin{array}{l}\text { - Any company that sells an } \\
\text { electrical product in EU } \\
\text { member nations after } \\
7 / 1 / 06 \text { must declare the } \\
\text { hazardous content } \\
\text { information. } \\
\text { - NIST work is assisting U.S. } \\
\text { industry to stay competitive } \\
\text { in Europe, and has } \\
\text { promoted information } \\
\text { exchange between large and } \\
\text { small firms. }\end{array}$ & $\begin{array}{l}\text { IPC (2006) } \\
\text { (also iNEMI) }\end{array}$ \\
\hline ITL & $\begin{array}{l}\text { Digital Encryption } \\
\text { Standard (DES) and } \\
\text { Advanced Encryption } \\
\text { Standard (AES) }\end{array}$ & $\begin{array}{l}\text { NIST developed DES standard to support } \\
\text { electronic transactions and implemented } \\
\text { conformance testing. In 1997, NIST } \\
\text { announced initiation of the effort to replace } \\
\text { DES with a new advanced encryption } \\
\text { module, which implements symmetric key } \\
\text { cryptography. Implemented as FIPS } \\
\text { standards in 2001. }\end{array}$ & $\begin{array}{l}\text { - DES was critical in } \\
\text { launching the commercial } \\
\text { encryption industry. } \\
\text { - Users realized significant } \\
\text { operational efficiencies } \\
\text { - DES was critical to rise of } \\
\text { electronic banking. } \\
\text { - Since introduction of AES, } \\
\text { approximately } 200 \text { AES } \\
\text { products have been } \\
\text { approved. }\end{array}$ & $\begin{array}{l}\text { FIPS } \\
46(1977) \\
46-3(1999) \\
197(2001)\end{array}$ \\
\hline MEL & $\begin{array}{l}\text { Quality Measurement } \\
\text { Data (QMD) }\end{array}$ & $\begin{array}{l}\text { The QMD spec is the work of the MEPT } \\
\text { Quality Measurement (MEQM) working } \\
\text { group of the Automotive Industry Action } \\
\text { Group (AIAG) Metrology Project Team } \\
\text { (MEPT). The goal of the MEQM has been } \\
\text { to produce a non-proprietary, computer- } \\
\text { readable, and widely implemented standard } \\
\text { for the interface between measurement } \\
\text { devices (not merely dimensional) and } \\
\text { Statistical Process Control (SPC) analysis } \\
\text { software packages. }\end{array}$ & $\begin{array}{l}\text { The QMD standard holds } \\
\text { promise to save statistical } \\
\text { process control (SPC) } \\
\text { software industry in the } \\
\text { U.S. alone around } \$ 50 \\
\text { million over the next few } \\
\text { years. This estimate is } \\
\text { based on verifiable data } \\
\text { from reliable sources. }\end{array}$ & AIAG \\
\hline MSEL & $\begin{array}{l}\text { Hardness } \\
\text { Standardization for } \\
\text { Metals }\end{array}$ & $\begin{array}{l}\text { NIST was instrumental in the research to } \\
\text { establish a traceability system for hardness } \\
\text { measurements, developing SRMs and is } \\
\text { refining test methods. NIST has most } \\
\text { accurate hardness machine in the U.S. }\end{array}$ & $\begin{array}{l}\text { - Huge impact on trade of } \\
\text { metals. Establishes national } \\
\text { chain of traceability to } \\
\text { fundamental SI units. } \\
\text { - Disputes between producers } \\
\text { and users curtailed. } \\
\text { - Information gained from } \\
\text { NIST's participation in the } \\
\text { CIPM has influenced } \\
\text { ASTM requirements. }\end{array}$ & $\begin{array}{l}\text { ASTM, ISO } \\
(1991-2007)\end{array}$ \\
\hline$\overline{\mathrm{PL}}$ & $\begin{array}{l}\text { Specifications for the } \\
\text { Chromaticity of Solid } \\
\text { State Lighting } \\
\text { Products }\end{array}$ & $\begin{array}{l}\text { NIST led the development of this standard } \\
\text { (ANSI C38.377), which is under final } \\
\text { approval. This standard specifies the white } \\
\text { light chromaticity ranges for solid state } \\
\text { lighting (SSL) products. This standard will } \\
\text { ensure that new lighting products using } \\
\text { LEDs will have high-quality white light and } \\
\text { appropriately classified according to color } \\
\text { temperature to allow smooth replacement of } \\
\text { traditional light sources or other SSL } \\
\text { products having similar color. }\end{array}$ & $\begin{array}{l}\text { - DOE is starting the Energy } \\
\text { Star program for SSL } \\
\text { products, which needs this } \\
\text { standard. } \\
\text { - All SSL products should be } \\
\text { designed to meet this } \\
\text { standard, and in turn, white } \\
\text { LEDs (used for the SSL } \\
\text { products) will also be } \\
\text { deigned and classified for } \\
\text { color according to this } \\
\text { standard. } \\
\text { - This standard will have } \\
\text { significant impact on both } \\
\text { white LED and SSL } \\
\text { industries. }\end{array}$ & ANSI \\
\hline
\end{tabular}


The cited projects cut across all laboratories and reflect diverse technical areas and applications. Based on an analysis of these projects, eight categories were specifically identified with the remainder grouped into 'Other'. The results are displayed in Table 3.

\section{Table 3. Application Areas}

\begin{tabular}{|l|r|}
\hline Category & Count \\
\hline Safety & $\mathbf{1 3}$ \\
\hline Homeland Security & 9 \\
\hline Environment & 4 \\
\hline Energy Efficiency & 8 \\
\hline Health & 5 \\
\hline Information Tech. & 10 \\
\hline Supply Chain & 10 \\
\hline Measurement Science & 14 \\
\hline Other & 5 \\
\hline Total & 78 \\
\hline
\end{tabular}

Also, 24 of the 78 projects (31\%) fit broadly under one of the 14 NIST budget initiatives for FY $2009^{15}$. Some can be categorized as falling under one of NIST's previous programmatic Strategic Focus Areas. This type of information could be useful in better focusing NIST standards development work in the future.

An additional observation is that 28 of the identified standards were adopted or developed by the three major international standards organizations (ISO/IEC/ITU). Based on SDO membership reported by NIST staff listed in Table 1, this figure is somewhat higher than would be expected. It may indicate that many of the standards efforts that were considered to have had a significant impact by the NIST OUs required broad, international cooperation where national participation is a priority. This is valued by industry-specific sectors and helps ensure that U.S. companies maintain their competitive advantage in the national and international market place. In the remaining 51 cases, NIST involvement focused on supporting U.S.-based standards developing organizations or consortia, most of whose standards and specifications are used globally. (see Figure 4). 


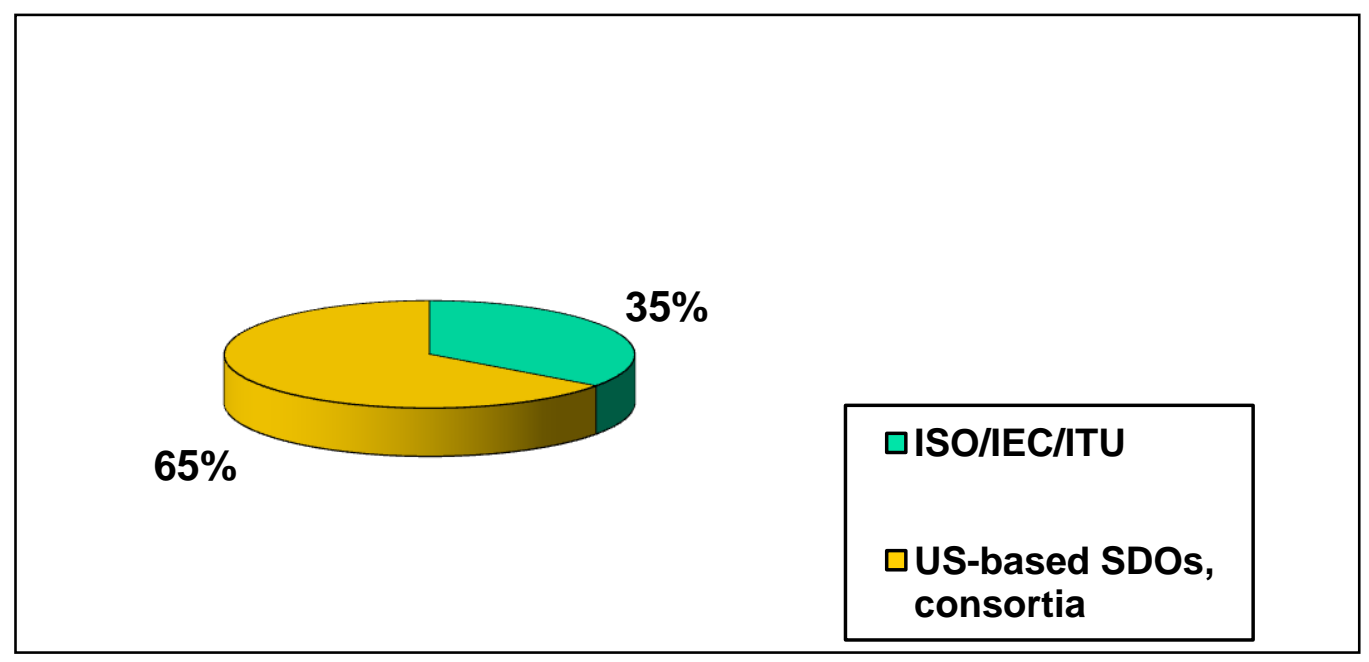

Figure 4: Breakdown of Standards Participation by Organization Type

\section{Reported Outcomes}

As part of this second phase of NIST's standards canvassing effort, seven (7) additional questions were posed to the OUs about the projects identified in the first and second rounds of canvassing. These seven questions attempt to capture evidence of outcomes from NIST's participation in voluntary standards development activity. Table 4 describes the additional information requested and the rationale for the outcomes.

\section{Table 4. Description of Intermediate Outcome Metrics}

\begin{tabular}{|l|l|}
\hline \multicolumn{1}{|c|}{ Additional Data Area Item } & \multicolumn{1}{c|}{ Impact Rationale } \\
\hline Non-NIST labor time & $\begin{array}{l}\text { The time that industry devotes to the } \\
\text { development of a documentary standard is } \\
\text { a lower bound estimate of the cumulative } \\
\text { (social) value of the standard to industry. }\end{array}$ \\
\hline NIST labor time & $\begin{array}{l}\text { The ratio non-NIST labor time to NIST } \\
\text { labor time is a gross indicator of a lower } \\
\text { bound net outcome from a documentary } \\
\text { standards project. The greater the ratio the } \\
\text { greater the potential leveraging effect of } \\
\text { NIST's labor time investment. }\end{array}$ \\
\hline Standard scope w/o NIST participation & $\begin{array}{l}\text { Because NIST participation frequently } \\
\text { supports the grounding of standards on } \\
\text { measurement science, the scope of } \\
\text { standards can apply to more products or } \\
\text { services. }\end{array}$ \\
\hline
\end{tabular}




\begin{tabular}{|l|l|}
\hline Standard timing w/o NIST participation & $\begin{array}{l}\text { Because NIST is frequently perceived as an } \\
\text { "honest broker," the time required to } \\
\text { negotiate consensus among industry } \\
\text { participants is reduced (resulting in lower } \\
\text { transaction costs) and standards are } \\
\text { implemented sooner than they would be } \\
\text { otherwise. }\end{array}$ \\
\hline $\begin{array}{l}\text { Publications resulting from NIST } \\
\text { participation }\end{array}$ & $\begin{array}{l}\text { These publications are project outputs. If } \\
\text { publications can be linked to indicators of } \\
\text { economic value, such as highly cited } \\
\text { patents, these can be claimed as secondary } \\
\text { evidence of economic benefits. }\end{array}$ \\
\hline $\begin{array}{l}\text { New or improved product/service } \\
\text { availability }\end{array}$ & $\begin{array}{l}\text { Some fraction of the value added from new } \\
\text { product/service availability can be claimed } \\
\text { as a benefit of NISTs standards } \\
\text { development activity. }\end{array}$ \\
\hline Industry group/consortium participation & $\begin{array}{l}\text { Participation in industry consortia is linked } \\
\text { to improvements in productivity and } \\
\text { profitability. }\end{array}$ \\
\hline
\end{tabular}

Responses were received for 53 of the 78 projects (68\%). Not all of them were complete, but some interesting observations begin to shed light on the impact of NIST's involvement with the standards development process.

- Observation: The average multiple of non-NIST hours to NIST hours for all 53 projects answering the questions was 11.77.

- Implication: This means that, on average, for every full-time-equivalent of NIST staff working on one of the high impact standards, almost 12 times that amount of non-NIST staff (primarily industry) were supporting the project. This suggests that NIST leverages valuable industry labor, and is indicative of the lower bound estimate of the social benefits of standards development activities.

- Observation: Of 21 projects that answered the question regarding when the standard would have been published without NIST participation, the average was 1.65 years later.

- Implication: This gap is an intermediate indicator of NISTs unique contributions from an economic perspective. It is a gross indicator of the transaction time savings that NIST involvement in a voluntary standards development effort affords industry.

\footnotetext{
${ }^{3}$ A. Jaffee and M. Trajtenberg, Patents, Citations, and Innovations, MIT Press, 2002.

${ }^{4}$ A. Link and D. Siegel, Technological Change and Economic Performance, Routledge, 2003, pp. 111-114.
} 
- Observation: Of the 53 respondents, approximately one-third (34 percent) indicated that the scope of the standard would have been narrower without NIST involvement.

- Implication: Increased standard breadth is another intermediate indicator of the unique contribution that NIST involvement in a voluntary standards development effort affords industry. It is a gross indicator of an increase in the number of newly available products or services enabled by the standard in question. Combined with time saving due to NIST's participation, the increase in scope scales up the economic benefits that flow from NIST's participation in voluntary standards development efforts. ${ }^{17}$

- Observation: Of the 53 projects, $62 \%$ had involvement from industry groups or consortia in developing the standard.

- Implication: This percentage is indicative of strong industry support and, ultimately, significant economic impact. If, as anticipated, the economic impact of NIST's involvement in documentary standards development efforts is highest when industry is most committed, and when NIST brings specialized and cost-effective resources to the effort, the involvement of industry groups, and especially of consortia (which usually are structured to achieve specific ends on the basis of the specialized resource contributions of members) are an early indicator of significant benefits. ${ }^{18}$

- Observation: Forty-two (42) percent of respondents stated that the standard resulted in having a product or service available, or available at a lower cost, or available more broadly, or available in different qualities, or available earlier that would not be in the absence of the standard. In addition, many of the other respondents who did not specifically claim new products or services did claim broader societal benefits such as: trade facilitation, increased homeland security, interoperability benefits, etc.

- Implication: Standards provide tangible results that could benefit from more precise characterization.

- Observation: Finally, as may be expected, a large majority ( 85 percent) of the projects resulted in professional publications, including journal articles, conference proceedings and presentations, NIST publications, magazine articles and other reports.

- Implication: These publications are a non-economic indicator of the secondary output of NIST's engagement with voluntary standards organizations.

We also analyzed two sub-sets of the data, looking at those projects which resulted in new or improved products or services, as well as all those projects which had industry 
group or consortia involvement to see if these two subsets had any differentiating characteristics.

- Observation: Taking a look at only those 23 projects that have reported claims that the standard has had an impact on actual products and services finds a higher ratio of non-NIST participants to NIST staff (15.3 v 11.8).

- Implication: This indicates a higher rate of external (likely industry) participation.

- Observation: These same 23 projects also reflect a very high rate of industry association/consortia involvement of 91 percent.

O Implication: This compares to 62 percent for the entire sample of 53 projects. Therefore, higher industry involvement in standards development is likely an indicator of greater focus on commercialization.

- Observation: The second group of 33 projects which claimed the participation of industry associations or consortia also yielded some interesting, but not unexpected, findings. For all these projects, 58 percent claimed new/improved products or services, as opposed to 42 percent of the entire sample.

Taken together, it is clear that many of these NIST standards projects leveraged the work of non-NIST participants and the participation of industry groups to develop high impact standards that were developed on average 1.5 years earlier and resulted in product and service improvements, general benefits to the country and a large number of publications and presentations. If we look at the subsets, industry involvement is, as expected, associated with a larger percentage of new or improved products/services. No attempt has been made yet to put an economic value on the resulting goods and services or the faster development time.

NIST involvement in voluntary standards development efforts need not result in new products or services to generate significant economic impacts. The only basic prerequisite is that NIST bring valuable resources to a process that is also of value to the marketplace of producers and consumers. Where new products and services are available, additional benefit streams will have been induced. Where NIST contributed uniquely to the flow of those benefits, the returns to NIST's resources investments, specifically, will be higher yet. $^{19}$

Each of the three following "Success Stories" begins to place these outcome indicators in context and to gather some more detailed information on how NIST's involvement contributed to the overall success of the standard development activity in question. 


\section{16 CFR Part 1633 Standard for the Flammability (Open Flame) of Mattress Sets}

\section{Executive Summary}

In the late 1990 's and early 2000 's, industry and public concern about loss of life from bedroom fires motivated a hard look at ways to reduce deaths and property damage. Participants struggling to resolve issues knew standards were part of the solution, but could not agree on ways to establish, test and codify standards. NIST, known as objective and technically proficient, got the call to engage with industry and regulators to help create standards that would be effective, but not onerous. Figure 1 is a thumbnail of the process, going from the need for new standards, to the research conducted by NIST, which led to a successful regulation. This report highlights the process and explains many of the benefits that resulted from NIST's work.

\section{Background}

From 1999 to 2002 about 15,300 fires occurred annually where the first item ignited was a mattress and its bedding. These fires resulted in an annual average of 350 deaths, 1,750 injuries, 295 million dollars in property loss, and untold human suffering. ${ }^{5}$ In June of 2007, the U.S. Consumer Product Safety Commission (CPSC) announced the implementation of a new product safety standard for mattresses. Mattresses manufactured on or after July 1, 2007 must

\footnotetext{
${ }^{5}$ David Miller, Mattress and Bedding Fire Loss Estimates for 1999-2000, USCPSC, 2005, cited in, Soumaya Tohamy, Final Regulatory Analysis of Staff's Draft Final Standard to Address Open-Flame Ignitions of Mattress Sets, Directorate of Economic Analysis, USCPSC, January 10, 2006.
}

meet the U.S. Consumer Product Safety Commission's (CPSC) flammability standard, known as 16 CFR Part 1633. The mandatory standard is designed to reduce the severity of mattress fires ignited by open flame sources such as candles, matches and lighters. Figure 2 shows a pre-standard bed ignited by a match-size flame; within 5 minutes the entire bed can be fully involved.

Working with the International Sleep Products Association (ISPA) and its research affiliate, the Sleep Products Safety Council (SPSC) through a special Cooperative Research and Development Agreement (CRADA), NIST's Building and Fire Research Laboratory (BFRL) developed the scientific basis for CPSC's mattress flammability standard. ${ }^{6}$

\section{The CPSC estimates that the 1633} standard will prevent as many as $\mathbf{2 7 0}$ deaths and 1,330 injuries every year. Without NIST's involvement, many of these lives would not be saved and many of these injuries and property losses would not be prevented. But over and above such immediate and obvious benefits, it seems clear that without NIST's technical support the mattress industry would have suffered significant economic losses by adopting a less substantiated standard. The cost of these mattress industry related losses in California alone, was estimated in 2002 to be

\footnotetext{
${ }^{6}$ ISPA and SPSC together account for more than 700 wholesalers, retailers, and manufacturers of mattresses and mattress foundations. Their members account for 80 percent of total U.S. sales of mattresses and mattress sets.
} 


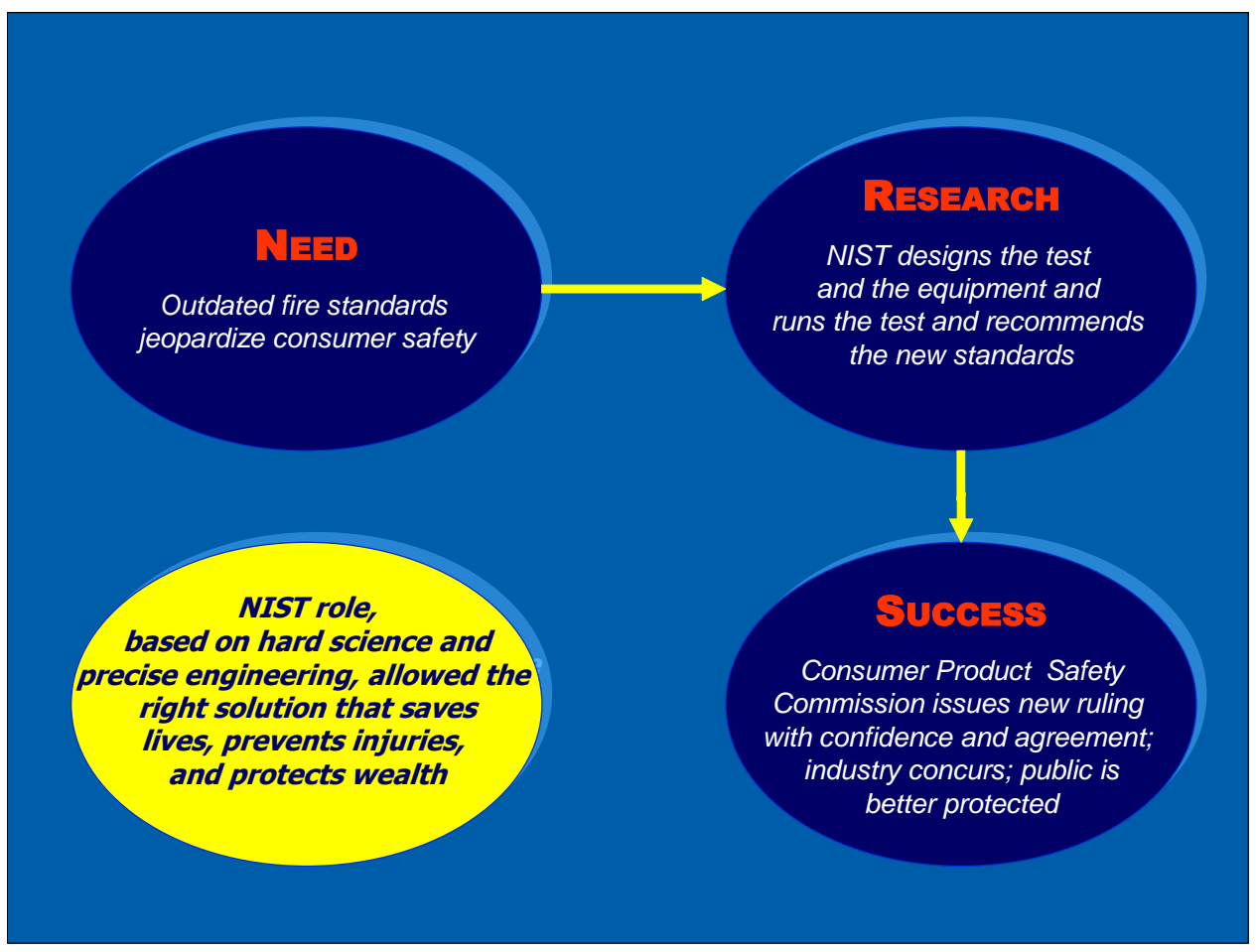

Figure 1F: NIST involvement in standards development directly affects public safety

approximately $\$ 276$ million less in mattress sales and $\$ 15$ million less in California state tax revenues. Since these losses reflect the difference between adopting the standard that was underwritten by NIST and adopting what industry argued was a less appropriate standard put forward by the California's Bureau of Home Furnishings \& Thermal Insulation (hereafter, "the California Bureau"), these potential net losses can be construed as part of the indirect economic benefits that flow to society from NIST's efforts.

\section{Origin of the effort}

The mattresses that U.S. consumers purchase must comply with fire safety regulations. In particular, since the 1970s mattress manufacturers have had to ensure that the materials from which their products were made do not readily ignite from dropped cigarettes, as codified in 16 CFR Part 1632. Industry efficiently implemented this standard nationwide and consistent industry compliance contributed significantly to a substantial reduction over the past 25 years in residential fire deaths.

\section{In 2000, the Consumer Product Safety} Commission received a petition to modify the current flammability standard to include sources of ignition other than cigarettes. The Commission initiated a proceeding to develop a mandatory federal standard to address open-flame ignitions in 2001 and published a proposed regulation in January 2005. Accordingly, a mattress manufacturer would test three mattress sets of the same prototype mattress set and pass technical criteria pertaining to the rate and total amount of heat a burning mattress releases 
in the first 10 minutes after ignition and the peak rate at which it releases heat for 30 minutes after mattress ignition. Since the first item typically ignited is bedclothes (sheets, etc.), the ignition source intended here must mimic burning bedclothes.

The fire resistance standards proposed by the California Bureau in its Technical Bulletin 603 would have required that a mattress and box spring combination be fire resistant when exposed to a particular open flame source. To qualify as a safe mattress under the California Bureau's criteria, a mattress and box spring had to burn at a low level (maximum instantaneous heat release rate of 150 kilowatts) for at least 60 minutes. The California Bureau intended to finalize its regulations in November 2003 and to require that all mattresses and box springs manufactured for sale in California beginning January 1, 2004 meet these standards. A major source of uncertainty here was that the California Bureau's flame source bore no known relation to burning bedclothes.

\section{NIST gets involved}

Part of NIST's core mission is to pursue research and develop technology that pertains to measurement: how long, how fast, how heavy, how hot, how accurate, how precise? Another NIST core mission is to support the development of U.S. industry's voluntary standards development activities. NIST's support of the CPSC's mattress regulation brings together these core mission areas.

The Sleep Products Safety Council (SPSC) initiated a CRADA with the Building and Fire Research Laboratory of NIST in response to a published notice from CPSC that they planned to investigate the possible need for a regulation in this area. NIST's involvement began in 1998 and continued until the regulation was imposed in July, 2007 on all new residential mattresses sold in the $U$. S. NIST developed the only science-based approach to the issue of mattress flammability, looking at the problem from beginning to end. Initial research was directed at a viable test method for simulating the damage that flaming bedclothes (sheets, blankets, etc.) inflict on a mattress. This required the development of a new technique for measuring the highly transient and spatially erratic heat fluxes that burning bedclothes entail. This was followed by the construction and calibration of a set of gas burners that could generate similar heat fluxes. It was then demonstrated that mattress fire behavior caused by exposure to these burners correlated with that seen with burning bed clothes on the same mattress. The final portion of the work focused on development of a basis for predicting what various levels of improved mattress fire performance implied in terms of potential lives saved per year. This gave a rational basis for the peak fire size that a regulator might allow from a mattress when tested with the gas burners (and a guideline for a costbenefit analysis of any regulation).

The research conducted by NIST showed that the peak heat release rate proposed by the California Bureau was unnecessarily low, and the duration of the test longer than necessary. In addition, as noted, their ignition conditions bore an unclear relation to the hazard. The risk of bedroom flash-over can be minimized if mattress, box spring, and bedclothes fire does not exceed 400 kilowatts. The California Bureau's proposed heat release rate of 150 kilowatts would have required much higher product design costs, but the products would not have been more effective in preventing flash-over. The 60minute test duration proposed by the California Bureau was regarded as both impractical (the vast majority of mattress producers could not make commercially- 
viable product under California's proposed rule) and ultimately counterproductive (as higher priced mattresses would significantly reduce the number of safe mattresses sold). Lab tests showed that when ignited some pre-standard bed ensembles proceed to flash-over conditions in the room of origin (invariably fatal to room residents and highly threatening to other home occupants) within five minutes. The typical time for a fire department to respond to a residential call is five to nine minutes, according to the National Fire Protection Association (NFPA). Avoiding flash-over within the first ten to twenty minutes post-ignition would significantly improve life safety by allowing sufficient time for escape and rescue.

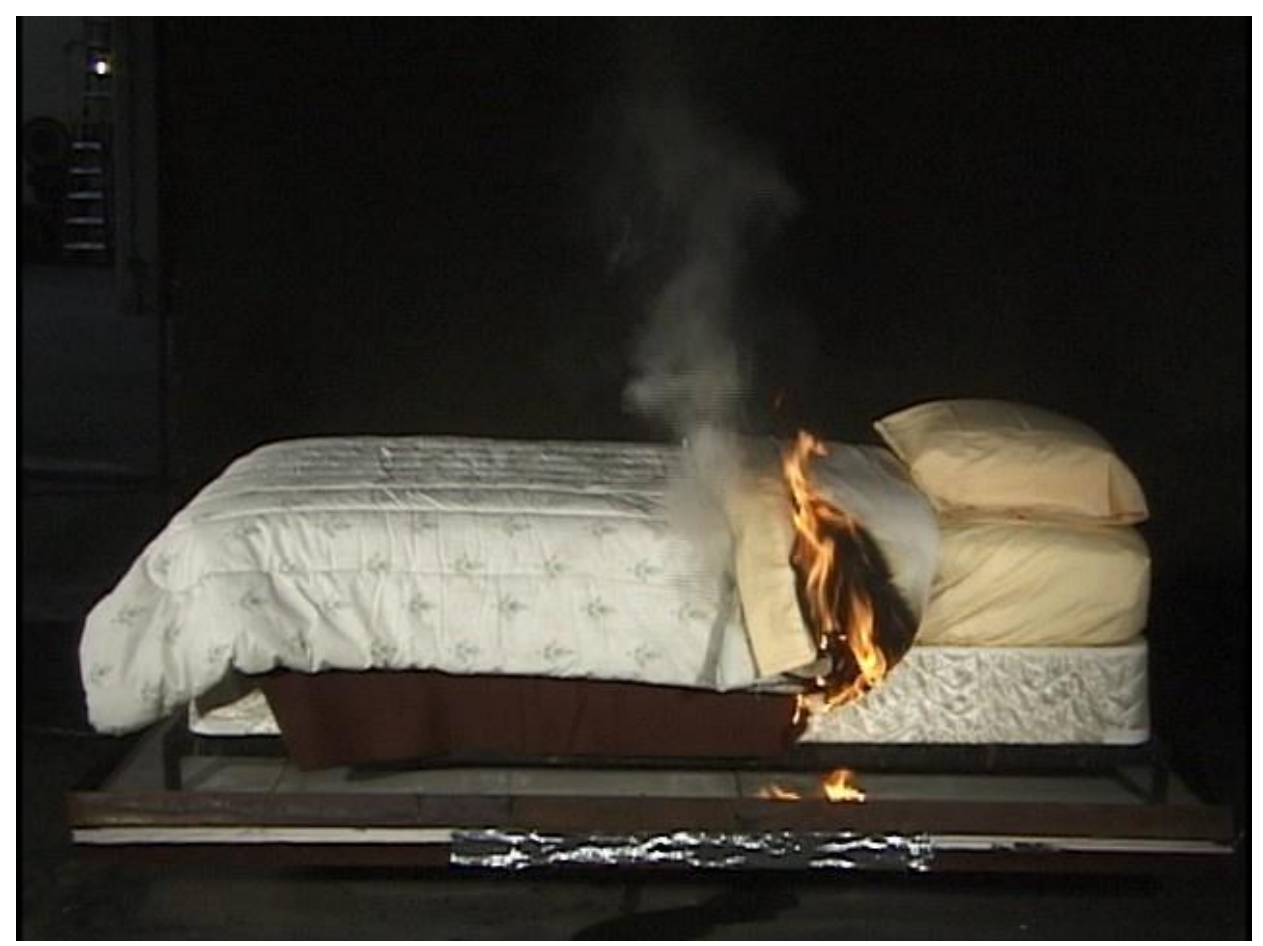

Figure 2F: Burning Bed at One and a Half Minutes

\section{What would have been done, absent NIST?}

If NIST had not participated, CPSC might have gone forward on the basis of its own limited resources. Presumably, it would have taken CPSC longer to develop an alternative to the criteria proposed by the California Bureau. Strong industry resistance to the imposition of such a standard can also be a "show stopper." Under this scenario, the lives lost, as well as the injuries and property loses that would have occurred in the intervening time gap can be interpreted as benefits unique to NIST's involvement. As an alternative to "new CPSC standard" scenario, we might well imagine industrysponsored efforts to modify the existing California public occupancy standard (Technical Bulletin 603).

It is unlikely that either of these two paths would have produced a test method that was based on an in-depth analysis of the problem since neither organization has the resources (money or trained staff) to do this.

Furthermore, the mattress industry is not an $R \& D$ intensive industry so it seems unlikely that a science-based consensus standard would have emerged. It is likely that a standard might have emerged after a few 
years whose potential effectiveness at solving the real world problem could not really be assessed. It seems certain that they would have gone no further than the methodology devised by NIST. They might have "gotten to market" sooner (since the TB 603 test already existed) but the effectiveness of that test would be unclear.

Compared to the NIST fire science based approach, the alternative approach made it very difficult to know if expensive compliance would translate into real world improvements in life safety. In such situations industry resistance can prevent the development of important safety standards and regulations, resulting in continued losses and injuries.

\section{Conclusion}

NIST's support in providing a factual foundation and rationale for the desired performance level in the standard represented a superior outcome to the proposed alternative standard and prevented a costly delay in implementing a standard nationwide. NIST's deep and unique experience with measurement technology provides a sure foundation for mattress safety and as a result consumers are safer. 


\section{Development of Radiation Detector Standards for Homeland Security Applications}

\section{Executive Summary}

Since $9 / 11$, one of the most frightening threats that has disrupted many a night's sleep were "dirty bombs," explosives salted with radiological materials and smuggled through an American port. It was feared that a single dirty bomb attack could cost billions, kill hundreds, and take years of recovery.

The chaos of $9 / 11$ quickly turned into widespread resolve to better protect U.S. citizens. The challenge faced was simple and profoundly daunting: create and deploy rugged detector equipment that could be used easily by non-specialists and first responders to scan massive amounts of cargo for nuclear-radiological threats.

Speed and precision were driving factors for the diverse group that coalesced to confront this challenge. DHS pressed hard on the group, urging them to "fast-track" detection equipment and training standards. Leadership quickly fell to NIST, with its wide and deep experience in creating, testing, and validating standards. NIST chaired the "N42 Committee" that coordinated and integrated the work of several diverse groups, addressing radioactivity measurements, homeland security, and protection instrumentation.
NIST guided the dedicated and highly proficient groups to create the technical foundation for a suite of standards that reflected the complexities of the challenges presented by equipment from small, handheld detectors to massive, port-screening monitors, including standard data formats to easily process readouts. These groups also designed the training essential to move the standards from the working groups to effective field protection practices. The initial effort took two years of intense work during 2002-2004.

The operational experiences that followed pointed to even more effective protocols, and NIST engaged in another two more years of concentrated proceedings refining the standards. Today, users and vendors have access to a set of nine specific standards for radiation detection, which cover instrumentation, alarms, and fixed and mobile systems, easing the burdens on industry and defenders 


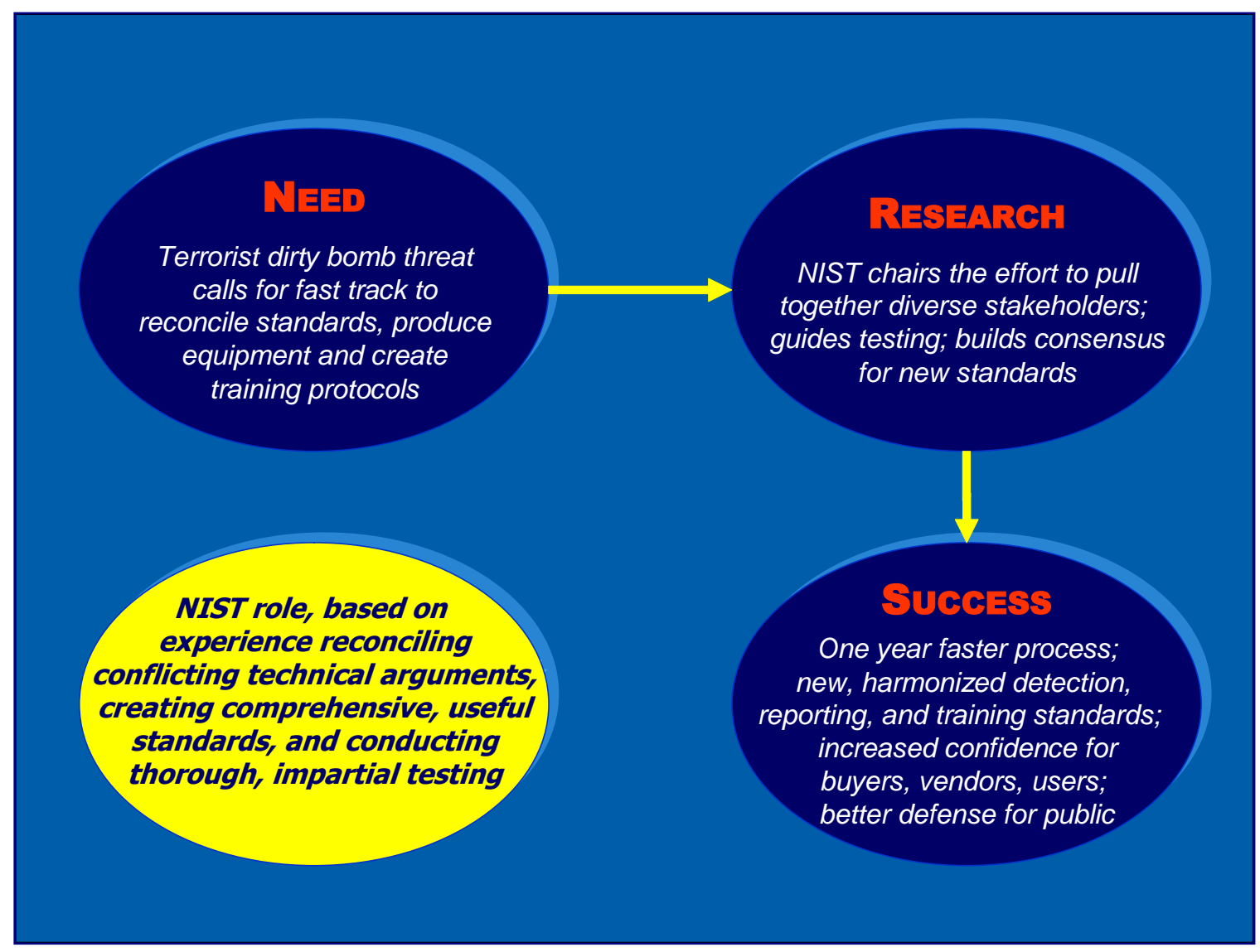

Figure 1R: NIST technical leadership contributes to protection of U.S. citizens and property

\section{Introduction}

In collaboration with the U.S. Department of Homeland Security (DHS), industry, and other national laboratories, the National Institute of Standards and Technology (NIST) responded to the nation's needs for increased port security in the post-9/11 environment. On DHS's behalf, NIST radiation experts took part in and led an effort to fast-track a suite of radiation detection standards through the voluntary consensus standard process. These standards set performance requirements for radiation detection equipment based on homeland security needs, and will increase the effectiveness and efficiency of cargo, vehicle, and other screening processes and reduce the risks of dramatic terrorist attacks on U.S. soil.

In one of the DHS planning scenarios, high explosives, radioactive sources, and other "dirty bomb" components are smuggled into the country in sea-land containers shipped to U.S. ports under assumed business names. The containers are picked up and transferred to safe houses near three target cities. After detonation, thirty-six blocks are contaminated by the initial explosion and the spread of radioactive contamination by mild winds. The scenario estimates several hundred fatalities and injuries, extensive environmental contamination, and the evacuation of 
thousands of individuals in each city. Bus, rail, and air transport routes are altered, and highway checkpoints are established to monitor incoming traffic for contamination. Hospitals in each region, already at maximum capacity with injuries from the blasts, are inundated with up to 50,000 "worried well." Sewage treatment plants are quickly contaminated; businesses are closed for an extended duration while radioactive contamination is remediated; and local tax revenues plummet. The entire contaminated area is economically depressed for years. The total economic impact is in the billions of dollars.7

With scenarios like this in mind after 9-11, efforts to screen the vast amount of cargo that floods into U.S. ports increased dramatically. While some of the equipment needed to monitor cargo arriving by vehicles and vessels had been available previously, it was not available in the ruggedized form required to handle greatly expanded throughput or use in diverse settings, nor was the available equipment designed for use by non-specialists or first-responders. Extraordinary effort was needed to alter the situation. NIST was called upon to provide its technical expertise and leadership.

\footnotetext{
${ }^{7}$ U.S. Department of Homeland Security, National Planning Scenarios, March, 2005, "Scenario 11: Radiological Attack - Radiological Dispersal Devices," pp. 11-1-11-8.
}

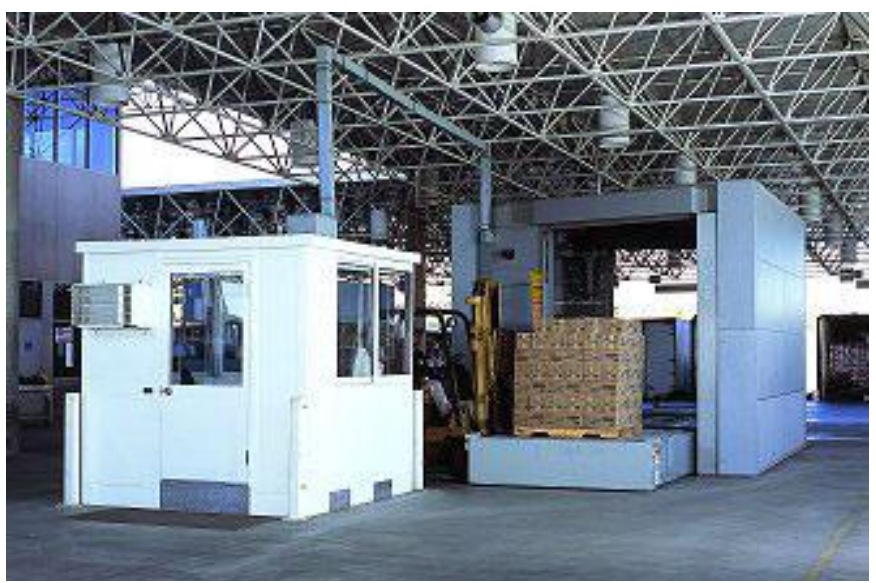

Figure 2R. Cargo screening equipment installed at an airport facility.

\section{Origin of the Effort}

To address the looming problem described above, DHS called on experts from NIST, the private sector, and other government organizations to "fast-track" a number of critical radiation detection equipment and equipment training standards through the Institute of Electrical and Electronics Engineers (IEEE), Radiation Detection Standards Program. The primary N42 Committee, chaired by NIST experts, oversaw and coordinated the work of subcommittees N42.RM (Radioactivity Measurements), N42.RPI (Radiation Protection Instrumentation), N42.HSI (Homeland Security Instrumentation), and working groups.

Through the efforts of a diverse group of stakeholders, IEEE's ANSI-accredited National Committee on Radiation Instrumentation developed a suite of consensus standards for personal radiation detectors, portable radiation detection instrumentation, hand-held instruments for detection and identification of radioactive materials, radiation detecting portal monitors, mobile and transportable radiation monitors, training for radiation detection instrumentation, performance criteria for 
spectroscopy-based portal monitors, performance criteria for active detection systems, and standard data formats for instrument read-outs.

The initial stage in the development of the standards covered the period from 20022004. After development and use of testing and evaluation protocols based on these standards, they were revised from 20042006. Table $1 \mathrm{R}$ lists the suite of radiation detection standard currently available to users and vendors of radiation detection equipment.

\section{Table 1R. IEEE's Radiation Detection Standards}

- 42.32 American National Standard Performance Criteria for Alarming Personal Radiation Detectors for Homeland Security

- 42.33 American National Standard for Portable Radiation Detection Instrumentation for Homeland Security

- 42.34 American National Standard Performance Criteria for Hand-Held

- Instruments for the Detection and Identification of Radionuclides

- 42.35 American National Standard for Evaluation and Performance of Radiation Detection Portal Monitors for Use in Homeland Security42.37 American National Standard for Training Requirements for Homeland Security Purposes Using Radiation Detection Instrumentation for Interdiction and Prevention

- 42.38 American National Standard Performance Criteria for Spectroscopy-Based Portal Monitors Used for Homeland Security

- 42.41 American National Standard Minimum Performance Criteria for Active Interrogation Systems Used for Homeland Security

- 42.42 American National Standard Data Format Standard for Radiation Detectors Used for Homeland Security

- 42.43 American National Standard Performance Criteria for Mobile and Transportable Radiation Monitors Used for Homeland Security

\section{NIST Gets Involved}

Representatives of the lonizing Radiation Division of NIST's Physics Laboratory have been involved with ANSI and IEEE in the development of numerous consensus standards over the years. N42, the ANSIIEEE committee for the development of radiation instrumentation standards, was chosen as the lead for this effort because of its ability to rapidly produce the desired standards. As part of its ongoing support for voluntary standards development, NIST personnel chaired the committee at the time of the DHS initiative At the time the fast track effort was initiated, a number of ANSI and ASTM standards were in place for similar applications in the health physics arena, but none of them covered the requirements needed for their use either by non-highly trained individuals nor for the additional environmental and mechanical ruggedness requirements inherent in homeland security applictions.

The standards that emerged in 2004 were subjected to two rounds of DHS-funded testing. The testing results were used by testing labs to evaluate instruments, by manufacturers to improve their product to be able to meet the requirements set by the standards that apply to homeland security applications, and by users for instrument procurement purposes. After the initial development, validation and implementation of these standards, and the failure of any of the equipment to meet them, the manufacturers began developing new equipment and, through an iterative process with industry, the standards were further refined.

This resulted in the establishment of the Graduated Rad/Nuc Detector Evaluation and Reporting (GRaDER) program, which establishes the current American National Standards Institute (ANSI) N42 consensus standards as the initial acceptable performance baseline for radiation detectors and lays the groundwork for more detailed instruction to enter the program. The GRaDER program is managed by DHS's Domestic Nuclear Detection Office (DNDO) 
together with NIST and NIST's National Voluntary Laboratory Accreditation Program (NVLAP) under which laboratories perform independent and consistent testing of the commercial-off-the-shelf radiation detectors. ${ }^{8}$ Results of the GRaDER program testing will be made available to law enforcement and first responder agencies to inform their procurement and grant awards processes.

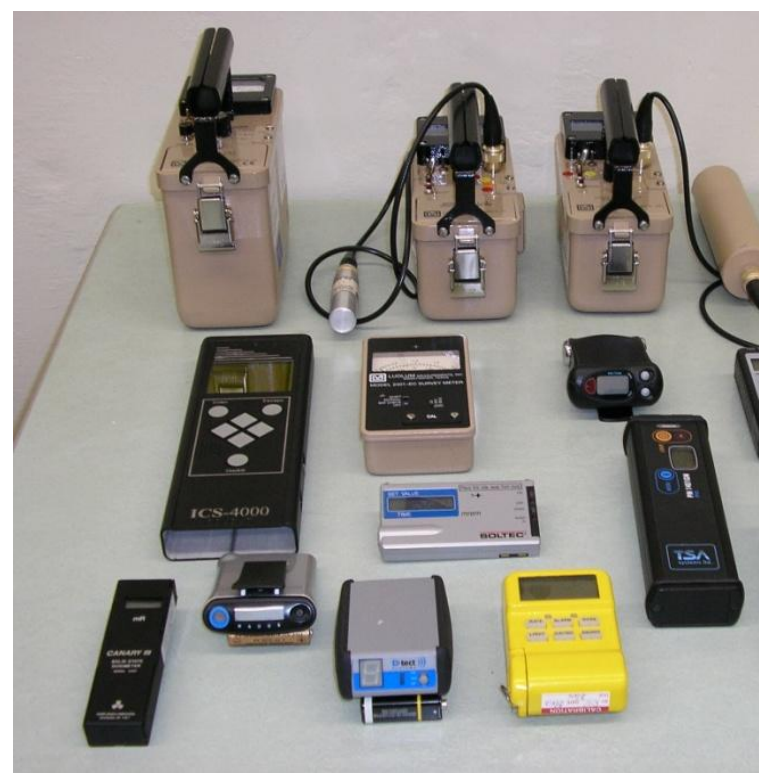

Figure 3R. Handheld radiation detectors.

\section{What would have been done, absent NIST?}

Without NIST in the lead, these radiation equipment standards would have taken longer to develop. The fact that NIST is viewed as an impartial participant greatly helped in resolving differences among the various groups involved in the writing of

\footnotetext{
${ }^{8}$ The Domestic Nuclear Detection Office (DNDO) was established in 2005 to improve the Nation's capability to detect and report unauthorized attempts to import, possess, store, develop, or transport nuclear or radiological material for use against the Nation, and to further enhance this capability over time.
}

these standards. For all the standards, NIST personnel led the harmonization of the sometimes unrealistic differences between user requirements and the manufacturers' concerns of what present technology can achieve. In addition, NIST provided the means for collaborators to access the information necessary to apply the standards to different types of instruments.

Through its voluntary public-private collaboration, the IEEE's suite of radiation detection standards was developed in under 2 years, at least a year earlier than for a typical documentary standard, and, as a result, problems could be addressed by port personnel in a much more effective manner than they would have been without the standards; industry could develop the new ruggedized and user-friendly detection equipment needed quickly and effectively; and the value added from the sales of new equipment would accrue to industry sooner than it otherwise would have.

From an economic perspective, NIST helped to lower the high transaction costs associated with organizing and harmonizing technical and quality assurance issues among diverse equipment users, designers, and manufacturers.

\section{Conclusion}

A joint effort between industry and government agencies to meet the critical DHS objective of increased port security led to the fast-track development of a suite of ANSI accredited documentary standards for radiation detection equipment performance and equipment training. These achievements would not have been achievable in the time accomplished had it not been for NIST's contribution. The economic impacts of these efforts would be measured in terms of shifting a stream of public and private benefits forward in time by 
a minimum of 1 year and in the dramatic reduction in transaction costs that would have been required to harmonize technical differences among the users and designers of new radiation detection equipment. This should result in a system of certified radiation detection equipment that reduces the ability of terrorists to smuggle radioactive material into the United States lowers the risk of the dire consequences depicted in DHS planning scenarios, and increases our sense of security. 


\section{Materials Declaration Standards to Support Environmental Regulations}

\section{Executive Summary}

In 2003, the U.S. electronics industry was already struggling with regulations that restricted tin-lead solder and did not focus on looming EU requirements on toxic materials in electronic products, thus finding themselves in a bewildering world of incompatible standards and complicated data exchange tools that threatened to severely impact U.S. high tech exports.

Little progress was being made on creating a Joint Industry Guide (JIG) that could guide industry design and production. Realizing that something needed to be done, in December 2004 NIST organized a meeting with IPC, a global trade association, and iNEM $^{9}$ to discuss the problem and need for a standard way of exchanging JIG and other compliance data. From an initial offer of collaboration, NIST was invited to expand its role and became chair of an international group of government agencies, industry representatives, and technical experts.

NIST guided the group through rigorous and open analyses that recognized and balanced the unique requirements and problems of small, medium, and large manufacturers. The challenges that NIST helped resolve included technical uncertainties, problem modeling, software programming, data standards documentation, and reference implementation. NIST expertise also enabled the group to design innovative ways to use alternative declaration standards, while eliminating many incompatibilities.

\footnotetext{
${ }^{9}$ International Electronics Manufacturing Initiative
}

The benefits of NIST involvement, like the challenges, were many and varied. NIST was able to reconcile competing approaches in a relatively short time. In only 16 months NIST guided the groups to consensus on the standard and supporting software tools. That short time frame would likely not have been possible without NIST's reputation for impartiality. NIST recognized that the 2004 standard and software would not be the final, but made the solutions easy to maintain and upgrade. From an industry perspective, the relatively speedy resolution and ease of use reduces up-front and compliance costs, a significant factor in the global competitive landscape, especially for smaller companies. Finally, the solution extends to alternative material declaration standards, offering compatibility between complementary standards. 


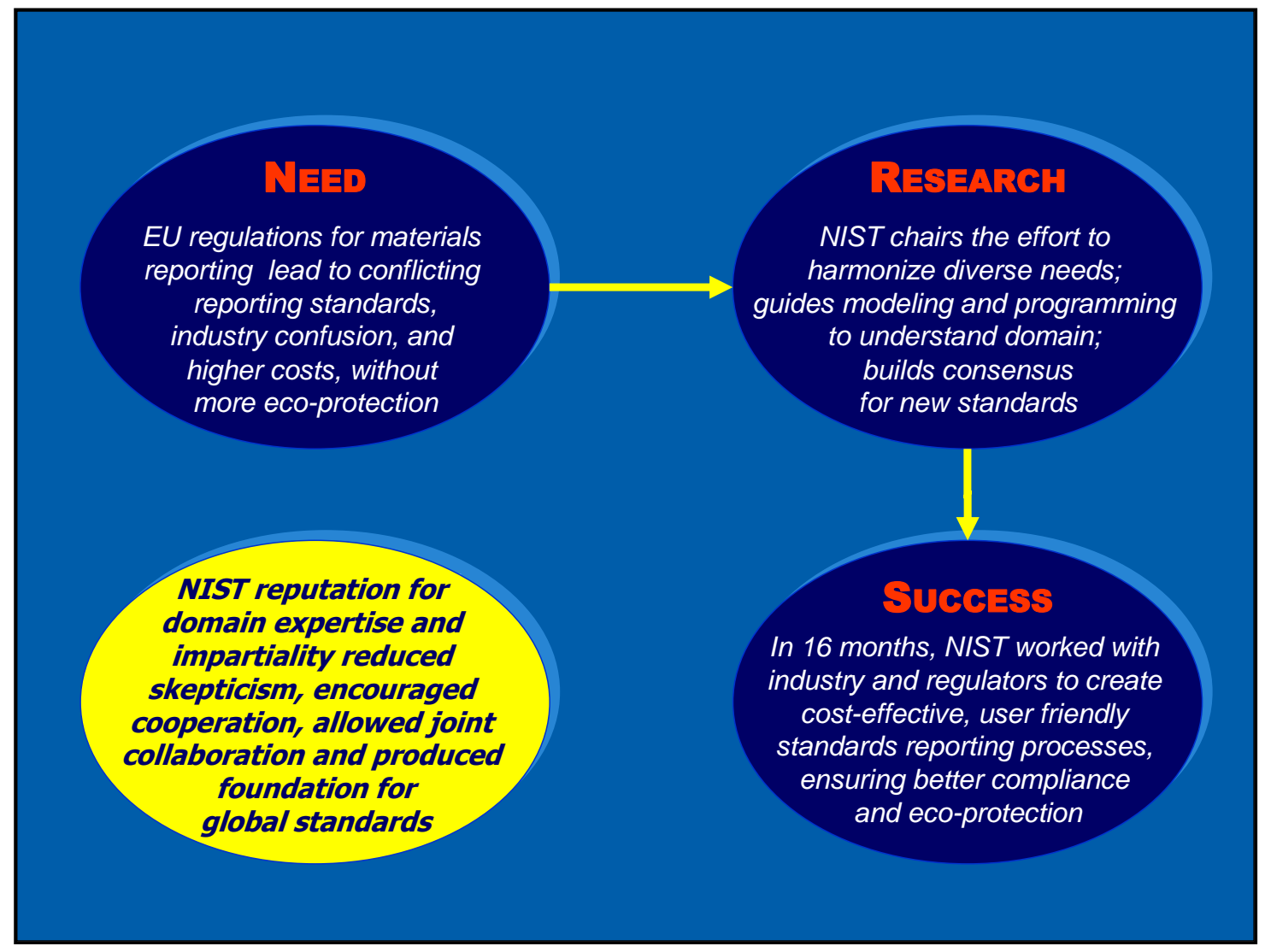

Figure 1M: NIST has positive impact on standards development process

\section{Introduction}

The Restriction on Hazardous Materials (RoHS) regulations recently adopted by the European Union (EU) and other U.S trading partners require significantly reduced maximum allowable concentrations of toxic chemicals in electronic products. Companies seeking market entry for consumer electronic and electrical products require stringent materials declarations from their suppliers at all levels of the supply chain.

RoHS regulations affect the worldwide market for "electrotechnical" products, a multi-billion dollar annual market. U.S. companies are significant exporters of these products and must comply with RoHS regulations by replacing components and designing new manufacturing processes to accommodate new or modified raw materials. The European Union (EU) is by far the largest export market for U.S. high-tech electronic goods with $\$ 46$ billion dollars exported in 2006. ${ }^{10}$

This issue crosses company, industry, domestic, and international lines so that a collective approach to addressing the exchange of compliance data in the new

\footnotetext{
${ }^{10}$ Source: AEA News, "U.S. Technology Exports Up by $\$ 21$ billion in 2007", July 17, 2007
} 
RoHS regulations was needed. The initial standard that emerged from the undertaking was the IPC 1752, Materials Declaration Management. IPC is a global trade association focused on the electronic interconnection industry. ${ }^{11}$

\section{Origin of the Effort}

An increased focus on recycling electronics led the European Union in 2003 to issue the Waste Electrical and Electronic Equipment (WEEE) Directive. The directive set collection, recycling, and recovery targets for all types of electrical goods. This was further expanded to restrict certain hazardous substances and the European Union's new Restriction of Hazardous Substance (RoHS) Directive was implemented on July 1, 2006. To ensure compliance with both Directives the electronics industry needed to be able to track the material composition of the final products being introduced to the EU before the July 1 st date. US industry was already struggling with the technical challenges of replacing tin-lead solder in its electronics products and processes. Other than a few large U.S. companies, there was little awareness within the U.S. electronics industry of the new EU emphasis on data exchange needs. For both these reasons, implementation efforts in the United States languished until 2004. Efforts to develop the Joint Industry Guide (JIG) which provides guidance to industry on what materials and substances are to be disclosed by suppliers of electronic and electrical products had begun, and some individual companies and software providers had developed nonstandard non-compatible data exchange tools, the proliferation of which actually increased industry's burden of compliance.

${ }^{11}$ Founded in 1957 Institute for Printed Circuits the industry association changed its name to the Institute for Interconnecting and Packaging Electronic Circuits and, in 1999, to IPC.
Realizing that something needed to be done, in December 2004 NIST organized a meeting with IPC and the International Electronics Manufacturing Initiative (iNEMI) to discuss the problem and need for a standard way of exchanging JIG and other compliance data. ${ }^{12}$ As a result, IPC created a new ANSIapproved material declaration standards development project with NIST providing the technical leadership. The 1752 standards development team consisted of IPC staff members, industry representatives from $\mathrm{Tl}$, Sun, E2Open, and staff from the Semiconductor Electronics Division of NIST's Electronics and Electrical Engineering Lab.

\section{NIST's Role}

NIST and IPC started collaboration in early December 2004, with other participants joining in shortly afterward. IPC created the standards working group and worked to pull in individual companies to provide the domain expertise needed. NIST provided the technical expertise, problem modeling, programming for an associated software application, documentation for an XML data standard, and eventually chaired the effort. The development work included creating the new documentary standard as well as a software reference implementation that could be used by industry. This was especially beneficial for small and medium manufacturers.

In addition to its role supporting the IPC standard effort, NIST also supported the efforts of alternative material declaration standards, most notably RosettaNet and IEC TC111. The IPC 1752 standard was

\footnotetext{
${ }^{12}$ iNEMIis an industry-led consortium whose mission is to assure leadership of the global electronics manufacturing supply chain. It has a membership that includes electronics manufacturers, suppliers, associations, government agencies and universities.
} 
designed so that data could be easily imported into a RosettaNet enterprise management system. Also, the model underlying 1752 was used a starting point for the IEC TC111's standard 62474. This allowed the IEC TC111 to leverage the work already done in 1752 , greatly diminishing incompatibilities between the two standards going forward.

\section{What would have been done, absent NIST?}

NIST's participation accelerated the process both because NIST was a ready source of technical expertise and because NIST's "honest broker" role reduced what economists refer to as the "transaction costs" of negotiating complex technical agreements among competing interests. NIST participation improved the technical veracity of the effort, reduced the cost to industry of getting a standard approach in place, and, most importantly, accelerated the flow of economic benefits that result from the implementation of solutions to such problems.

The IPC 1752 working group managed to create the new standard from start to finish in 16 months, releasing both the standard and software tools in April 2006. A second version will soon support a broader scope and can be used for REACH and China ROHS.

From an economic impact perspective, this time saving is critical. Compliance with the EU standard was essential. Even without
NIST participation, an approach to material declaration standards for electronic products would have been developed. In fact a number of competing approaches had been developed. The longer the industry went without a common standard, the harder and more costly it would have been to adopt standard practices. NIST provided technical leadership and an "honest broker" function that would have been time consuming and costly for industry to replicate.

Second, in addition to accelerating the standard development process NIST's modeling and software development experts improved the quality of the 1752 standard by ensuring that it captured the appropriate scope and needs. Industry did not have the XML schema and programming resources needed to develop the solution in the given timeframe and it is unlikely that a broadly compatible technology such as XML would have been selected. The NIST approach was based on rigorous software development processes for data exchange standards that included: defining scope, business cases, and use cases up front, then using modeling to understand the domain, and finally generating the data exchange standard itself from the models. This approach ensured that the final standard more accurately captured the needs of industry, was easy to maintain and update, and could be integrated in data management solutions with minimum effort. 


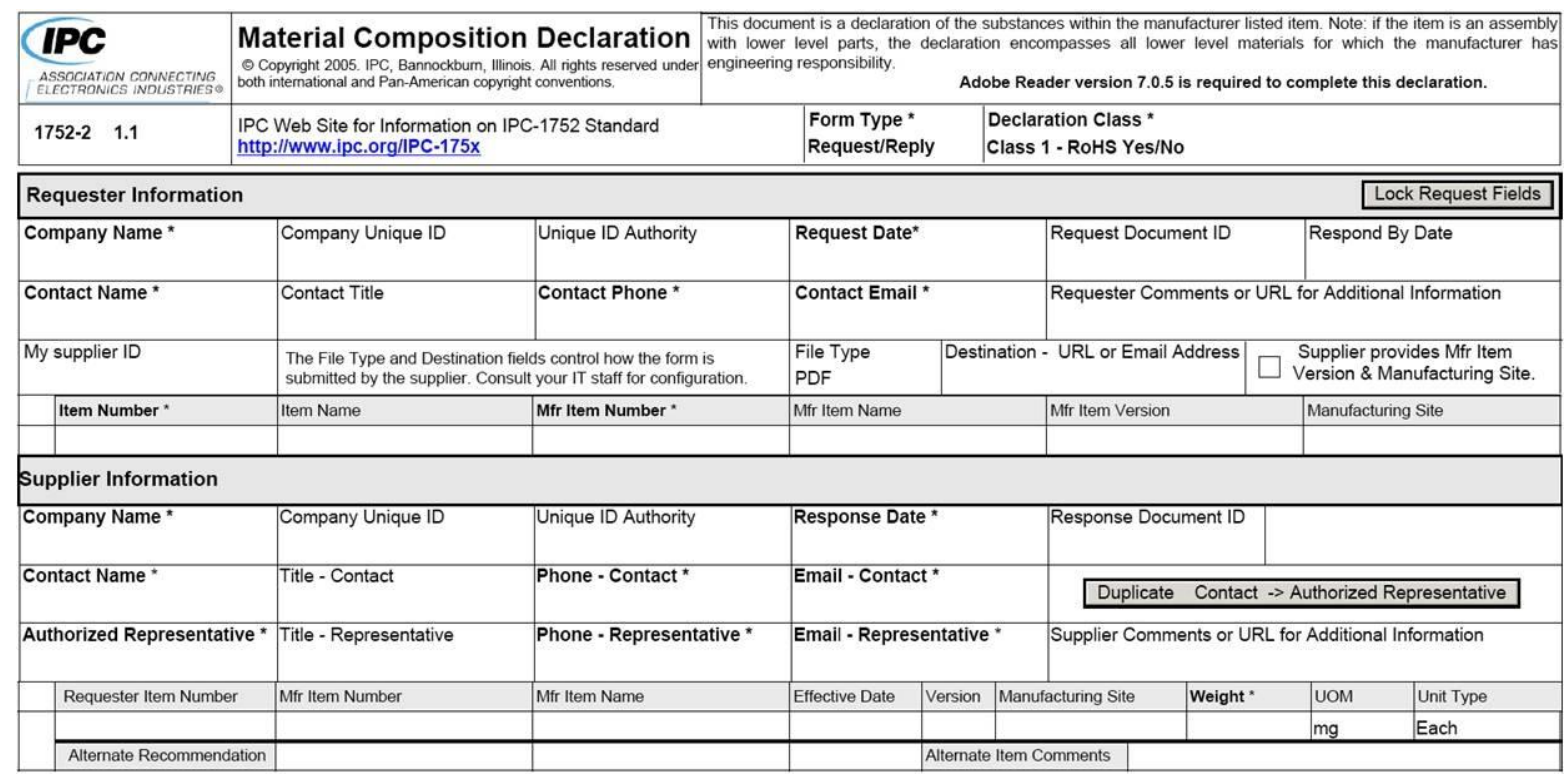

Figure 2M: IPC 1752 tool screen shot showing Class 1\& 2 declarations

The net difference between the cost to NIST of participating in the effort and what it would have cost industry to replicate the functionality and quality of NIST's participation is an important measure of NIST's economic impact.

Third, IPC 1752 reduced the cost of compliance by providing a data exchange standard and freely available software tools. Prior to 1752, compliance was a laborintensive processes requiring the operation and staffing of phone banks and the compilation of spreadsheets to answer customer requests for information. By accelerating the IPC 1752 development process, the compliance cost savings accrued to industry sooner than they would have otherwise, and could be construed as a benefit uniquely attributable to NIST's participation.

Fourth, the high cost of compliance may have forced some small manufacturers out of the business. To the extent that the lower cost of compliance allowed small manufacturers to continue operation, the value added that would have accrued to firms forced to exit the business during the acceleration time attributable to NIST's involvement, so can be construed as an economic impact attributable to NIST.

Fifth, some spillover benefits may have accrued to NIST's involvement in the IPC 1752 development effort to the extent that NIST's methodology served as an example to industry of how to use a rigorous development approach for creating standards that could provide similar results if used for other data exchange standards.

Finally, NIST also participated in alternative material declaration standards, notably the Rosettanet and IEC TC111 efforts. By participating in the initial efforts of these other groups, NIST was able to ensure a high degree of compatibility between the standards. Due to NIST efforts the Rosettanet, IEC TC111, and IPC material declaration standards are all based on the same underlying data model, greatly improving interoperability among the standards. If NIST had not engaged in these activities, the new environmental standards would be largely incompatible; the various 
efforts would have duplicated efforts to develop underlying data models; and the implementation times would likely have been extended. ${ }^{13}$ All these eventualities have associated economic costs. To the extent that they were (or will be) mitigated by NIST's involvement, these reduced costs can also be construed as economic benefits attributable to NIST's involvement in the documentary standards development process.

\section{Conclusion}

The dual challenges of trade globalization and the globalization of environmental consciousness pose difficult technical issues for U.S. manufacturers, especially small and medium sized manufacturers. The EU's recently adopted Restriction on Hazardous Materials (RoHS) regulations are emblematic of these trends. U.S. companies are significant participants in the a multi-billion dollar annual market for "electrotechnical" products and now require stringent materials declarations from their suppliers at all levels of the supply chain.

In cooperation with industry NIST has taken a technical leadership role in the development of voluntary documentary standards that address these concerns. The development of IPC 1752, Materials Declaration Management, is exemplary. By providing unique reputational and technical expertise to this effort, NIST's investments have led to economic impacts in the form of process acceleration, quality improvement, reduced costs of compliance, support of small business, and improved interoperability.

\footnotetext{
${ }^{13}$ As of August 2008, the IEC TC111 standard is not yet available.
} 


\section{Future Steps and Conclusion}

Technology Services has launched a long-term effort to assess the extent, nature, and outcomes of NIST's involvement in documentary standards development activities. The initial and on-going canvassing activities (as reported in this paper) are part of three-step approach to thoroughly understanding NIST's role in these activities and their impact, with the long-term goal of developing an assessment capability and integrating it into NIST's planning, evaluation, and resource allocation cycle. The benefits from NIST involvement include producing standards faster than otherwise would have been the case without NIST participation; creating specific improvements to products and services; and developing broader standards. We have also learned that the efforts cut across many application areas and technologies.

Some broad findings from this study to date are:

- NIST personnel are a ready source of information needed to screen documentary standards projects for their economic impact potential.

- On the basis of experience conducting outcome assessments, "indicators" can be formulated that aid in the selection of outcome assessment candidates

- On the basis of a straightforward interrogatory process of questions and answers with NIST personnel, "success stories" can be developed that at least illuminate NIST's unique role in the development process and at best clarify both the basis of an activity's economic impact and the sources of evidence that can be used to develop formal, quantitative economic impact assessments.

The three cited success stories also show us concretely how NIST was involved in supporting the development of some important standards, what its role was vis-à-vis industry input in developing the standard, and some concrete outcomes in terms of lives saved and injuries prevented, reduced risk of terrorist actions, and industry-wide transaction cost savings.

From the 78 projects identified in this canvassing effort, one or two will be chosen as case study candidates. A project will be selected based on indications that substantial market impact has occurred or is likely in the near future ${ }^{20}$ The perceived importance of NIST's contribution to the standardization effort will also be considered in the selection of the case study.

These studies should yield analytical methodologies that will support NIST efforts to implement a more strategic approach to its standards efforts, including more alignment with government-wide or NIST priority or focus areas. The studies will also enhance NIST's ability to better support industry, government and other stakeholders by 
participating in standards areas that are most likely to result in safer, more reliable, interoperable products and enhanced U.S. global competitiveness and innovation.

Although a full canvassing report is not necessary each year, the contents of Table 5 could be updated on an annual basis to keep this listing current. Such updating would serve to emphasize that participation in documentary standards activities is an important component of NIST's mission.

In conclusion, the canvassing results presented in Table 5 reflects NIST's important work in supporting standards development activities and how these efforts result in broadbased economic and social benefits. This information also forms the foundation for future work in assessing the extent, nature, and outcomes of NIST's involvement in documentary standards efforts to help promote U.S. innovation and industrial competitiveness. 


\begin{tabular}{|c|c|c|}
\hline 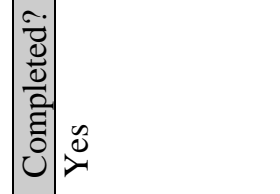 & $\mathscr{x}_{x}^{\infty}$ & 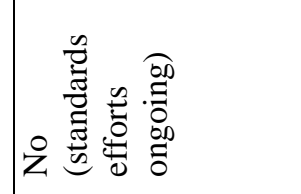 \\
\hline 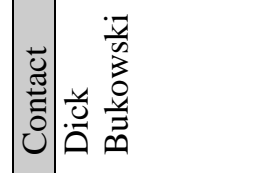 & 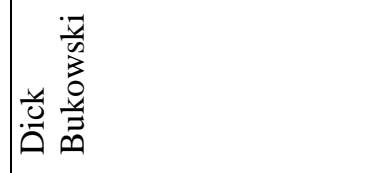 & 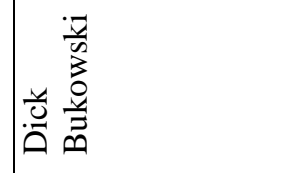 \\
\hline 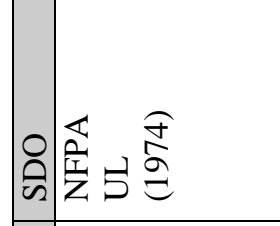 & 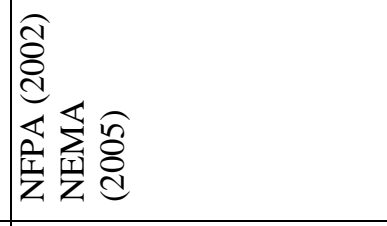 & 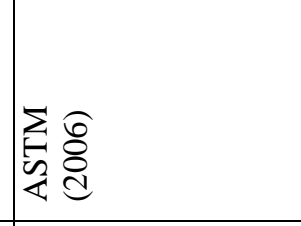 \\
\hline 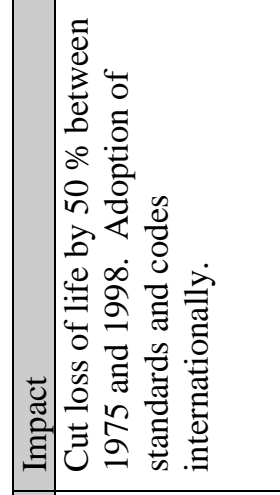 & 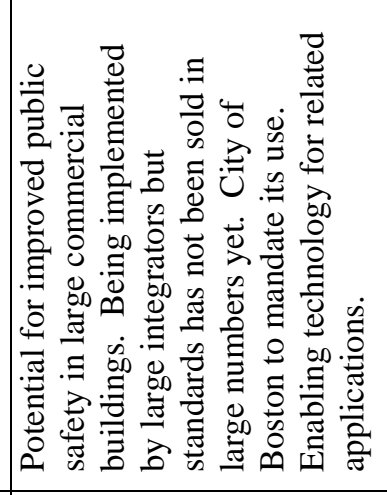 & 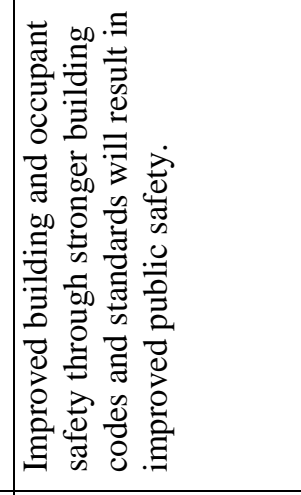 \\
\hline 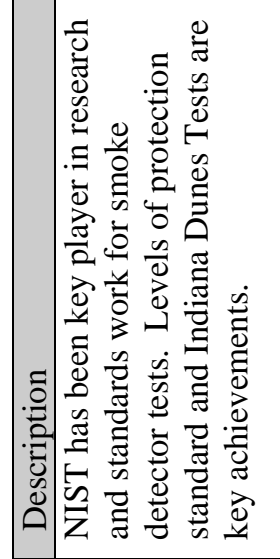 & 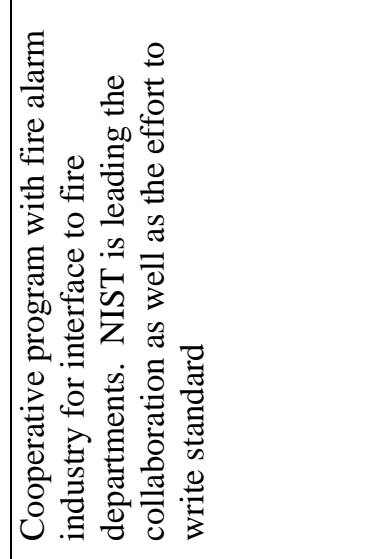 & 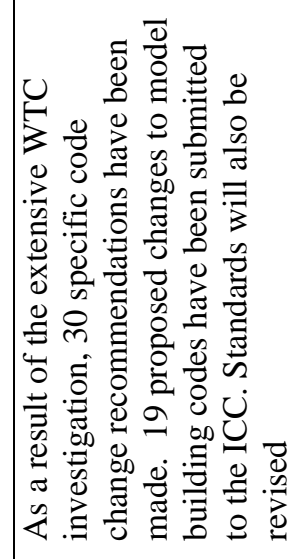 \\
\hline 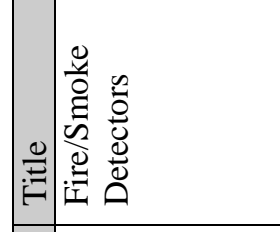 & 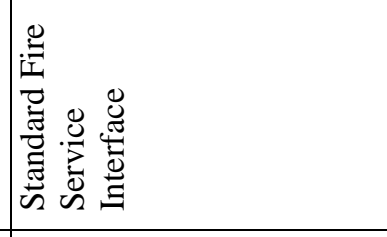 & 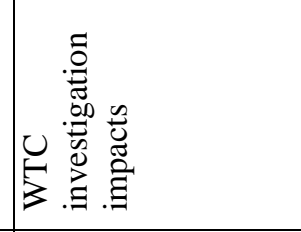 \\
\hline 㞼 & 崖 & 奠 \\
\hline
\end{tabular}




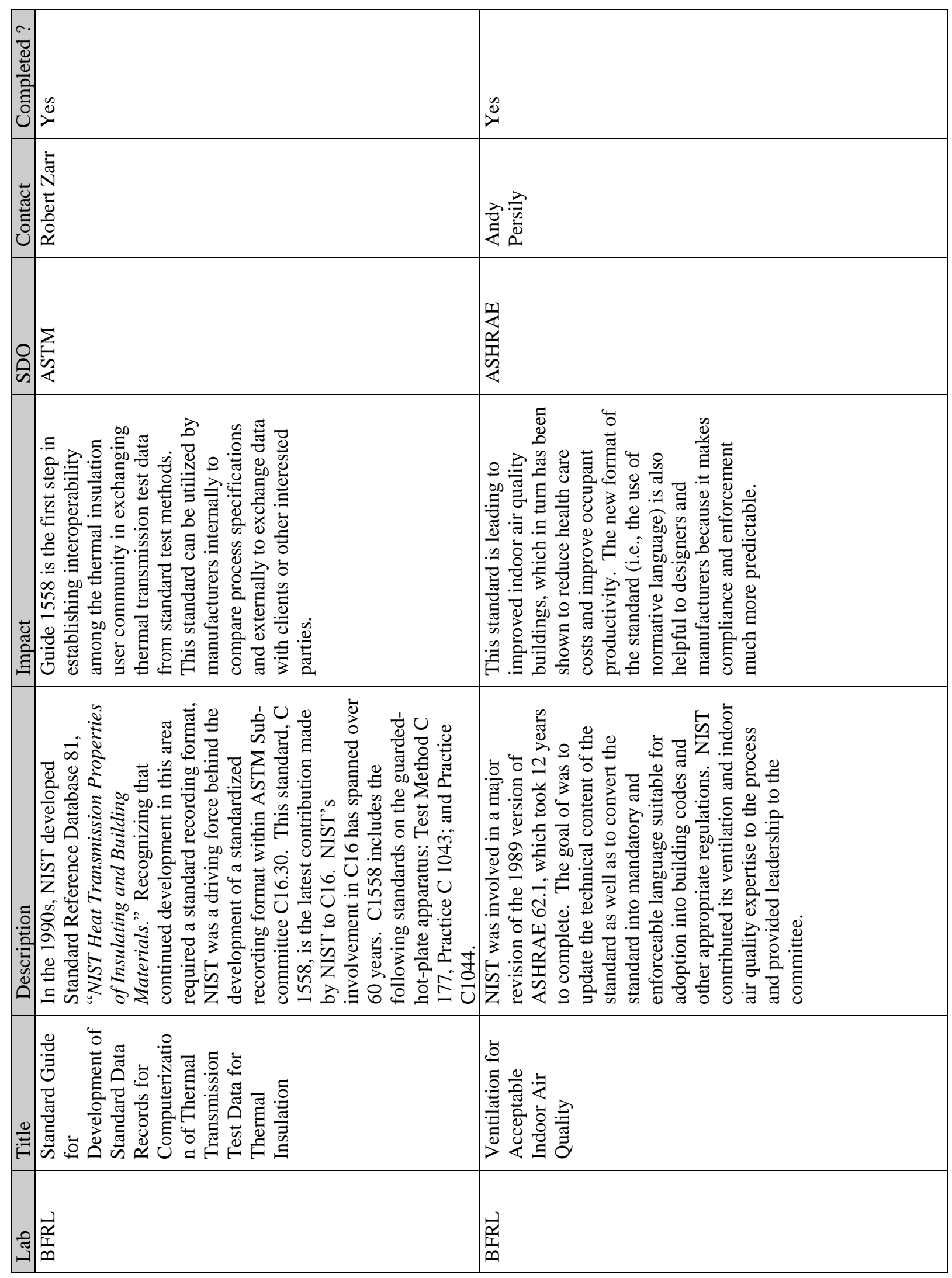




\begin{tabular}{|c|c|}
\hline 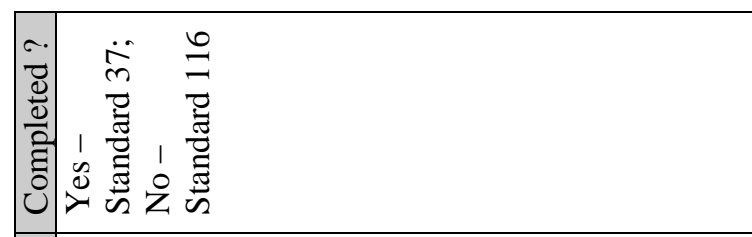 & 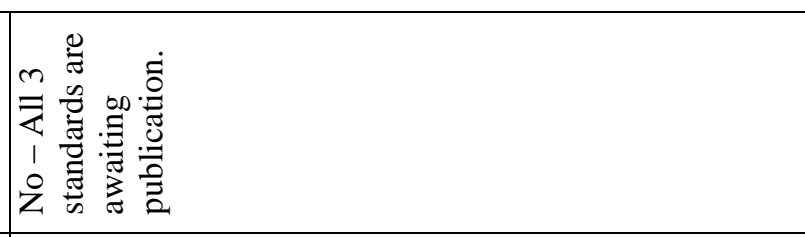 \\
\hline 竎 & 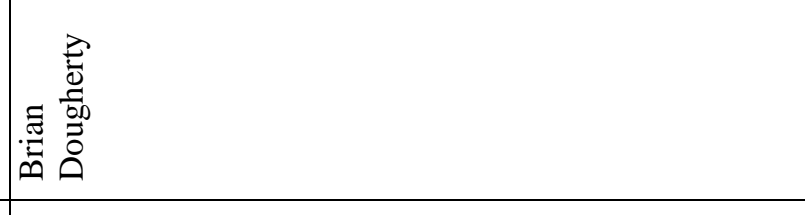 \\
\hline 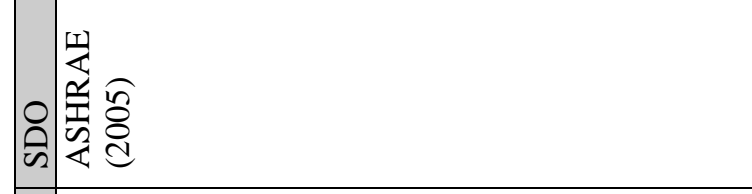 & 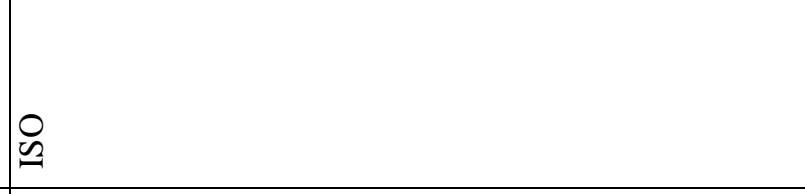 \\
\hline 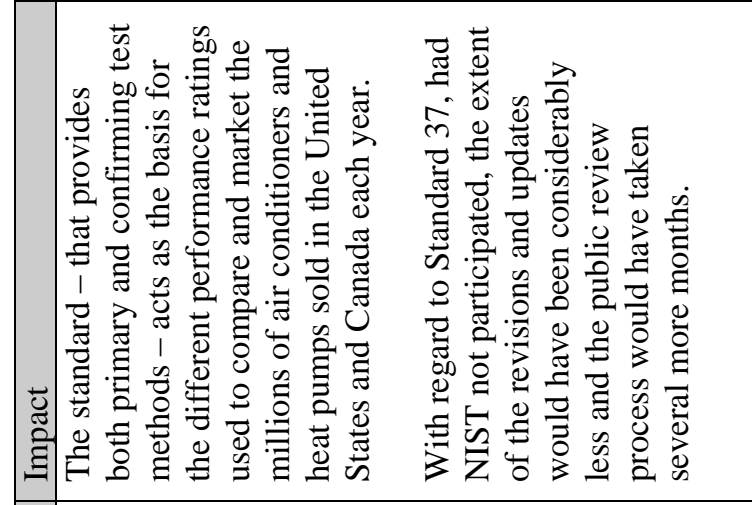 & 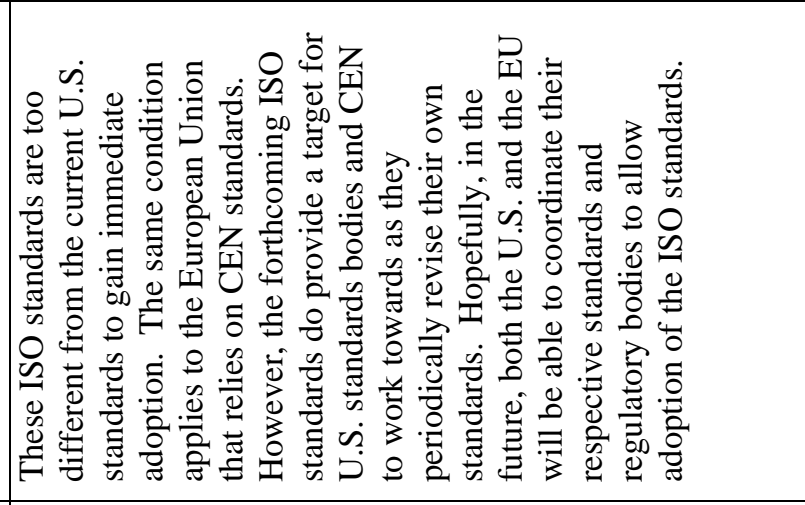 \\
\hline 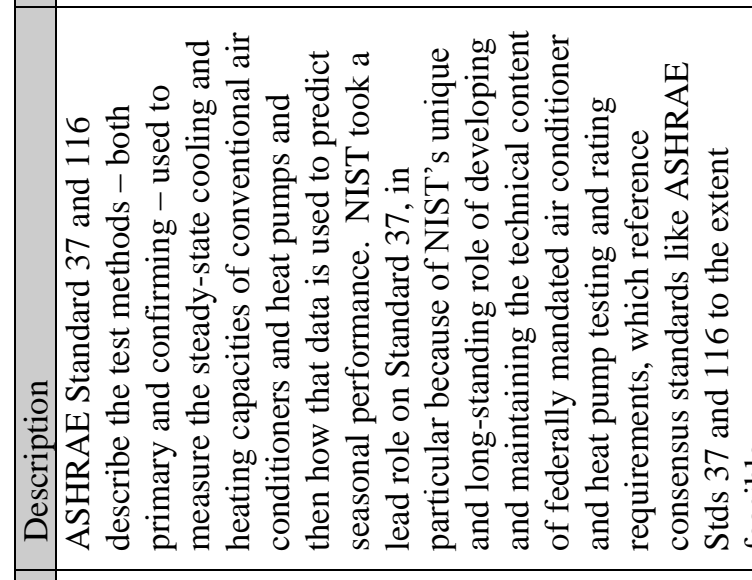 & 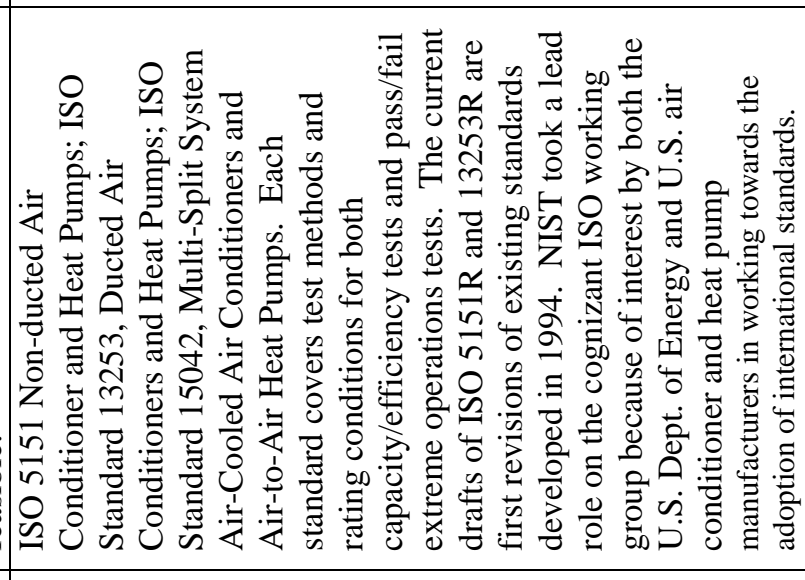 \\
\hline 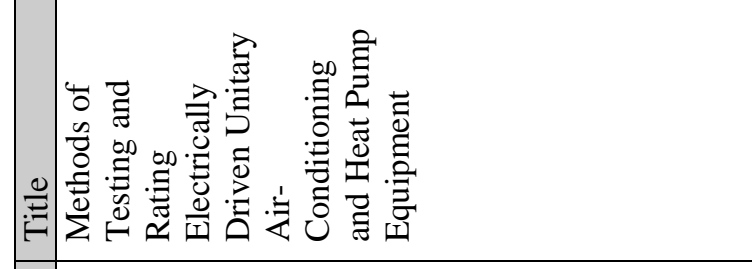 & 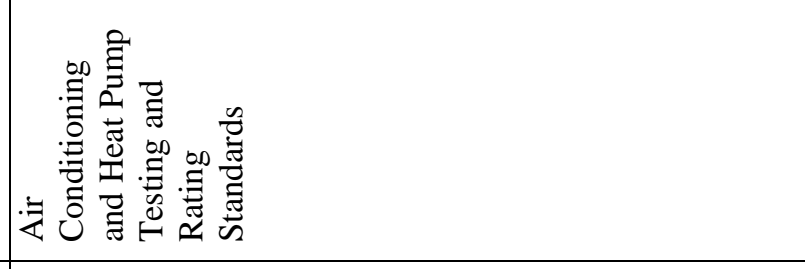 \\
\hline 运 & 茎 \\
\hline
\end{tabular}




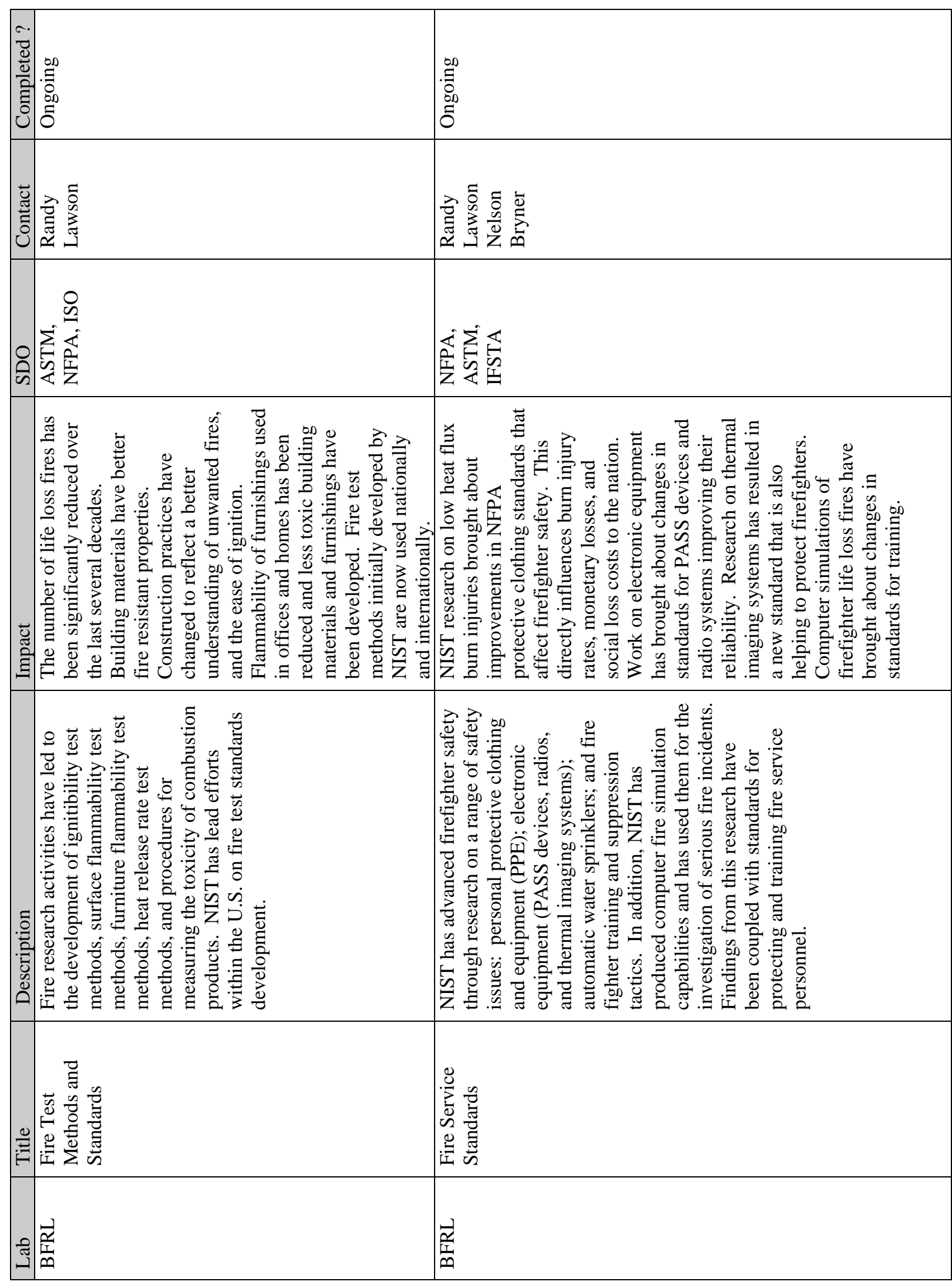




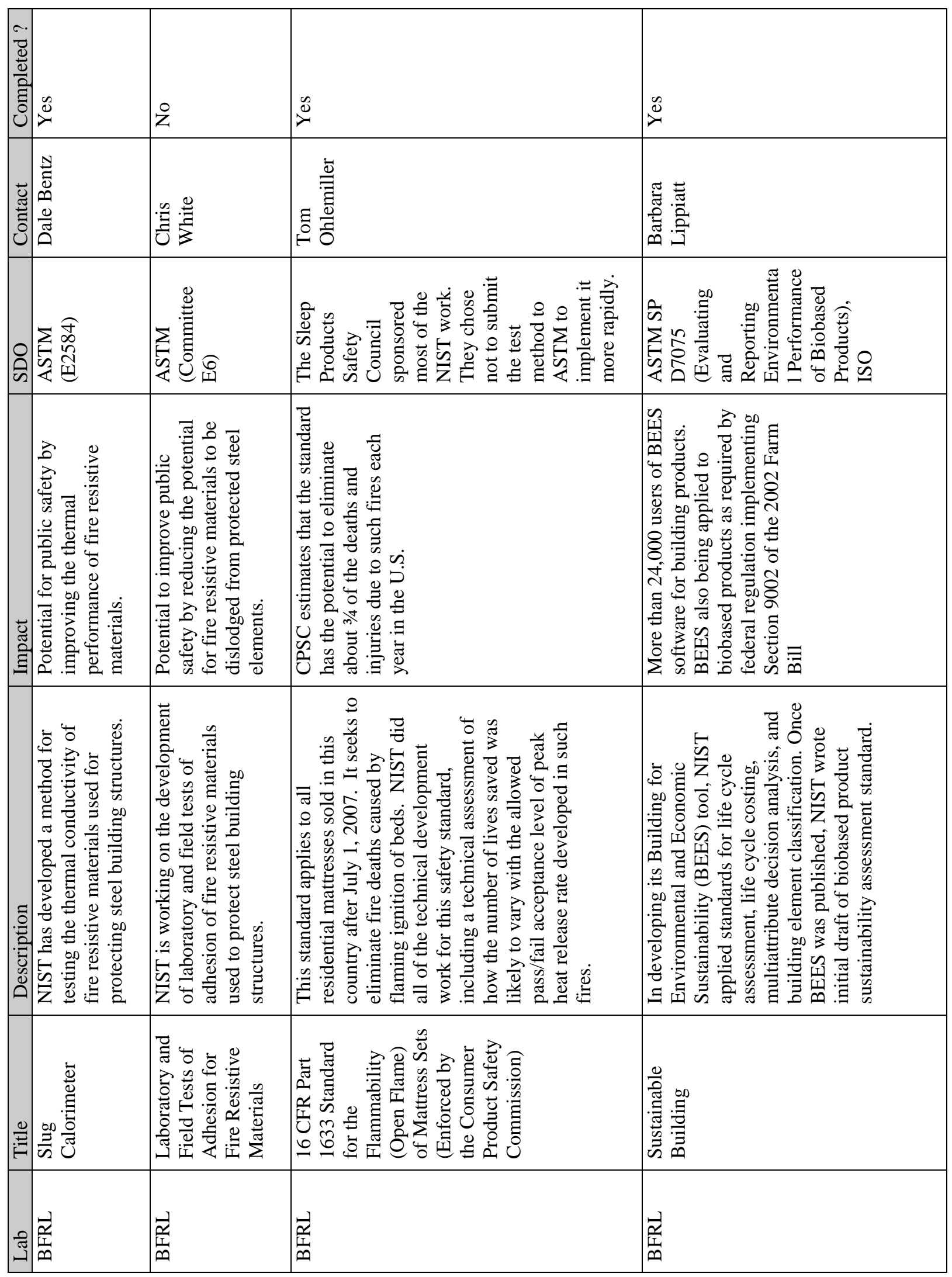




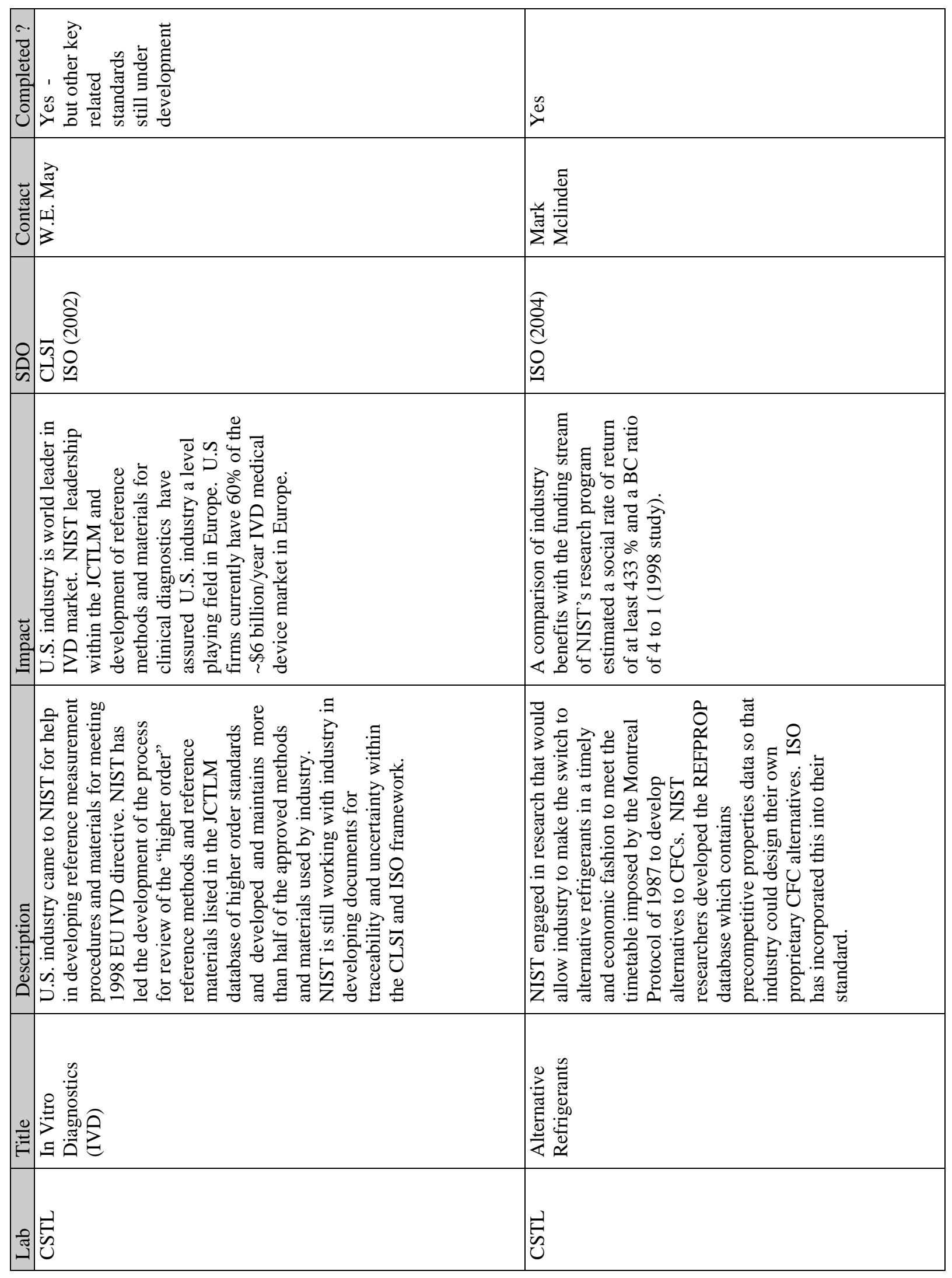




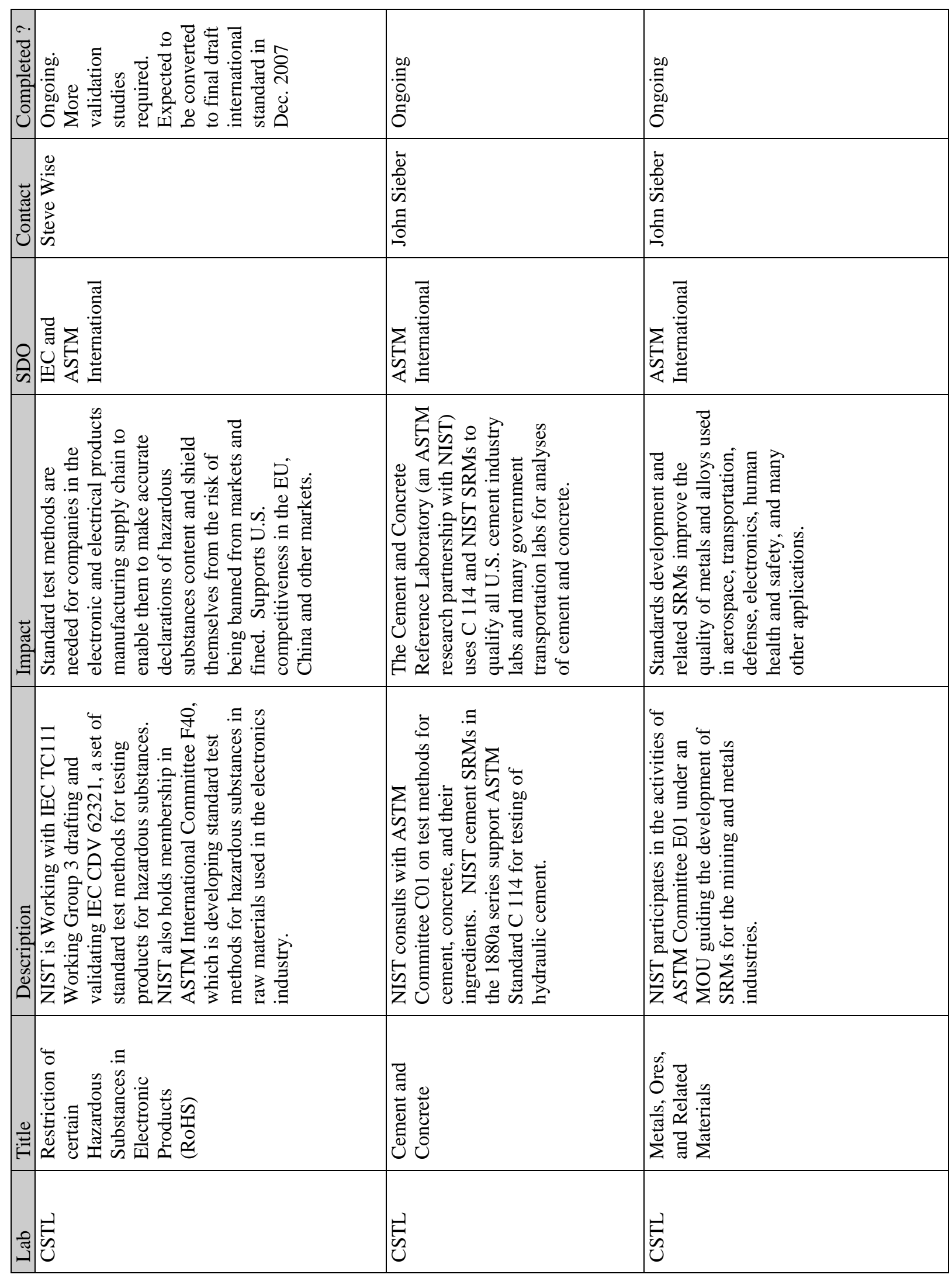




\begin{tabular}{|c|c|c|}
\hline 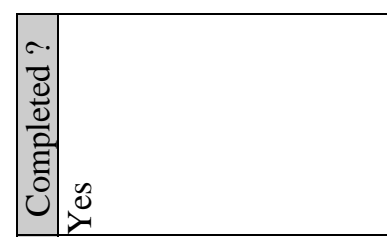 & $\underset{\sim}{\mathscr{\varkappa}}$ & 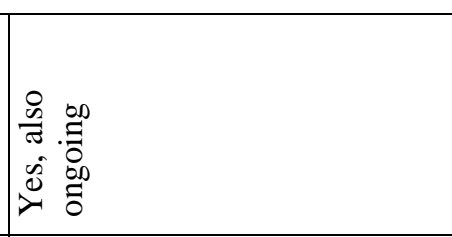 \\
\hline 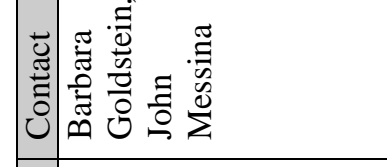 & 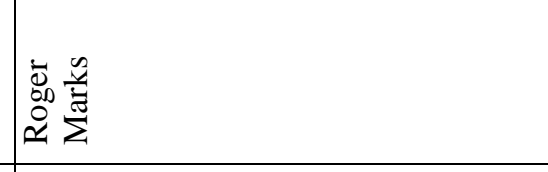 & 总咅 \\
\hline 竞 & 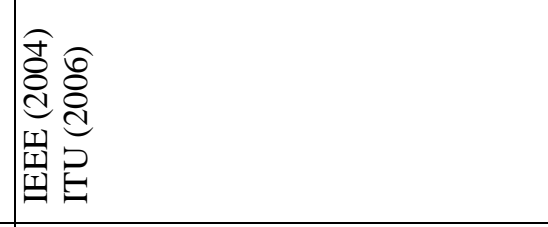 & 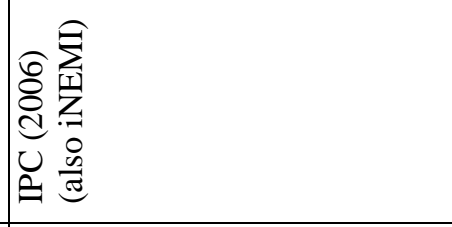 \\
\hline 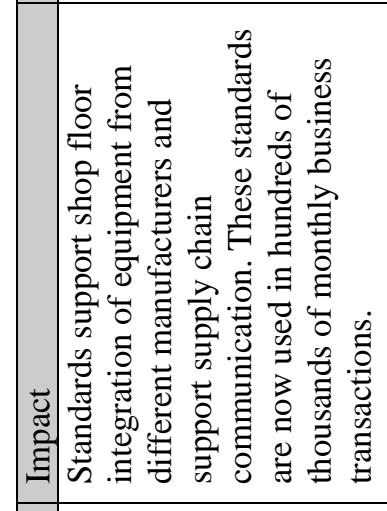 & 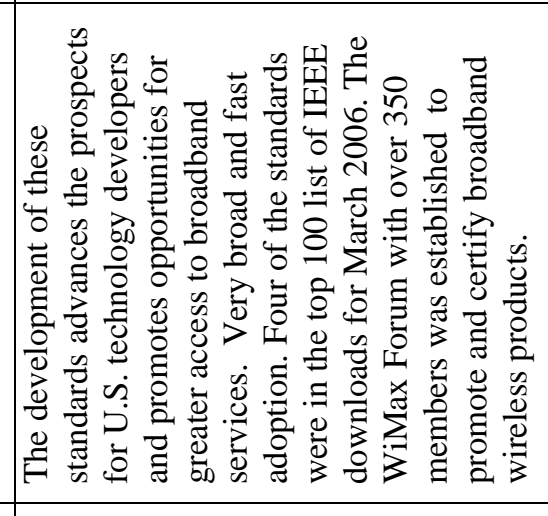 & 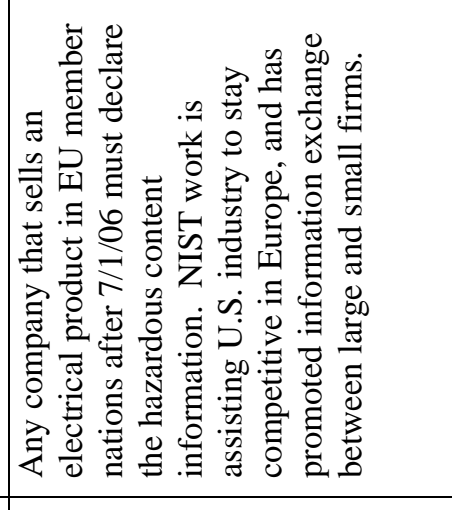 \\
\hline 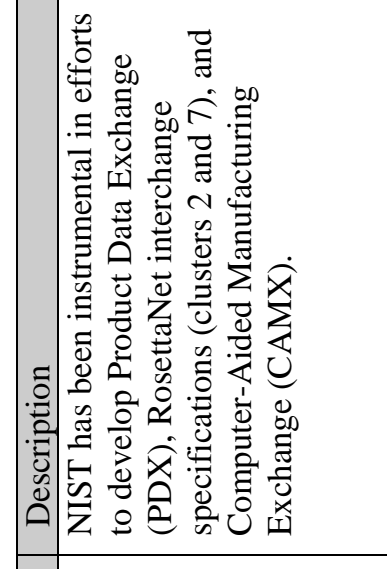 & 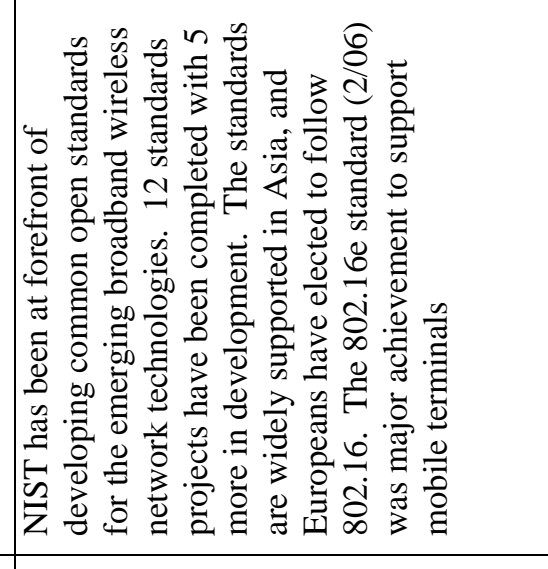 & 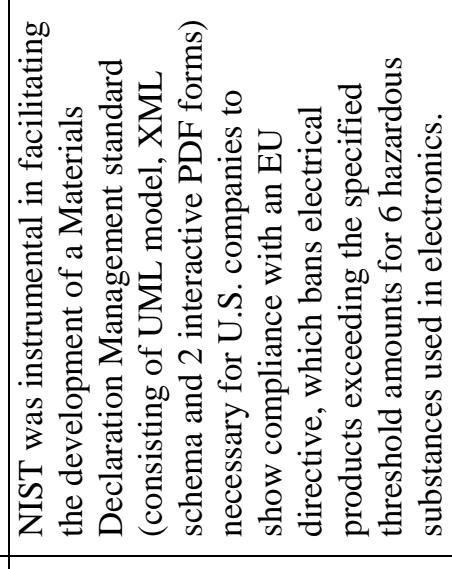 \\
\hline 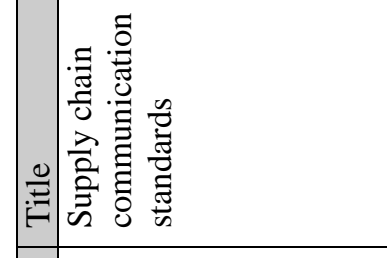 & 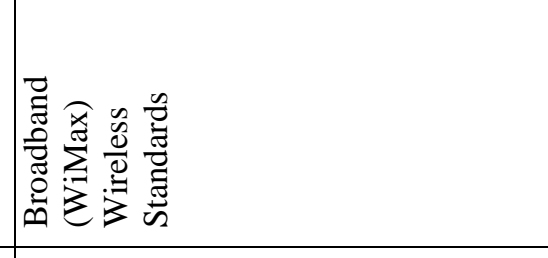 & 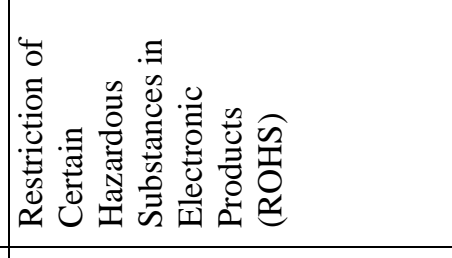 \\
\hline 迅 & 密 & 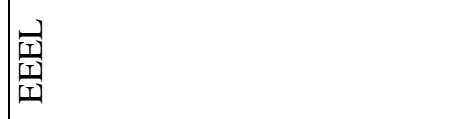 \\
\hline
\end{tabular}




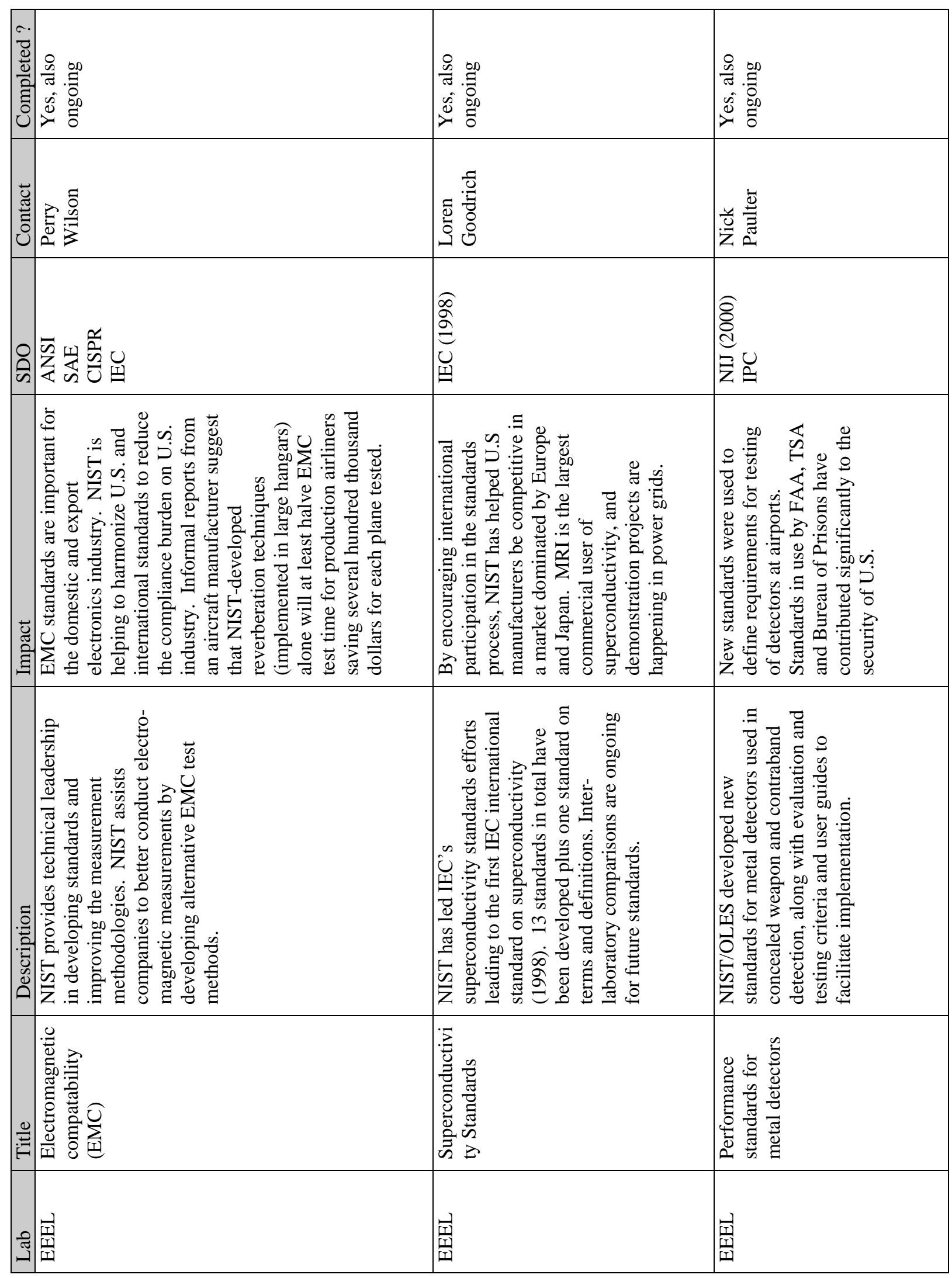




\begin{tabular}{|c|c|c|}
\hline 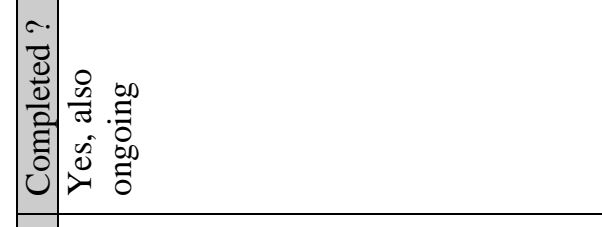 & 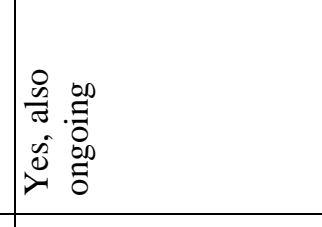 & 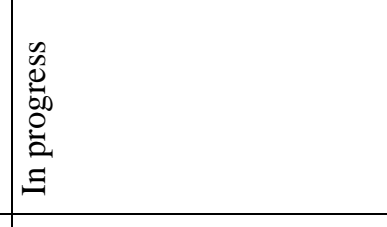 \\
\hline 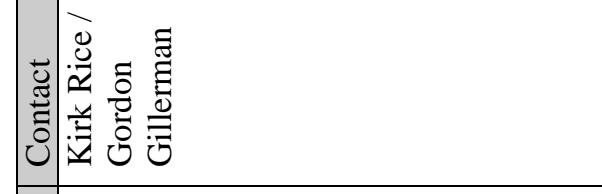 & 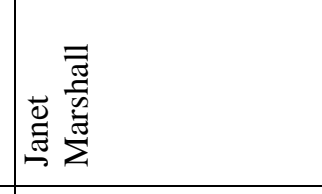 & 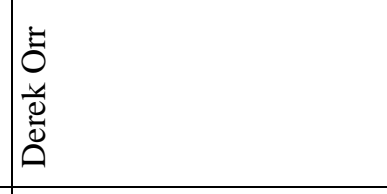 \\
\hline 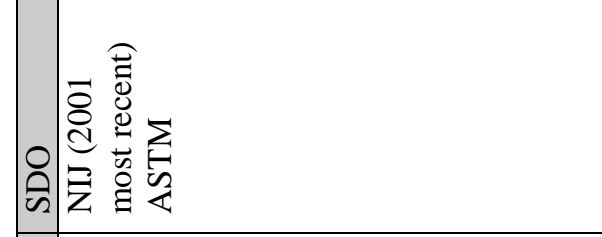 & 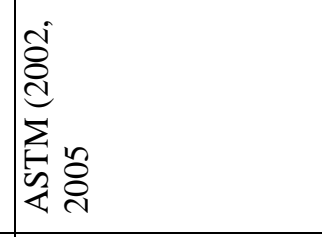 & 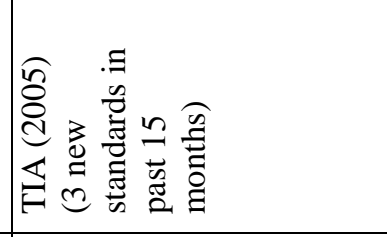 \\
\hline 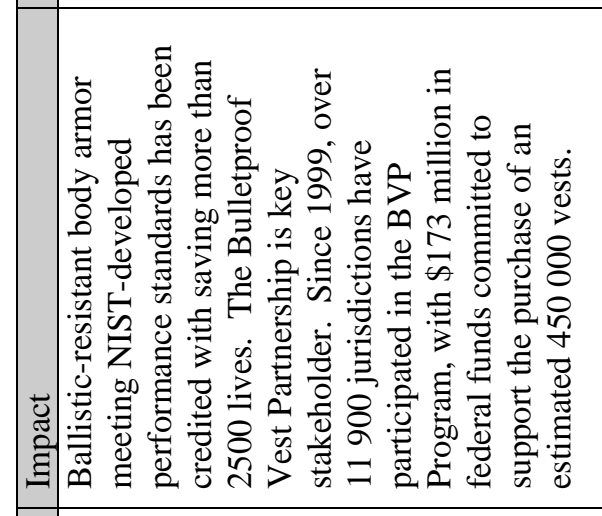 & 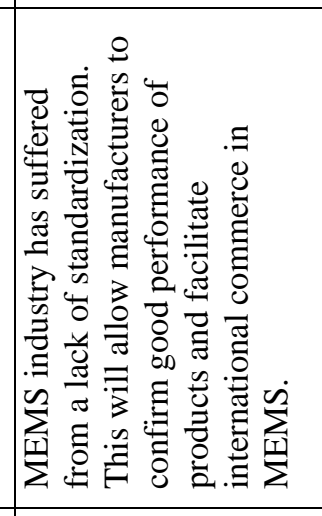 & 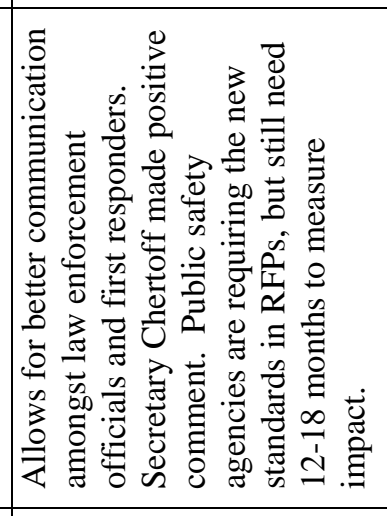 \\
\hline 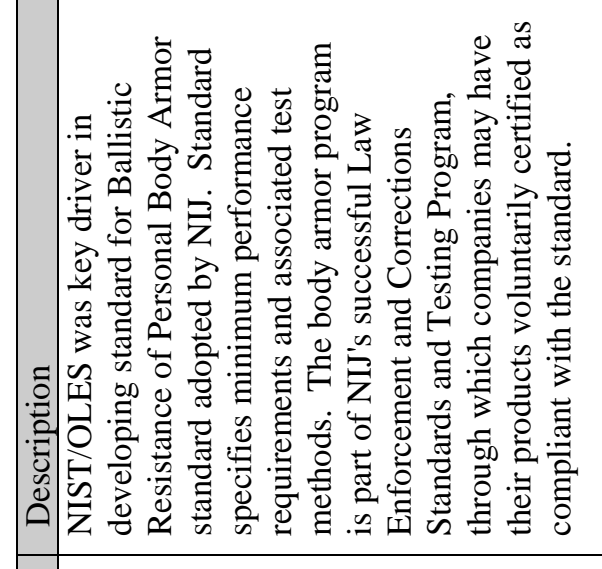 & 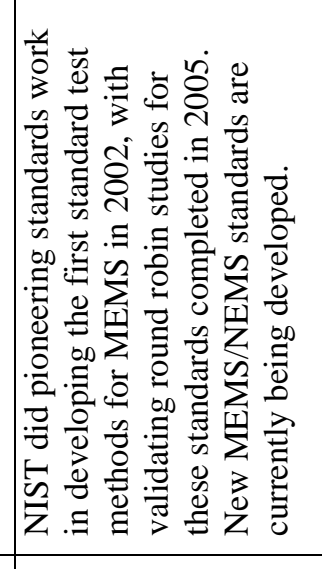 & 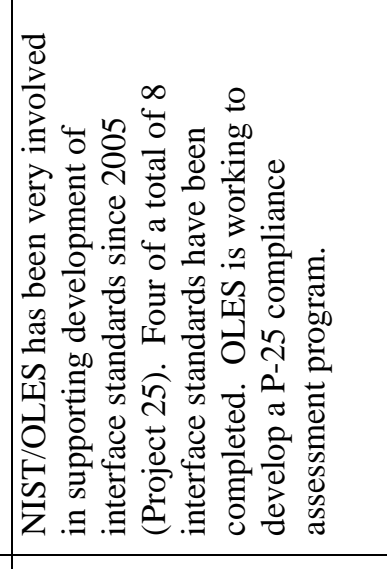 \\
\hline 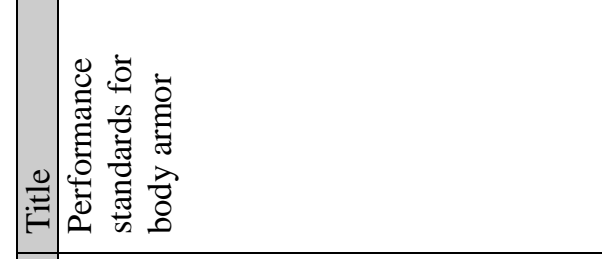 & 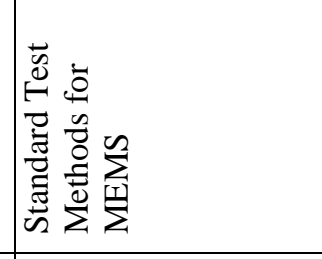 & 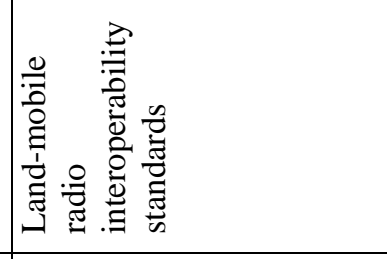 \\
\hline 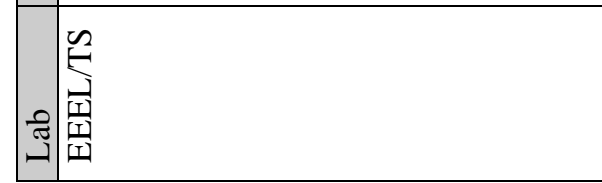 & 畐 & 㞒 \\
\hline
\end{tabular}




\begin{tabular}{|c|c|c|c|}
\hline 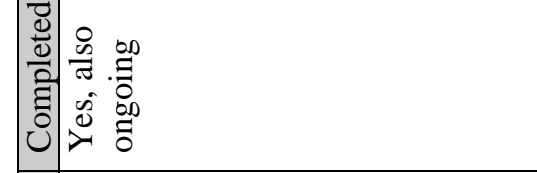 & 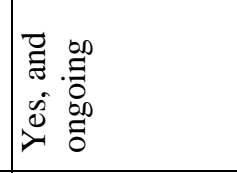 & $\stackrel{\circlearrowright}{\rightleftharpoons}$ & 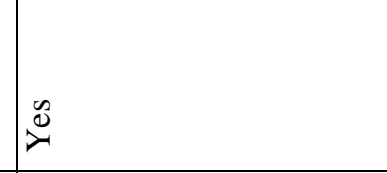 \\
\hline 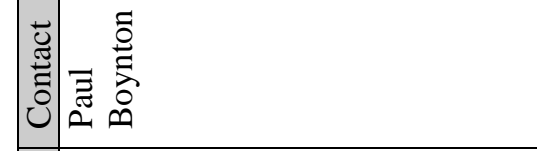 & E & 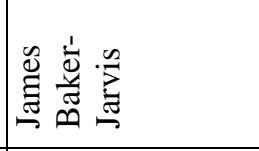 & 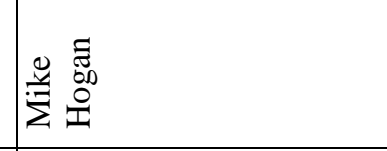 \\
\hline 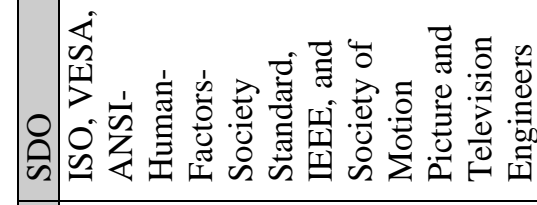 & 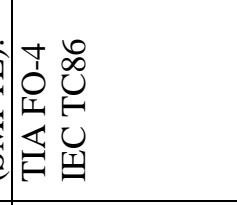 & 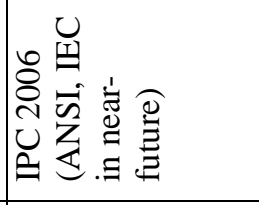 & 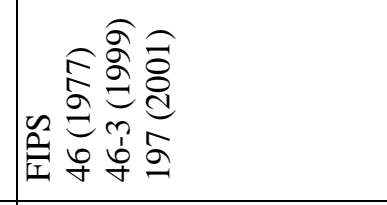 \\
\hline 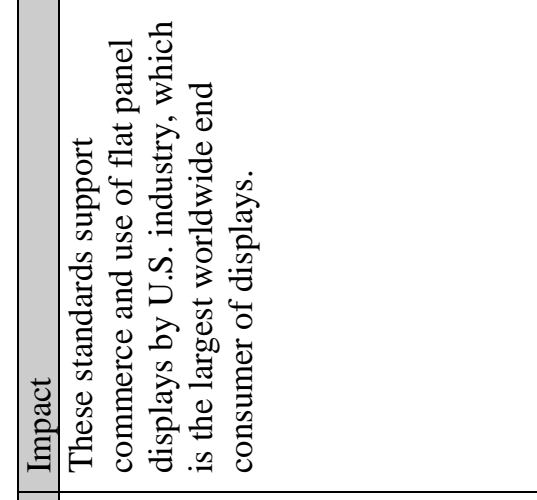 & 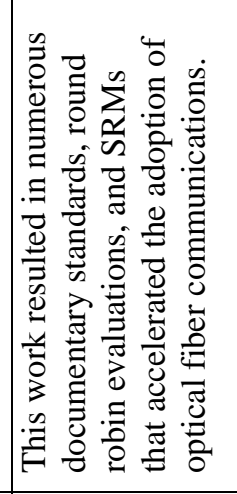 & 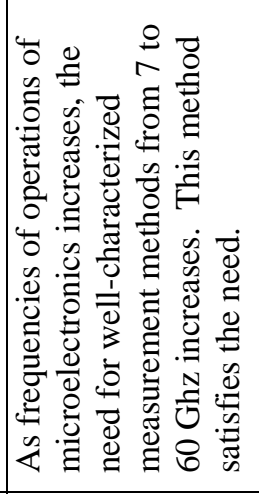 & 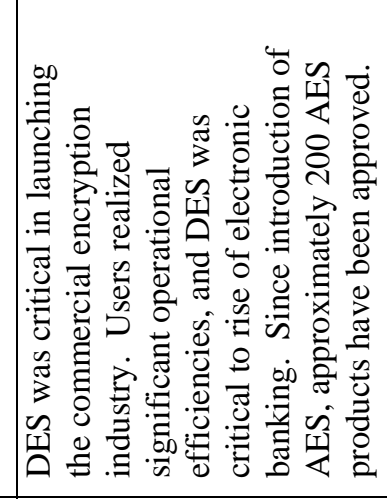 \\
\hline 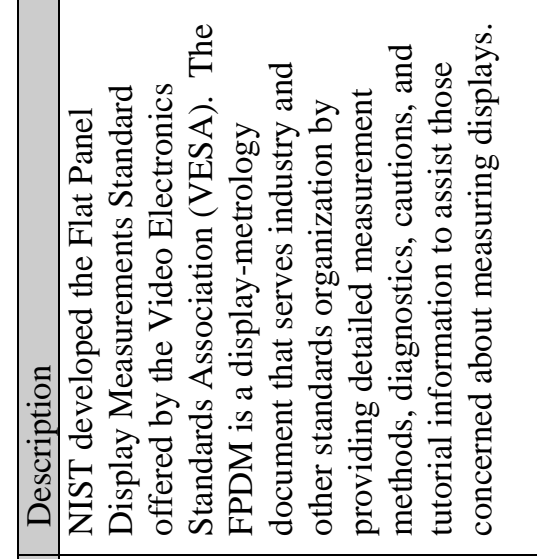 & 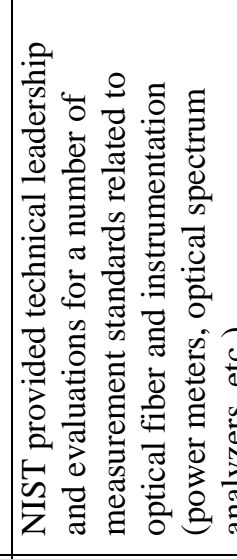 & 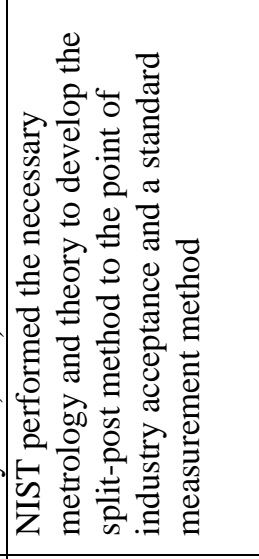 & 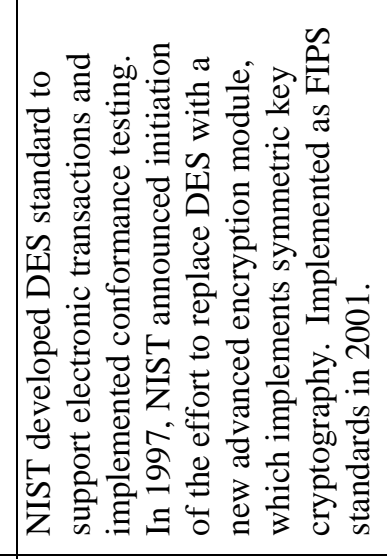 \\
\hline 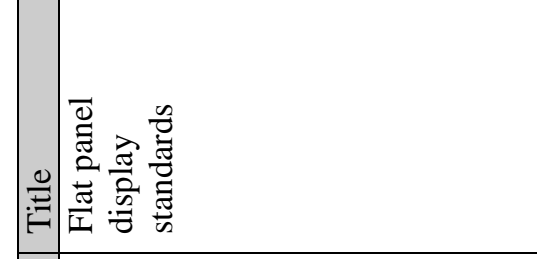 & 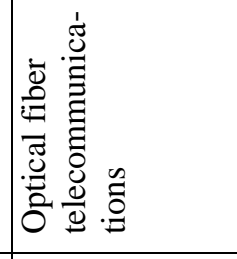 & 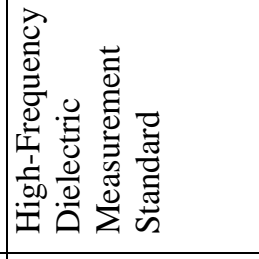 & 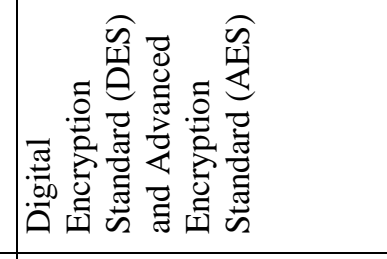 \\
\hline 웝 & 漓 & 畐 & $\vec{E}$ \\
\hline
\end{tabular}




\begin{tabular}{|c|c|c|}
\hline 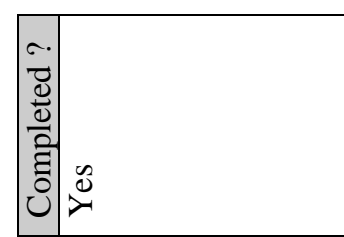 & 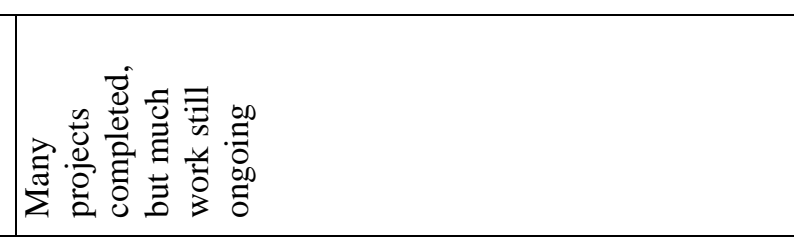 & 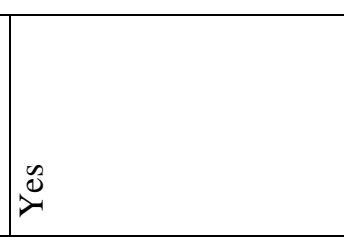 \\
\hline 莺 & 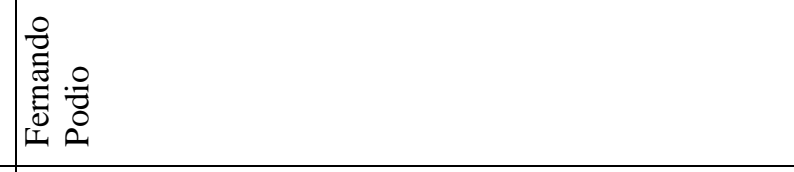 & 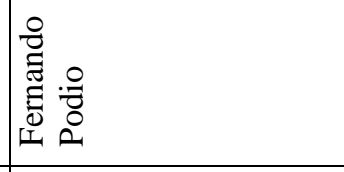 \\
\hline 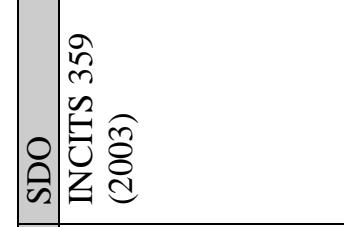 & 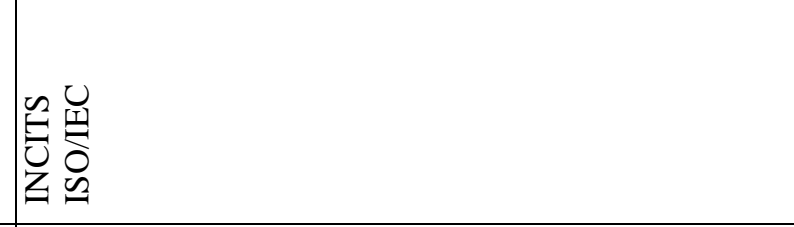 & $\begin{array}{l}\infty \\
\infty \\
\infty \\
\infty \\
\omega \\
0 \\
\vdots \\
\vdots\end{array}$ \\
\hline 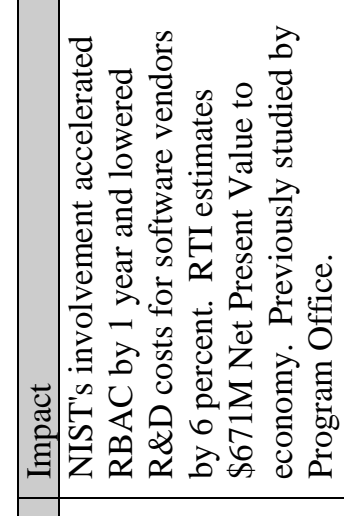 & 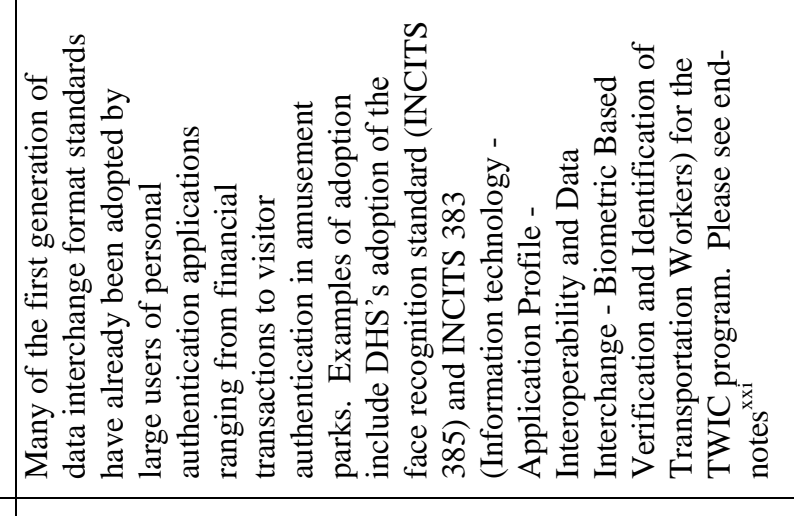 & 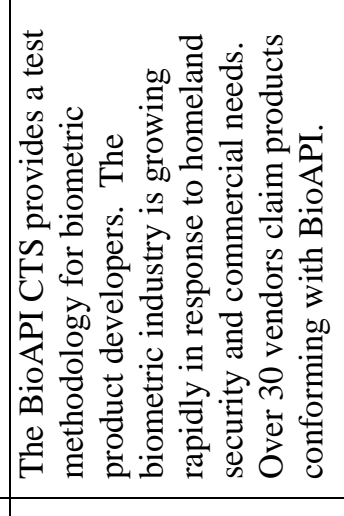 \\
\hline 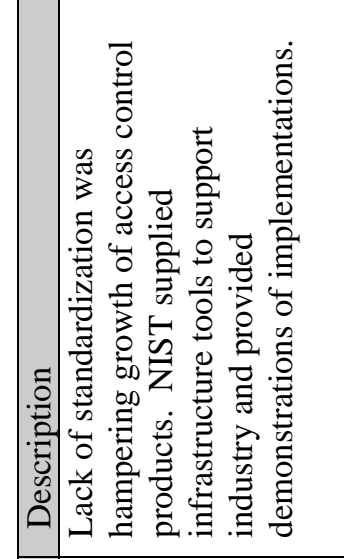 & 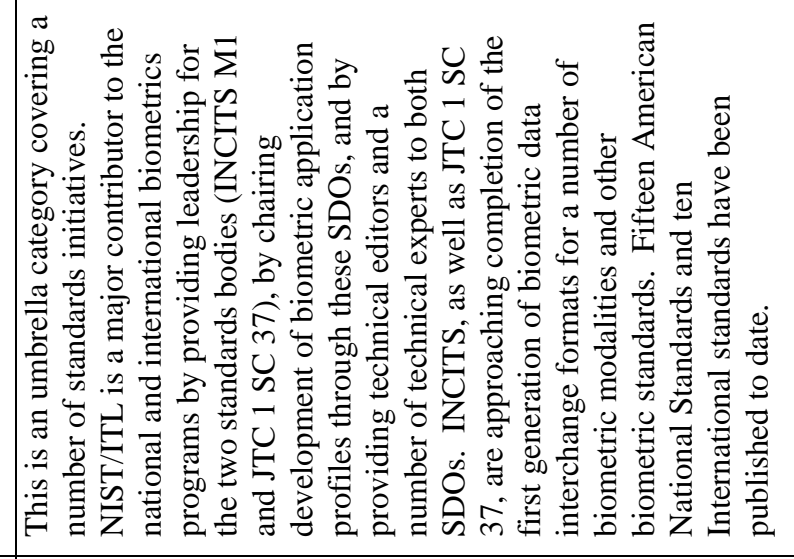 & 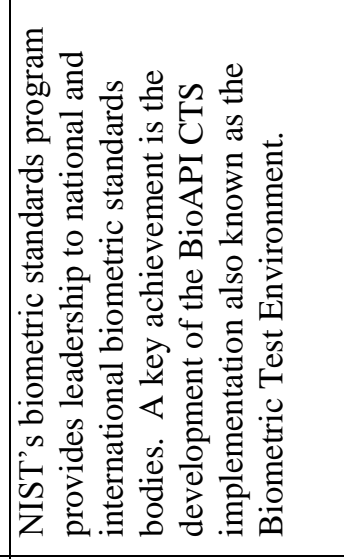 \\
\hline 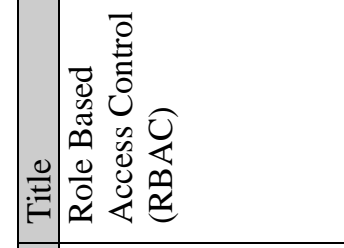 & 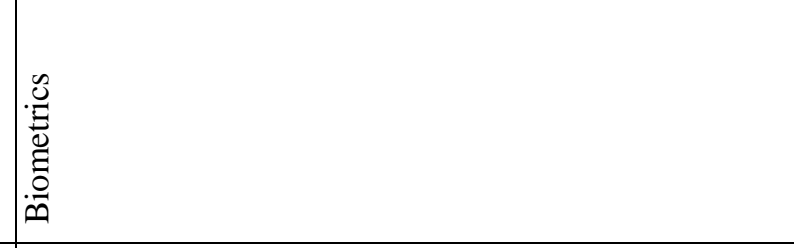 & 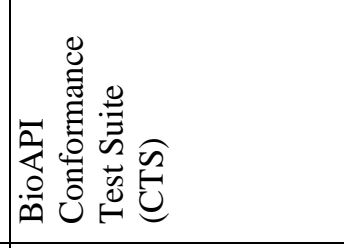 \\
\hline 专寻 & $\vec{E}$ & $\vec{E}$ \\
\hline
\end{tabular}




\begin{tabular}{|c|c|c|}
\hline 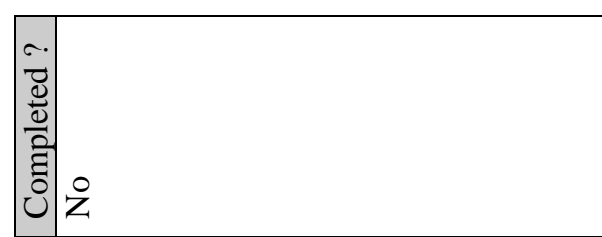 & 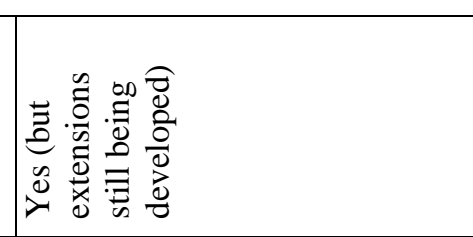 & 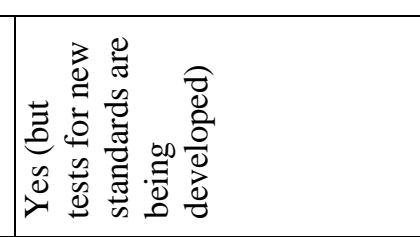 \\
\hline 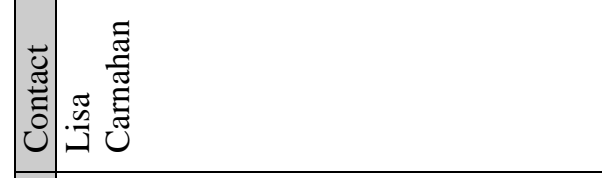 & 蒿 & 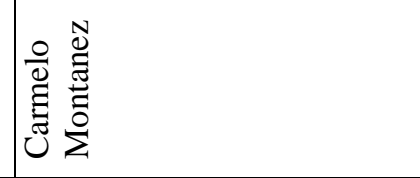 \\
\hline 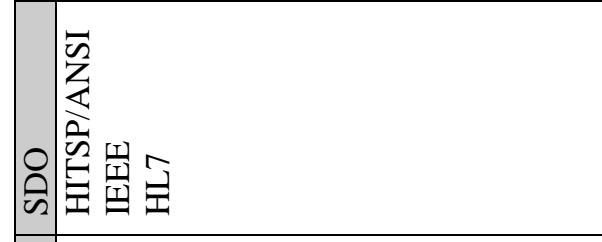 & 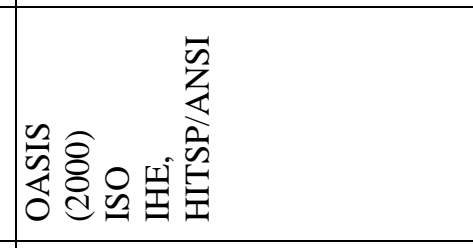 & 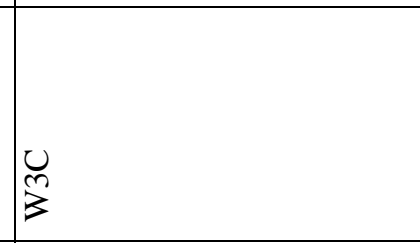 \\
\hline 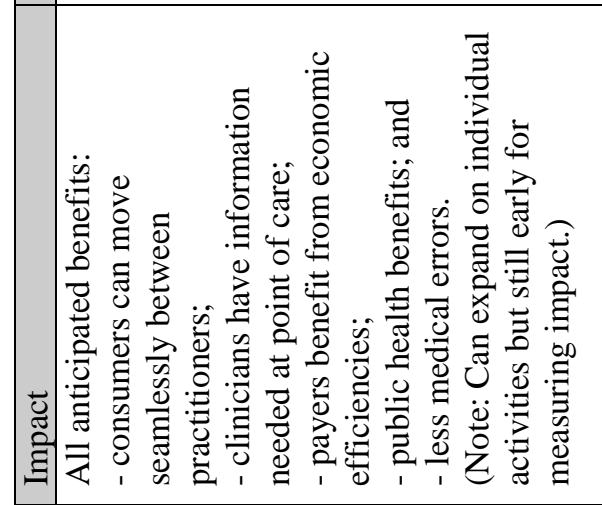 & 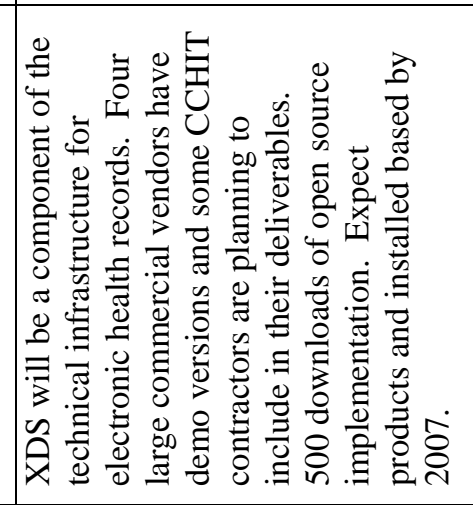 & 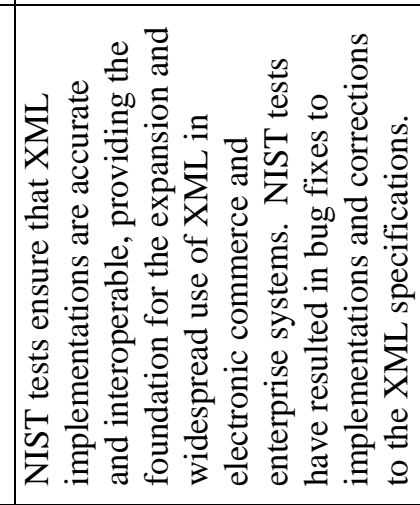 \\
\hline 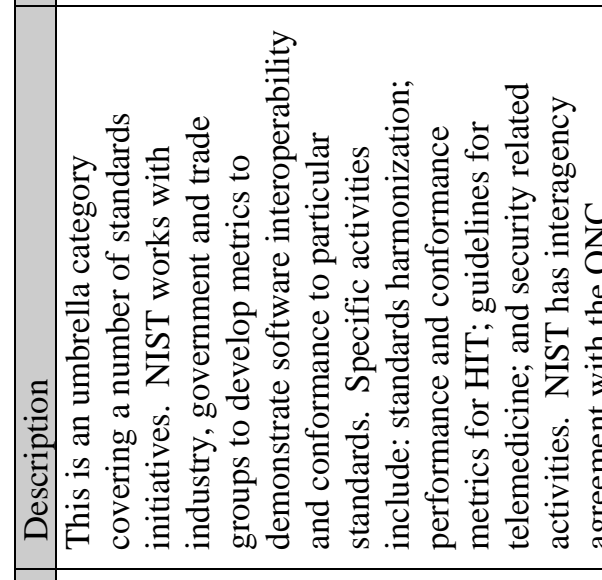 & 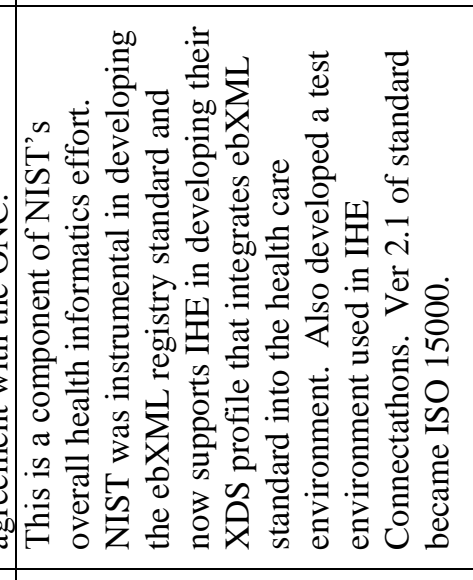 & 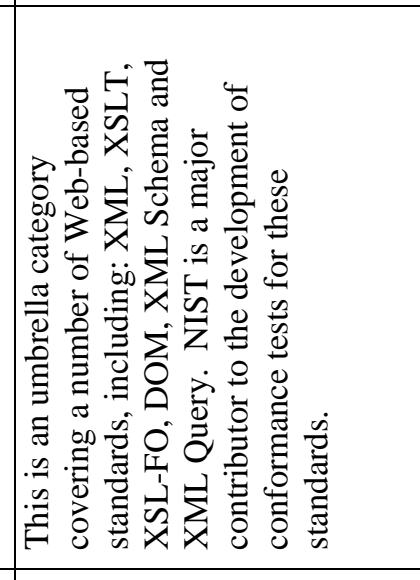 \\
\hline 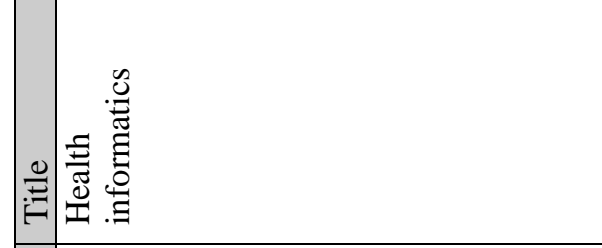 & 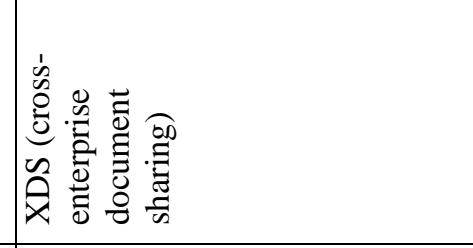 & 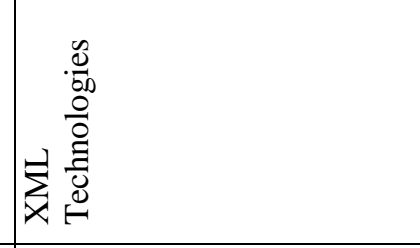 \\
\hline 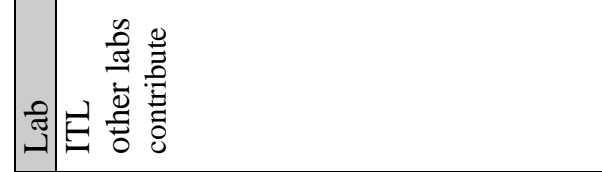 & $\vec{E}$ & $\mathrm{E}$ \\
\hline
\end{tabular}




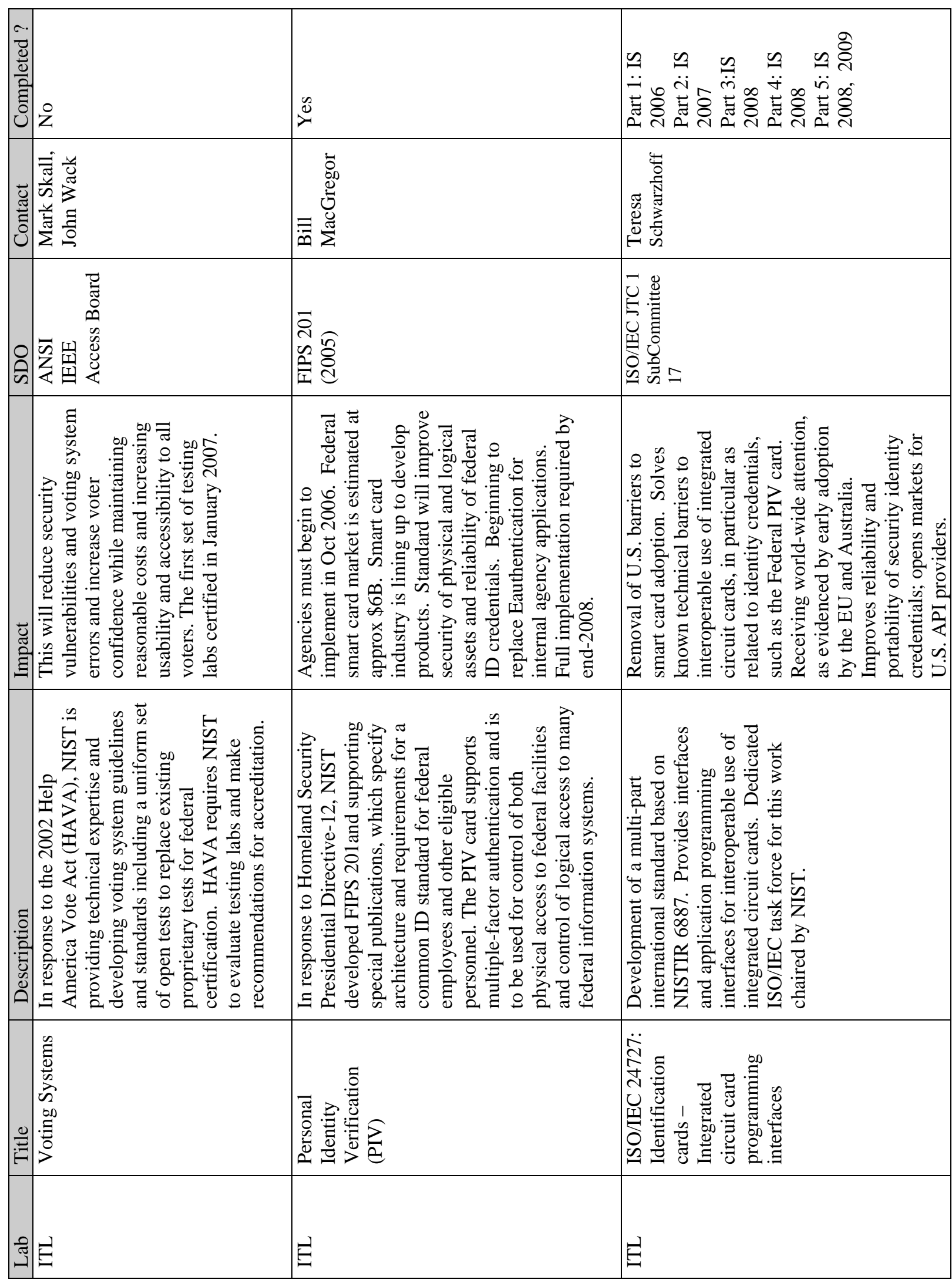




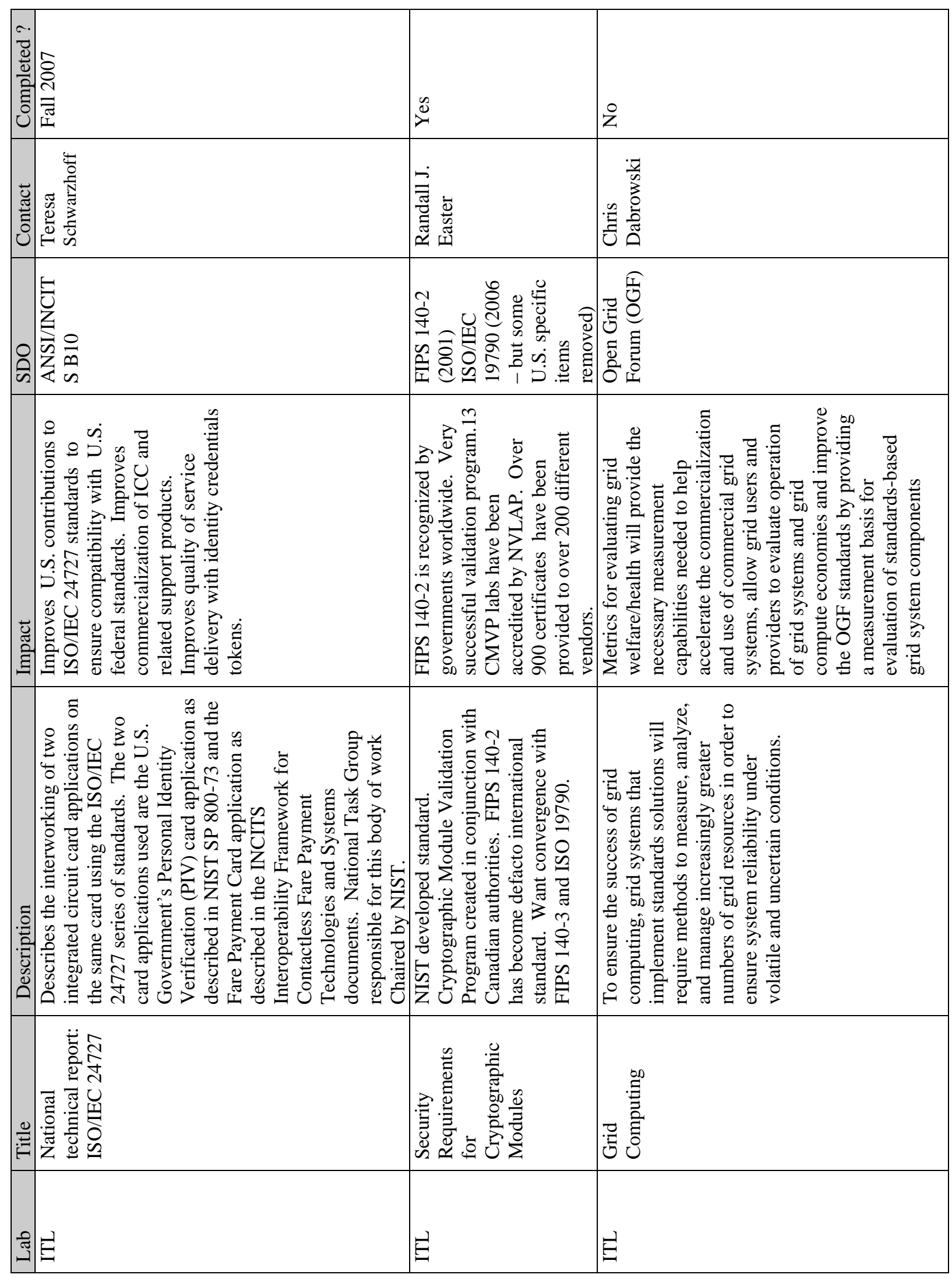




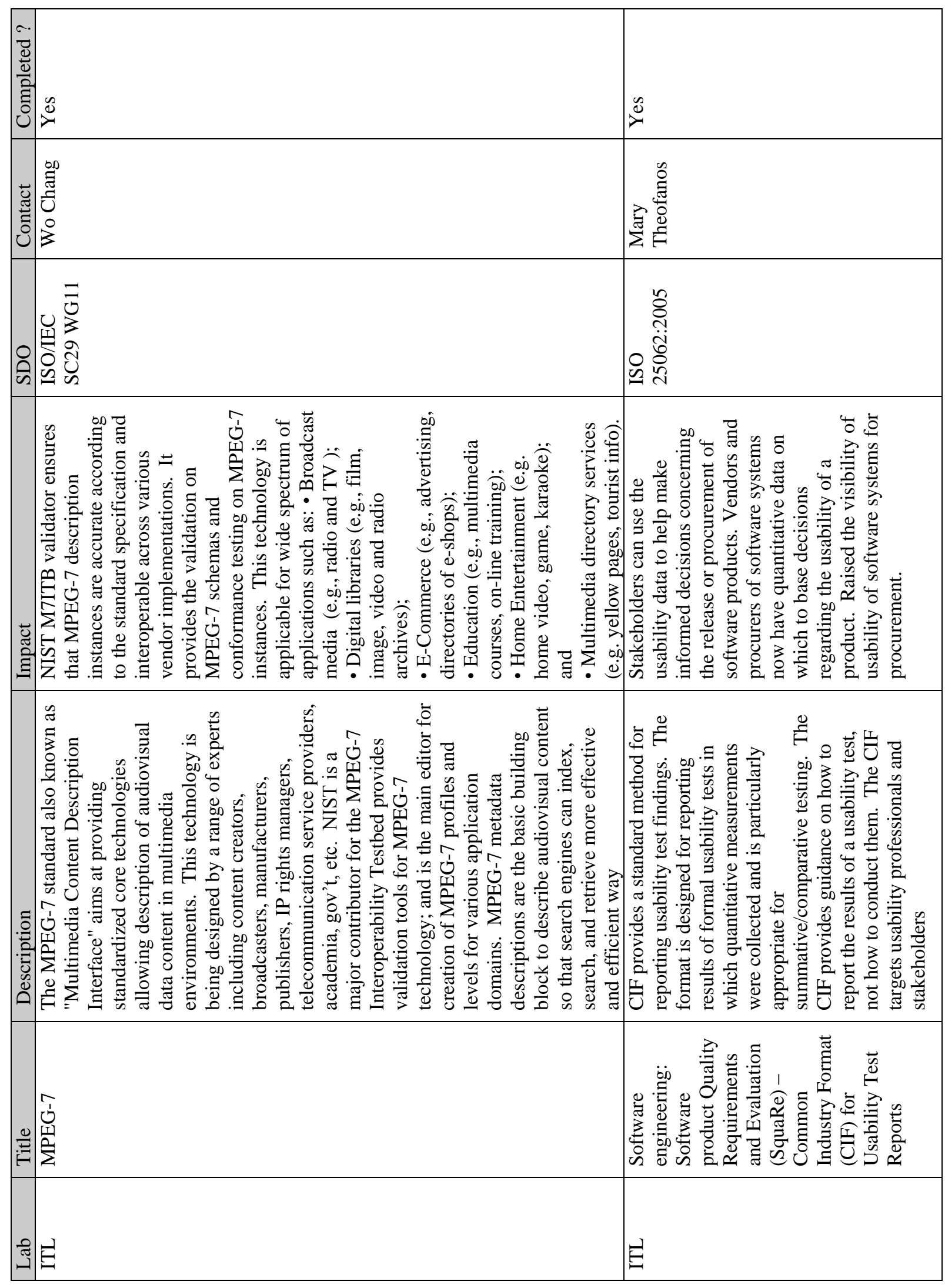




\begin{tabular}{|c|c|c|}
\hline 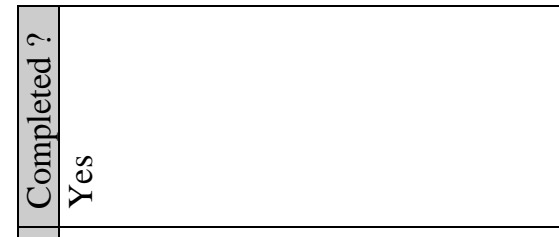 & 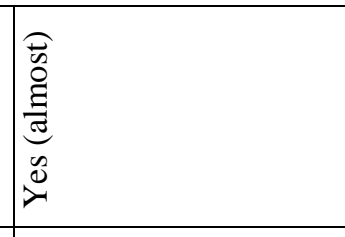 & $\AA$ \\
\hline 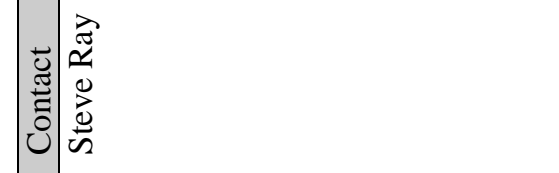 & 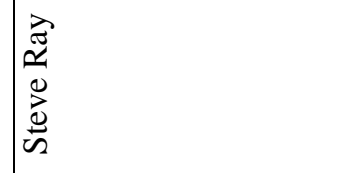 & 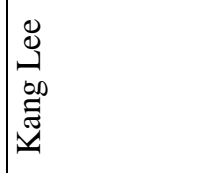 \\
\hline 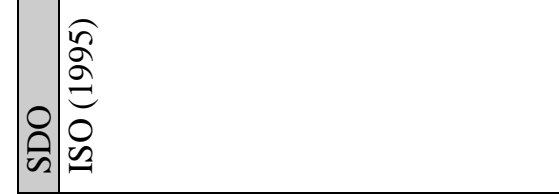 & O' & 婳 \\
\hline 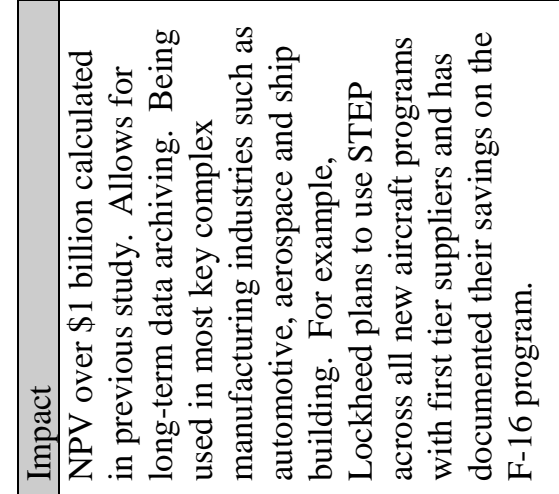 & 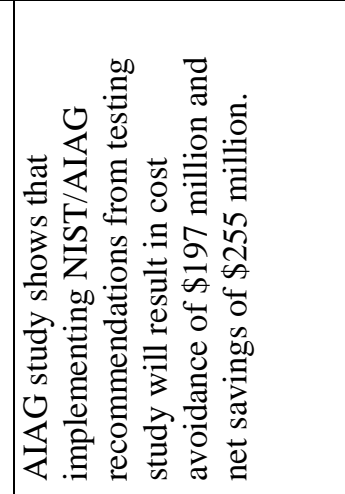 & 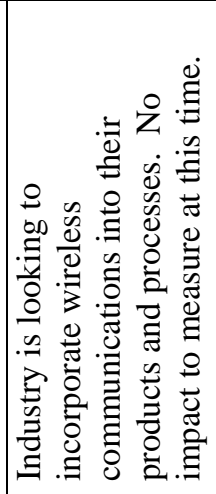 \\
\hline 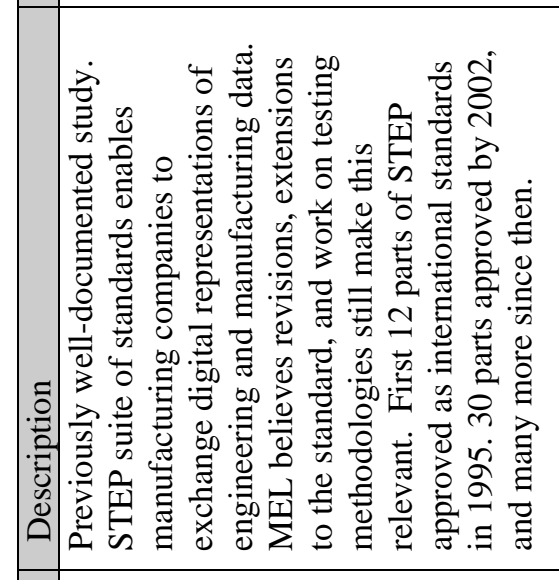 & 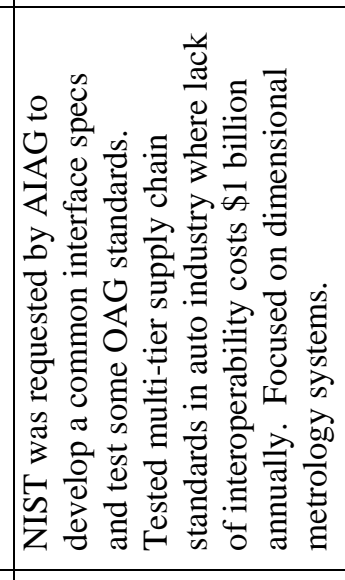 & 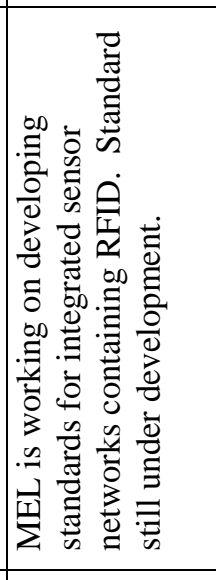 \\
\hline 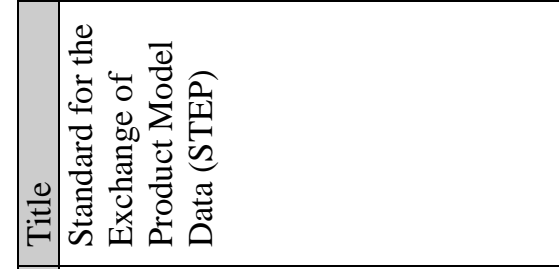 & 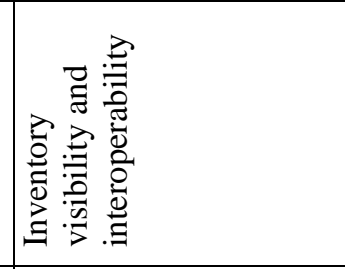 & 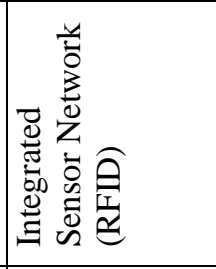 \\
\hline 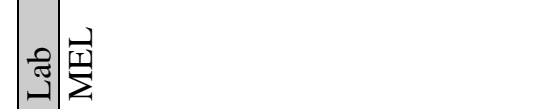 & $\frac{\overrightarrow{⿴ 囗 十}}{2}$ & $\overrightarrow{\vec{\partial}}$ \\
\hline
\end{tabular}




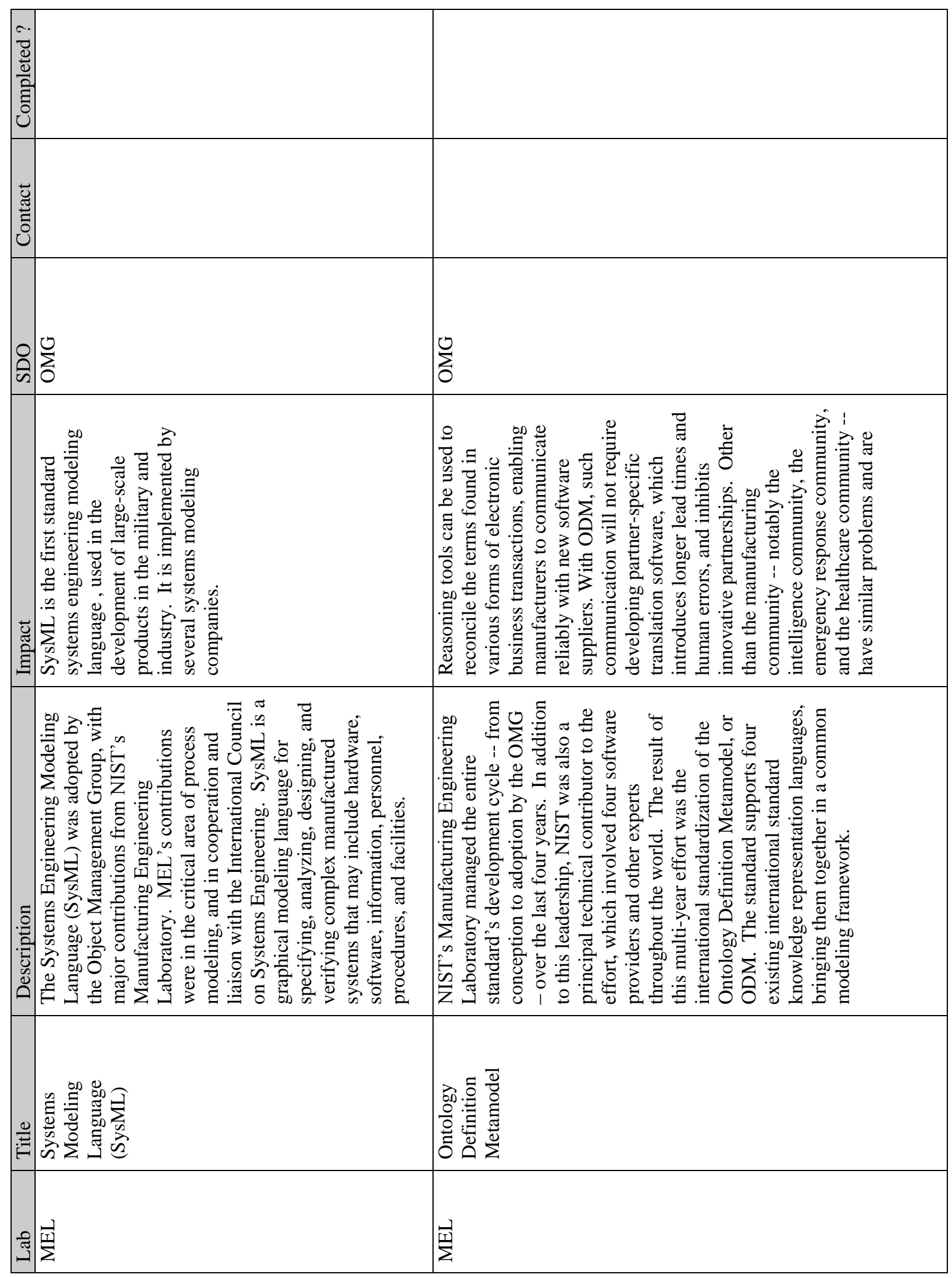




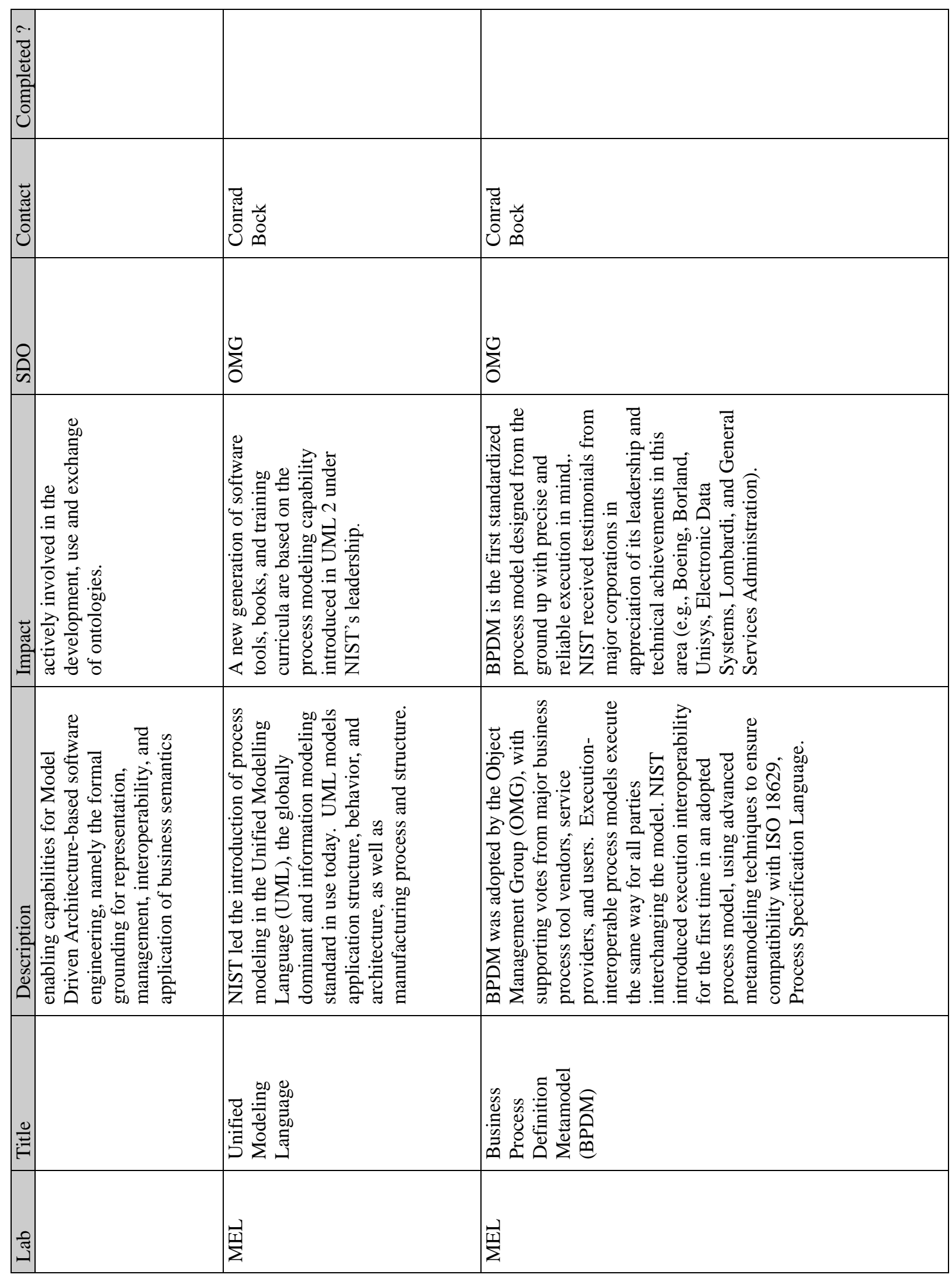




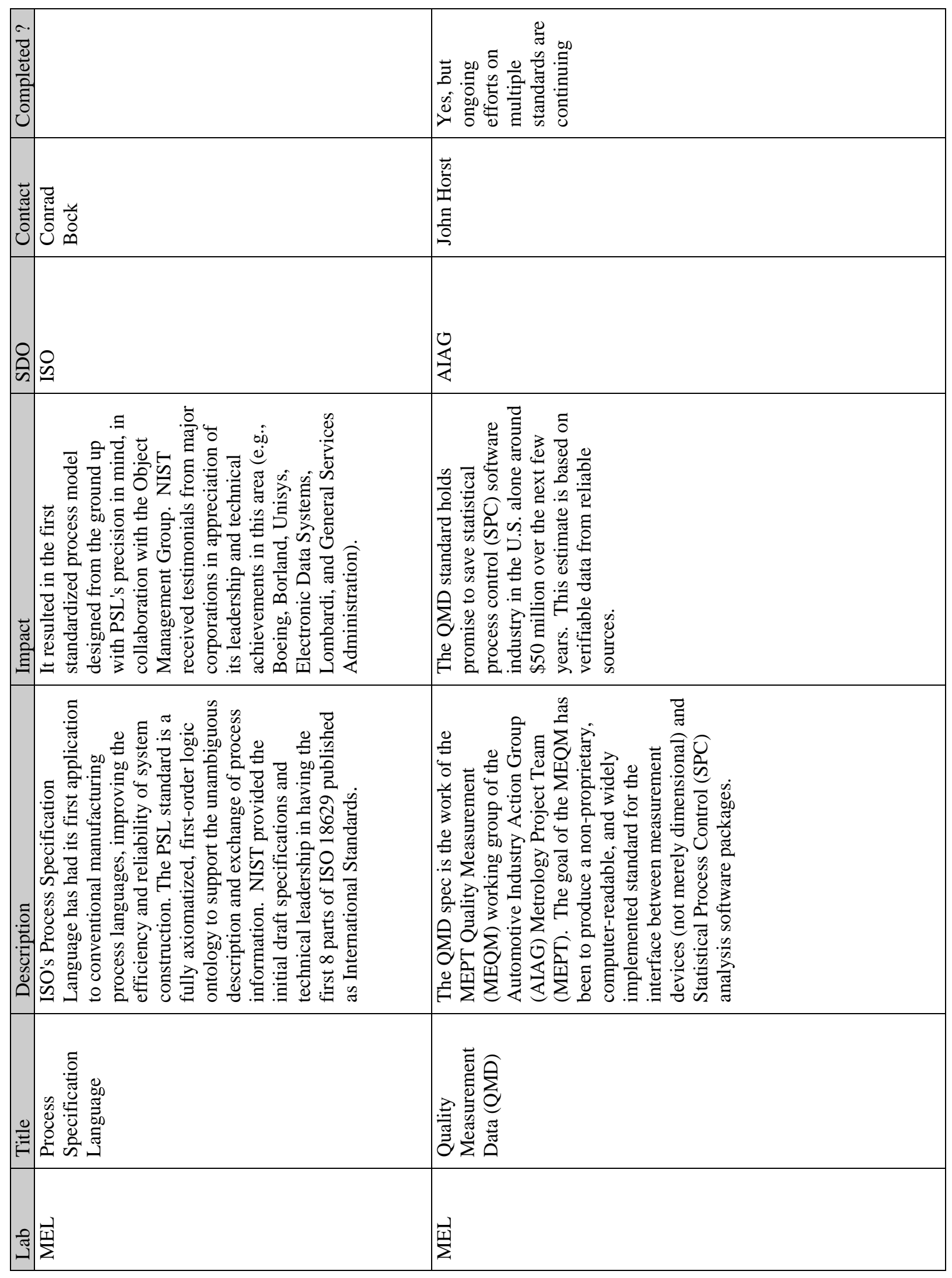




\begin{tabular}{|c|c|c|}
\hline 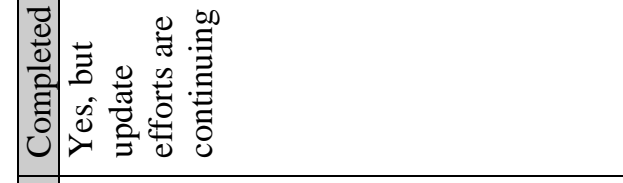 & 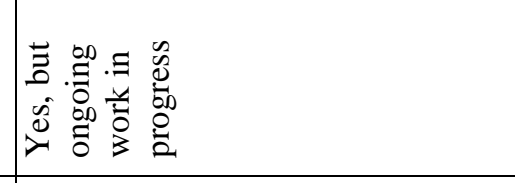 & 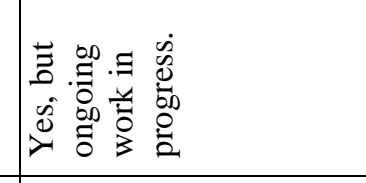 \\
\hline 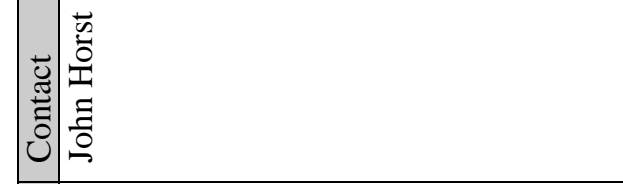 & 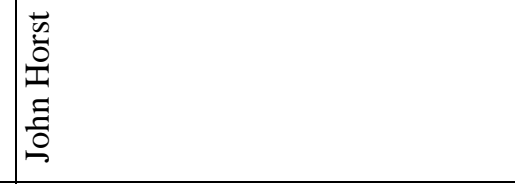 & 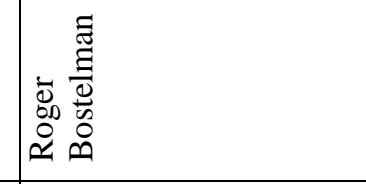 \\
\hline 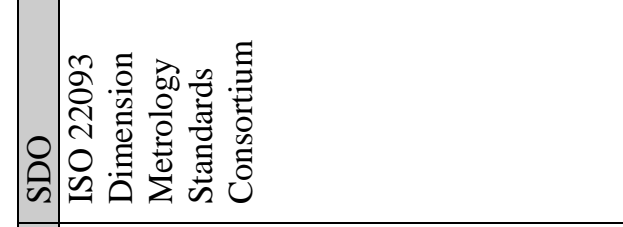 & 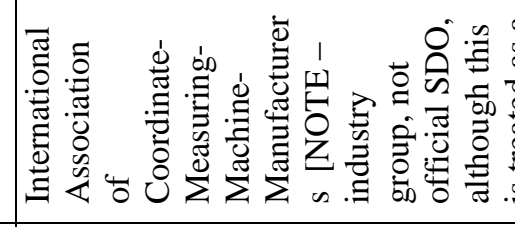 & تصأ \\
\hline 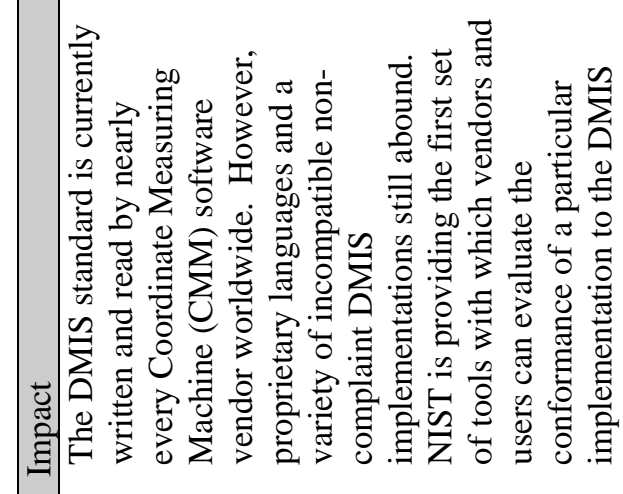 & 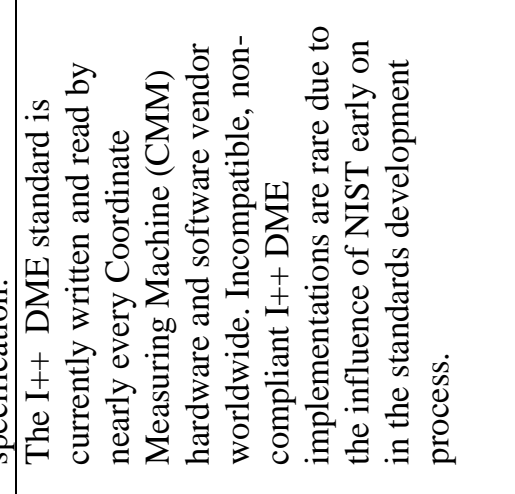 & 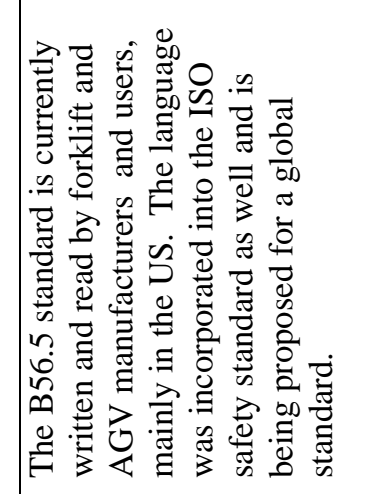 \\
\hline 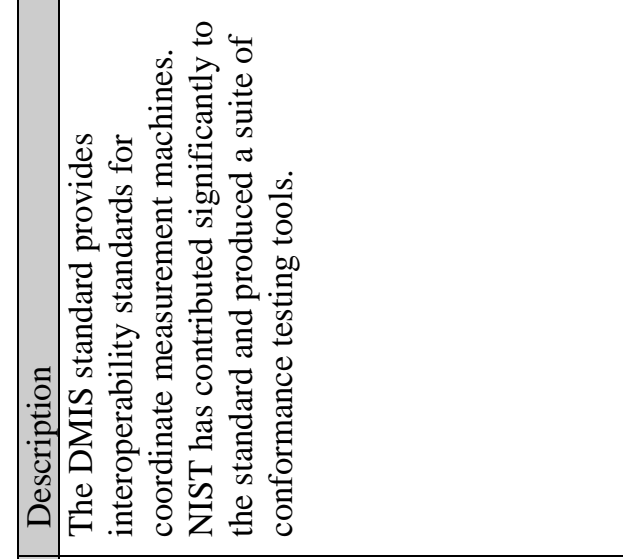 & 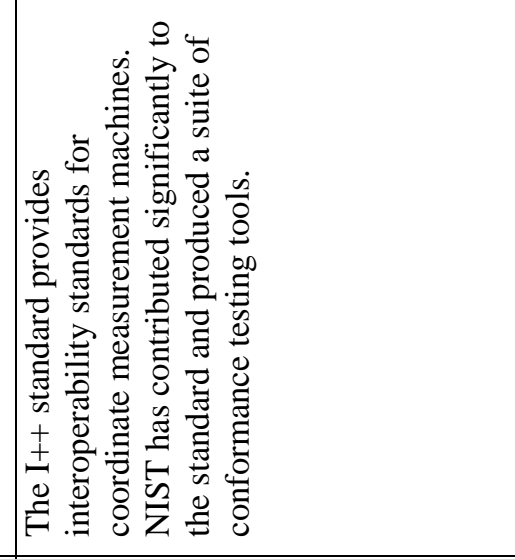 & 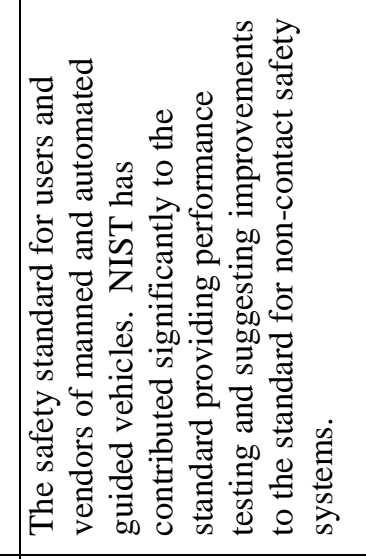 \\
\hline 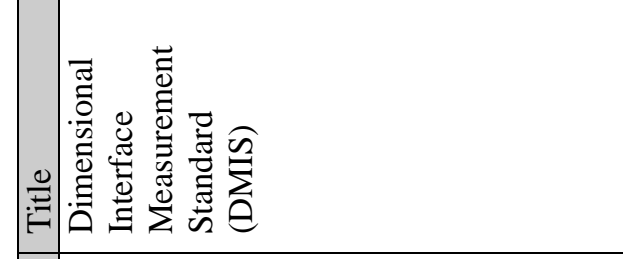 & 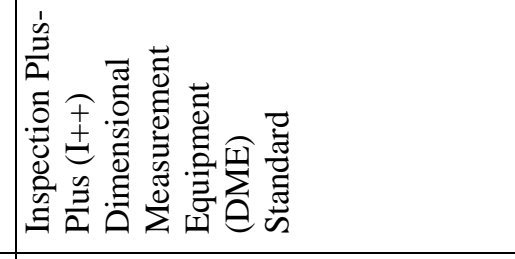 & 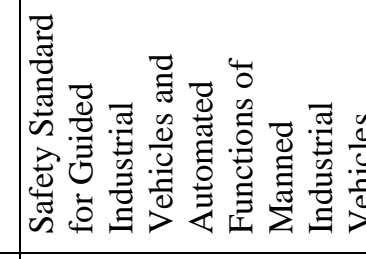 \\
\hline 욜 & 要 & $\overline{\frac{1}{2}}$ \\
\hline
\end{tabular}




\begin{tabular}{|c|c|c|}
\hline 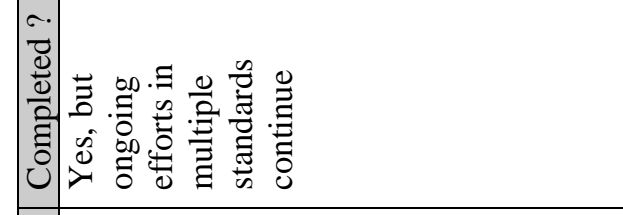 & 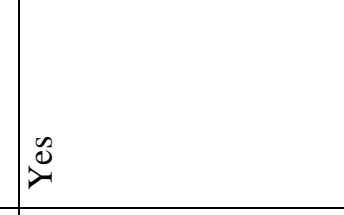 & 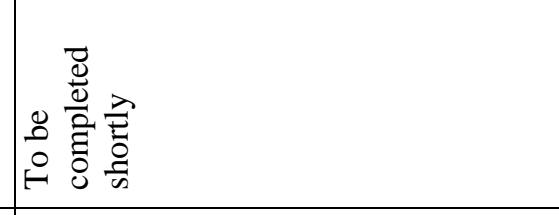 \\
\hline 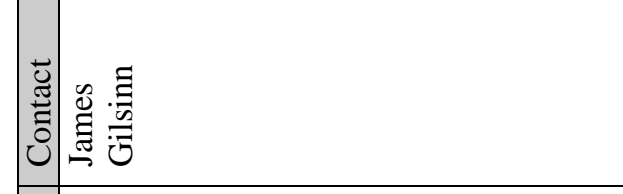 & 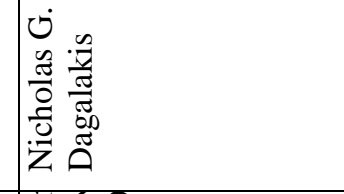 & 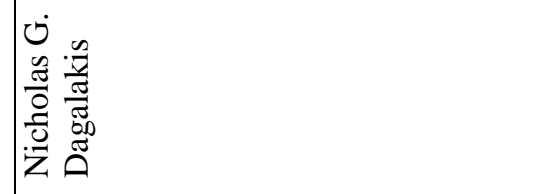 \\
\hline 总 & 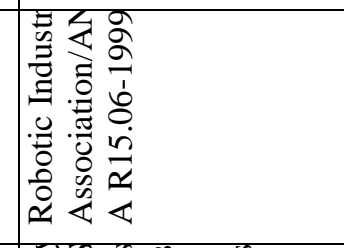 & 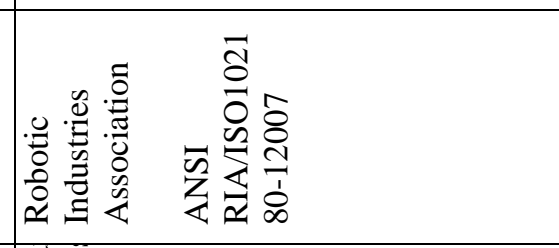 \\
\hline 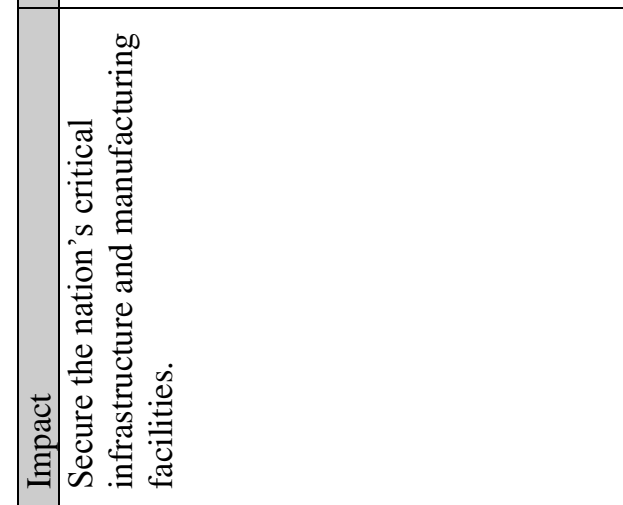 & 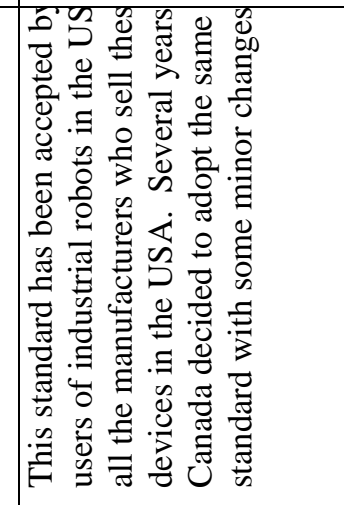 & 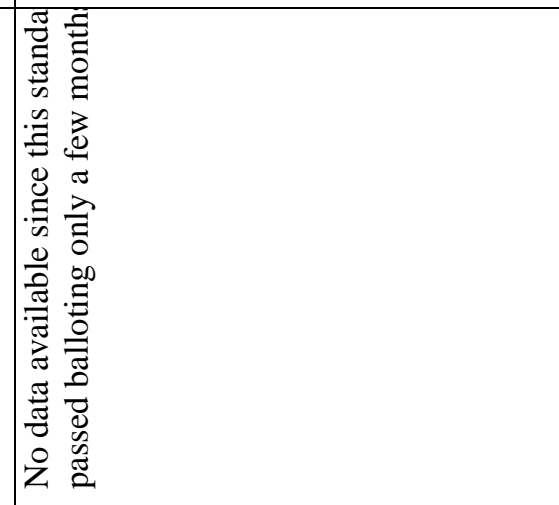 \\
\hline 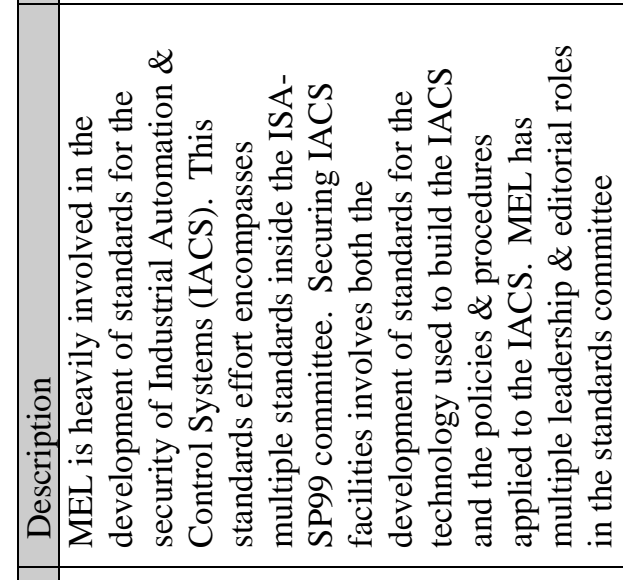 & 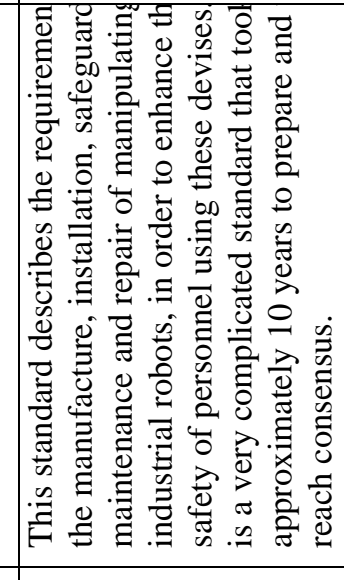 & 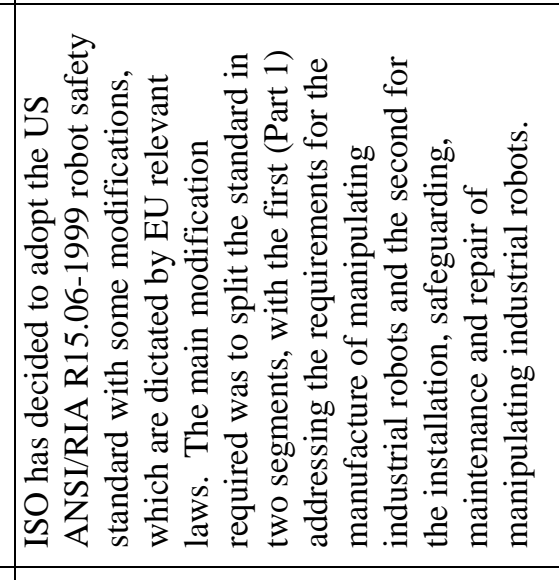 \\
\hline 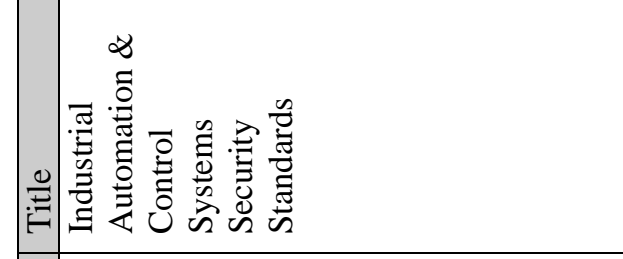 & 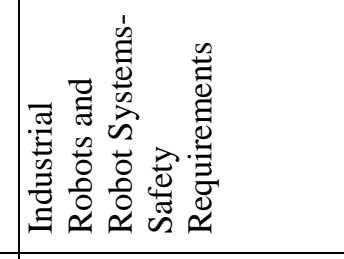 & 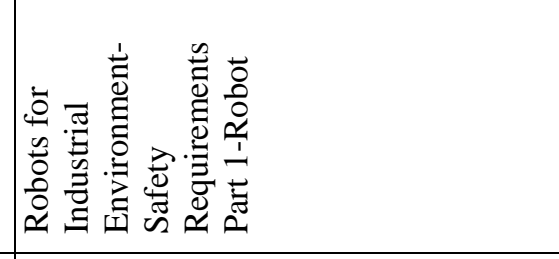 \\
\hline 雱 & 芝 & 医 \\
\hline
\end{tabular}




\begin{tabular}{|c|c|c|c|c|}
\hline 完 & 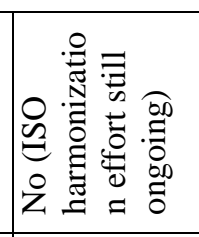 & $\Phi$, & $\overbrace{x \rightarrow}^{\infty}$ & 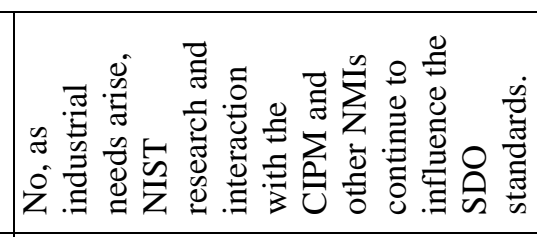 \\
\hline 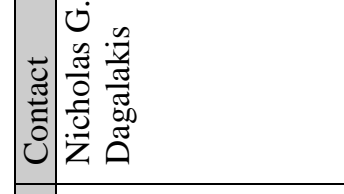 & 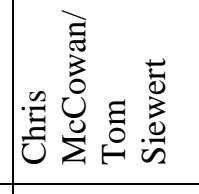 & 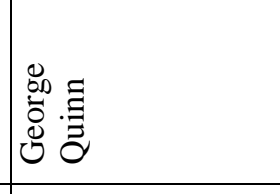 & 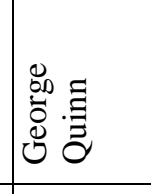 & 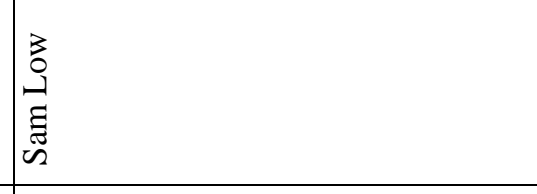 \\
\hline & 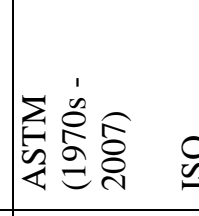 & 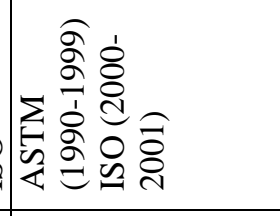 & 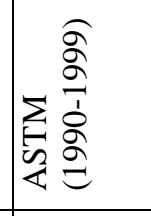 & 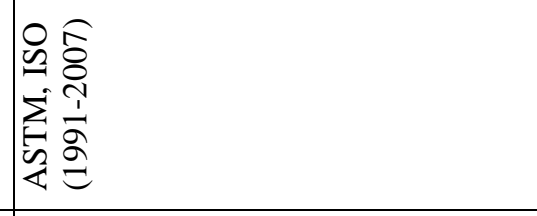 \\
\hline 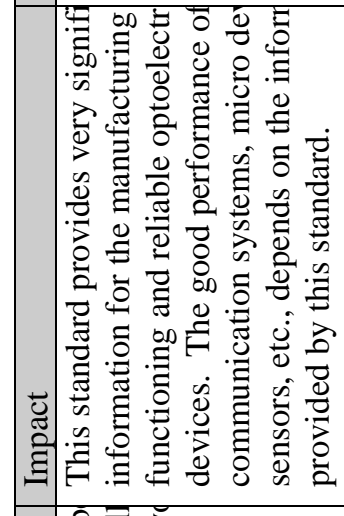 & 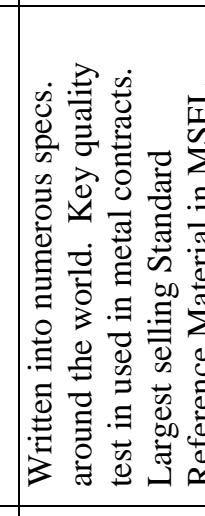 & 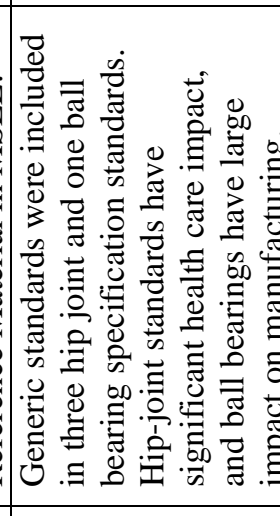 & 5 & 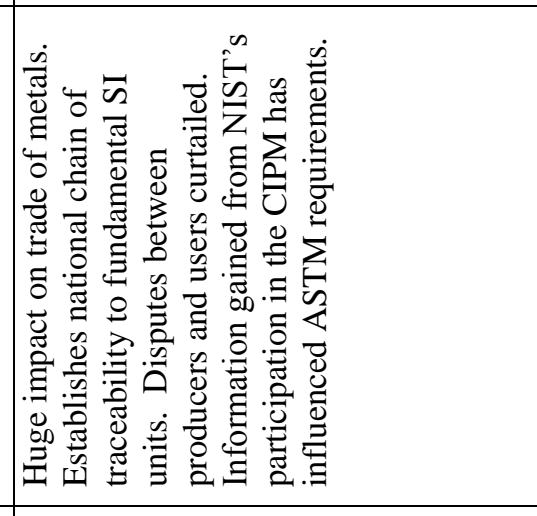 \\
\hline 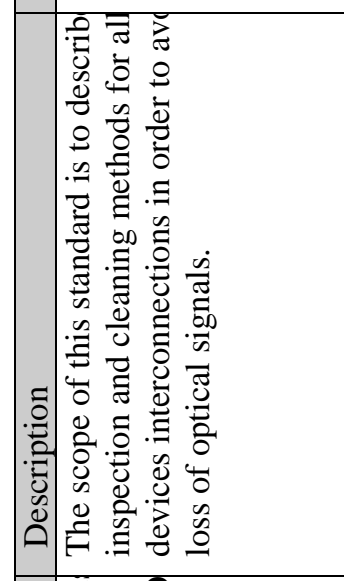 & 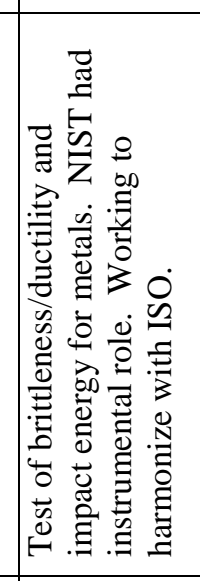 & 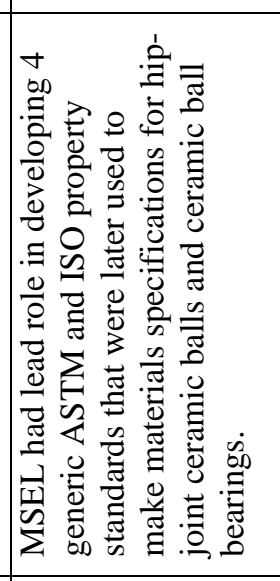 & 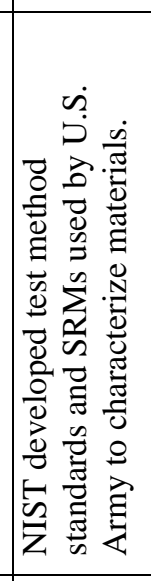 & 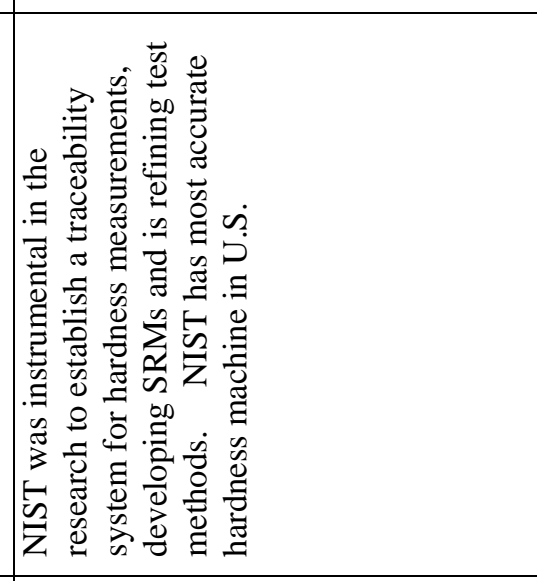 \\
\hline 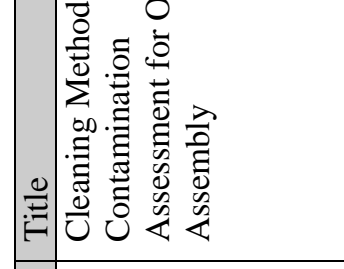 & 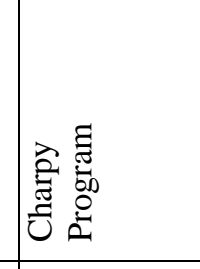 & 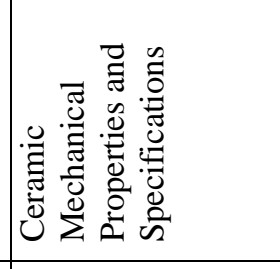 & 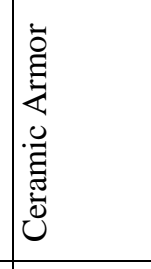 & 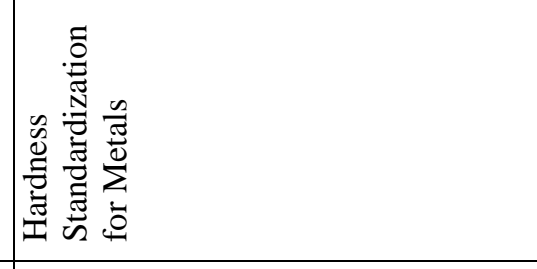 \\
\hline$\Xi \Sigma$ & $\frac{\bar{n}}{2}$ & $\frac{\vec{v}}{\Sigma}$ & $\frac{\sqrt[n]{2}}{2}$ & 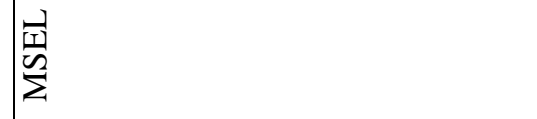 \\
\hline
\end{tabular}




\begin{tabular}{|c|c|c|}
\hline 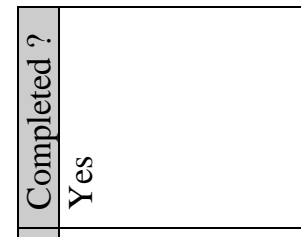 & \multicolumn{2}{|c|}{ 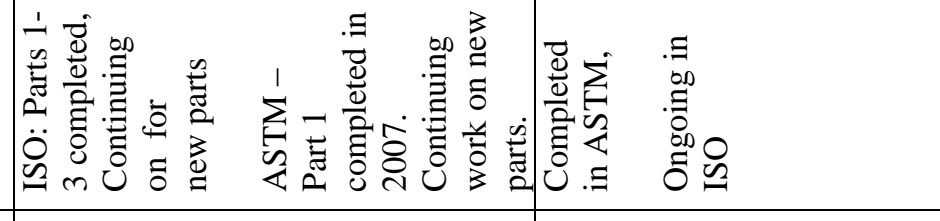 } \\
\hline 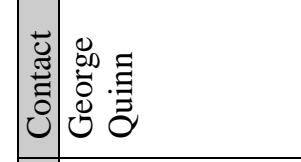 & 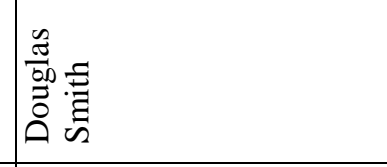 & 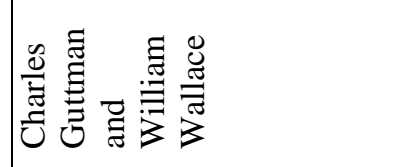 \\
\hline 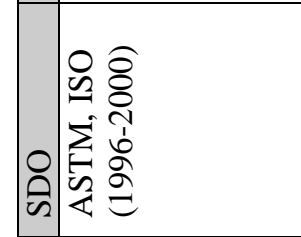 & 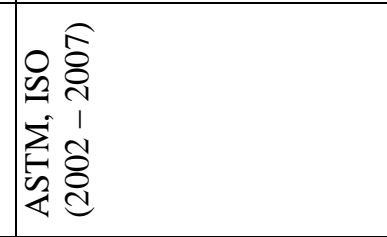 & 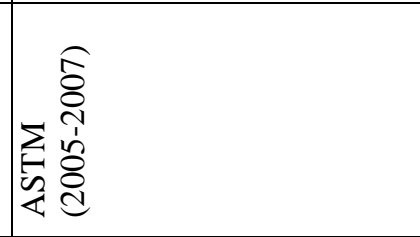 \\
\hline 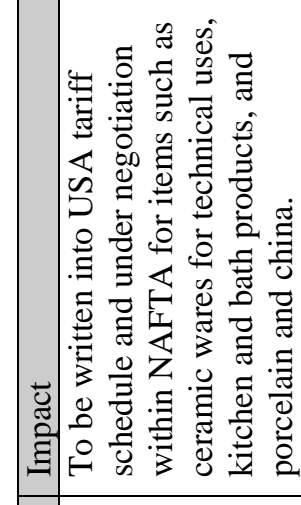 & 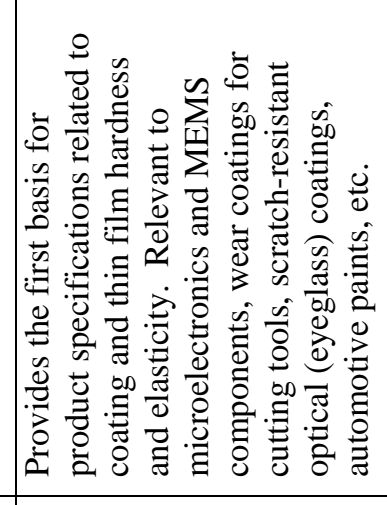 & 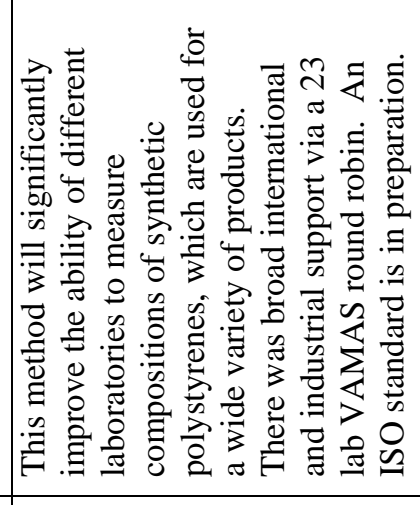 \\
\hline 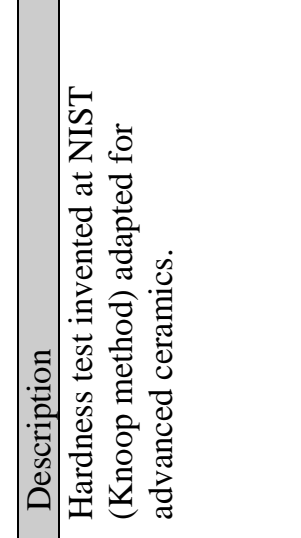 & 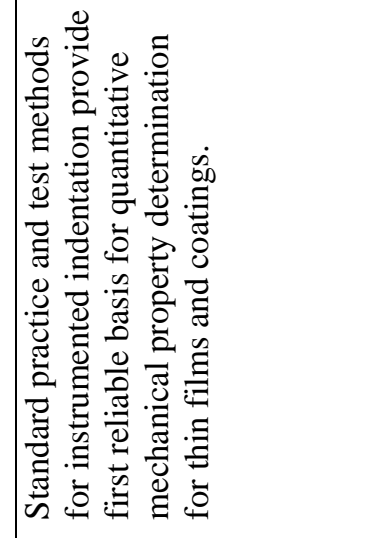 & 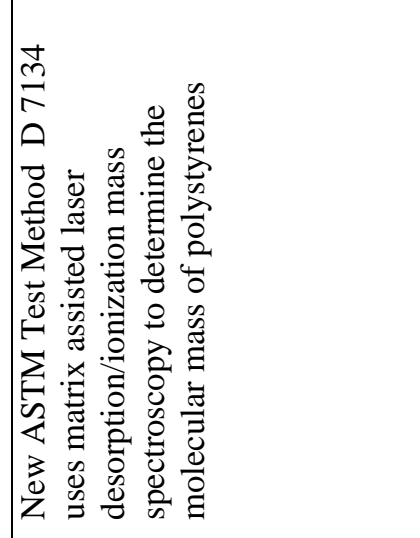 \\
\hline 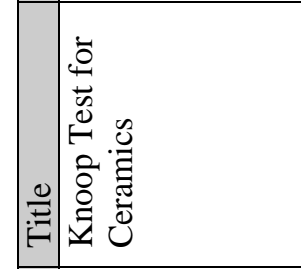 & 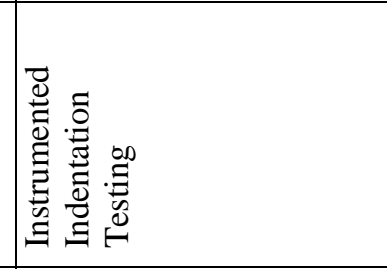 & 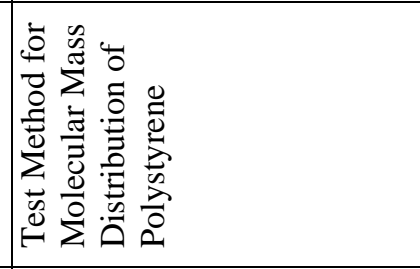 \\
\hline 思楞 & 或 & $\begin{array}{l}\sqrt{1} \\
\frac{2}{2}\end{array}$ \\
\hline
\end{tabular}




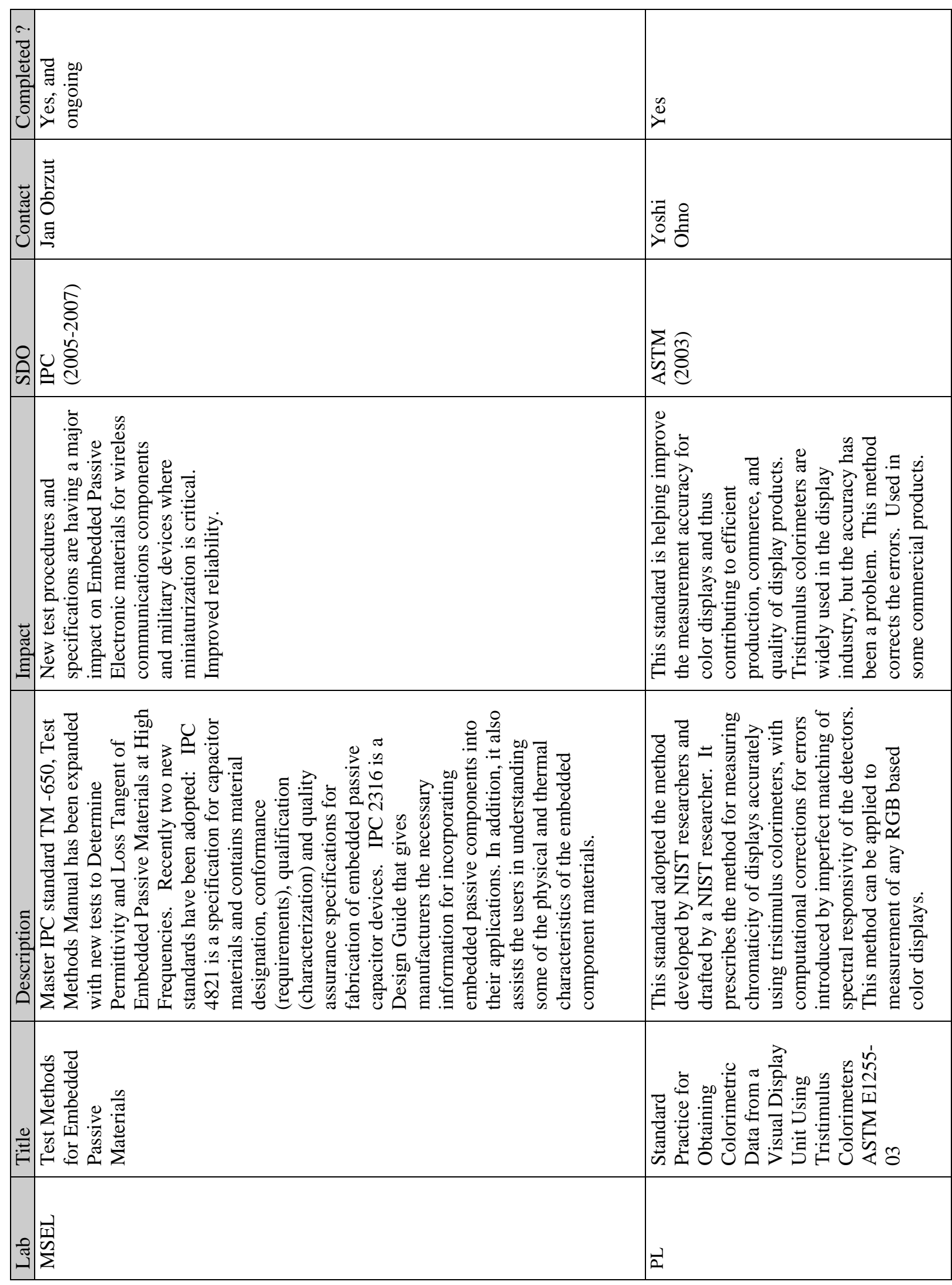




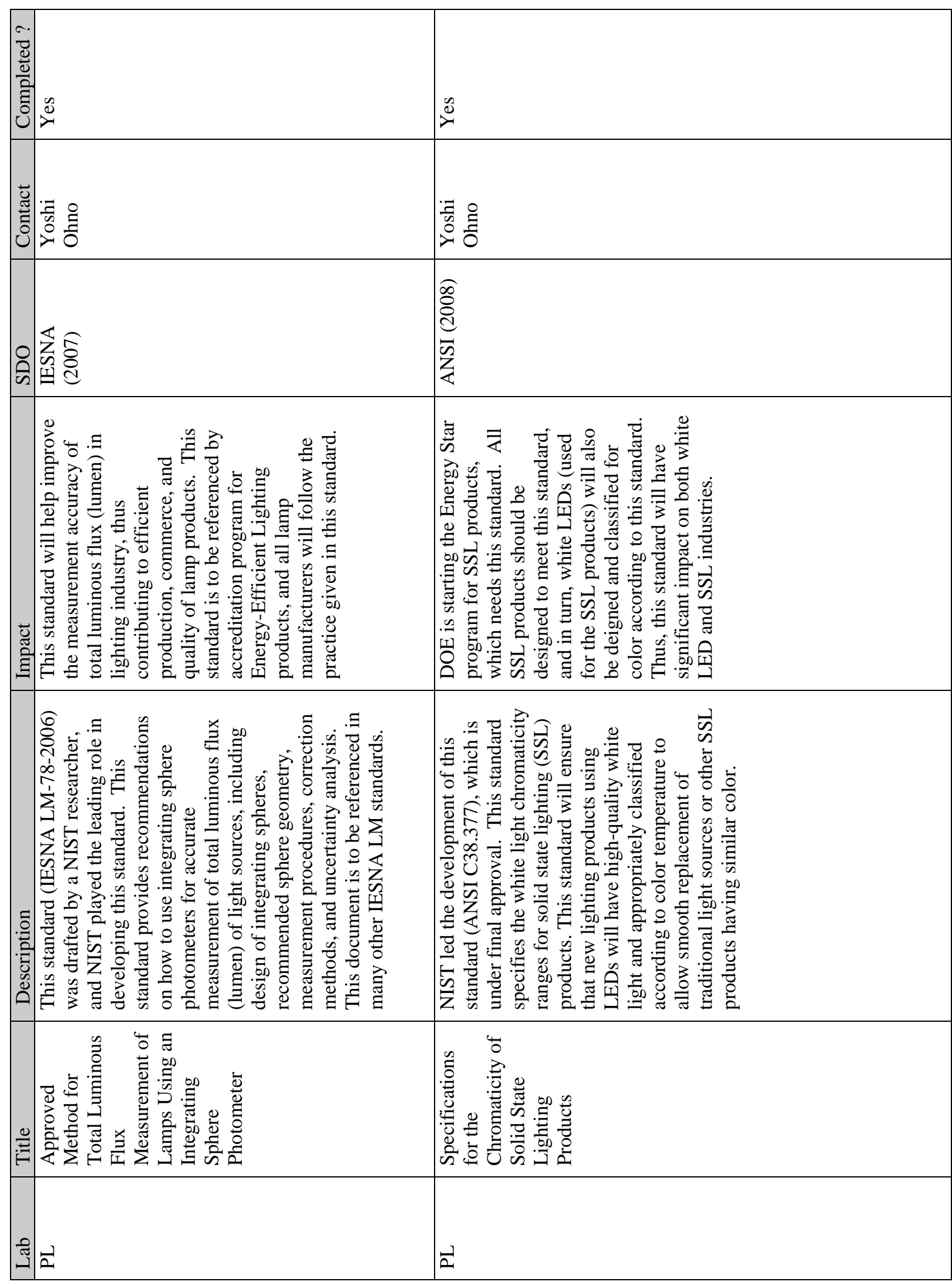




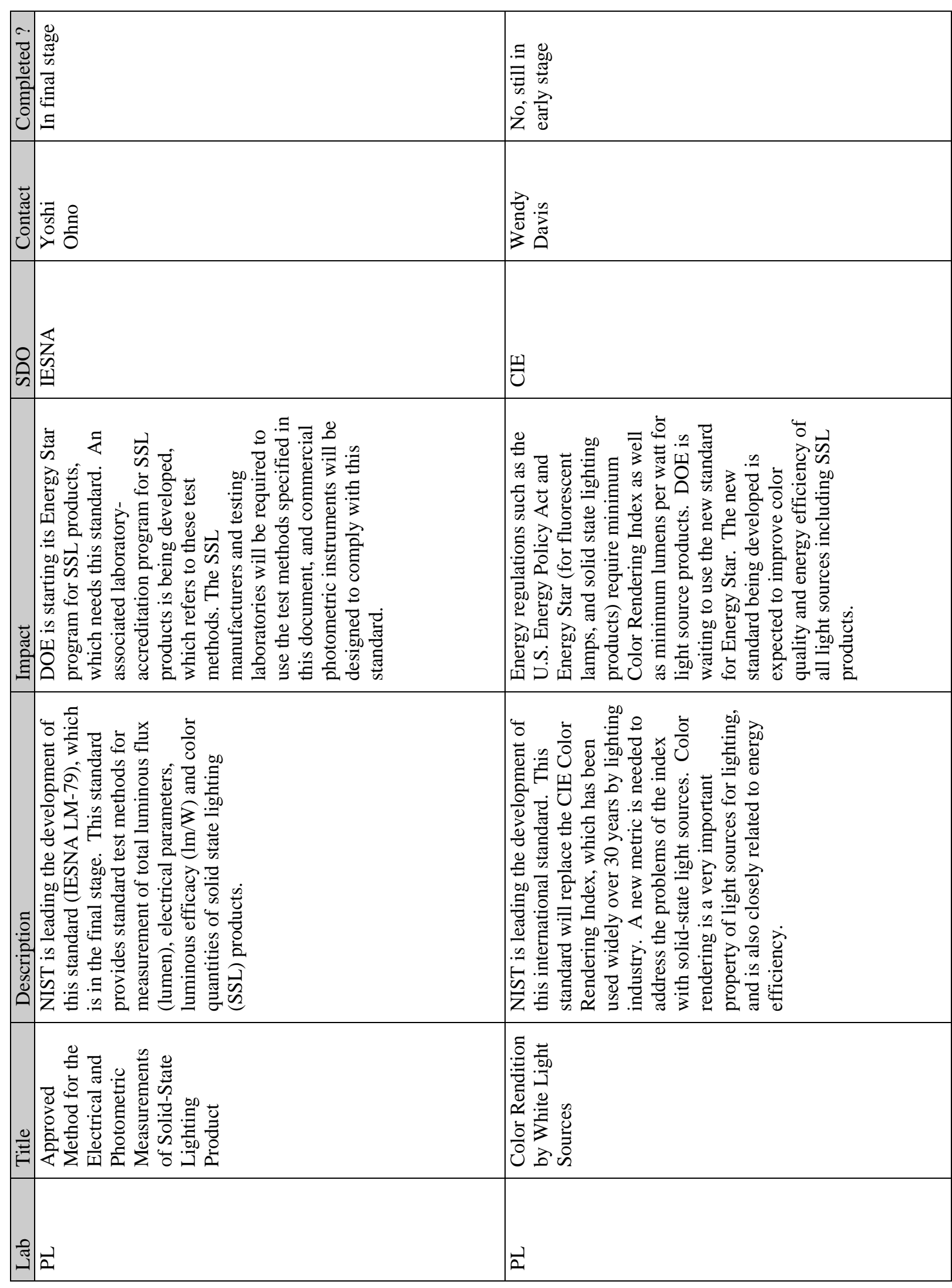




\begin{tabular}{|c|c|c|}
\hline 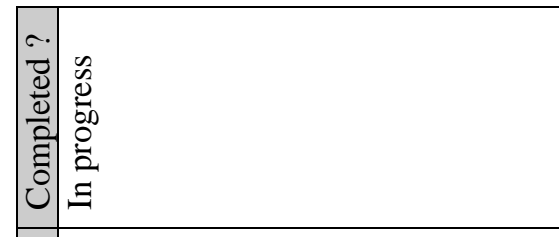 & 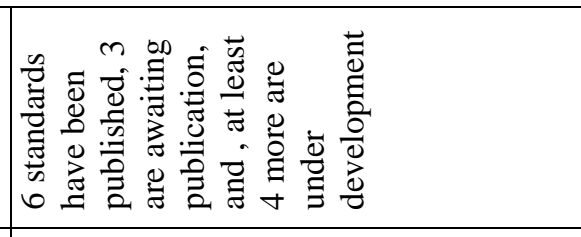 & 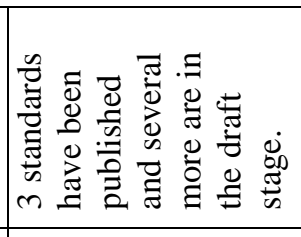 \\
\hline 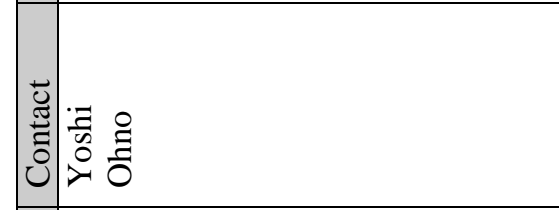 & 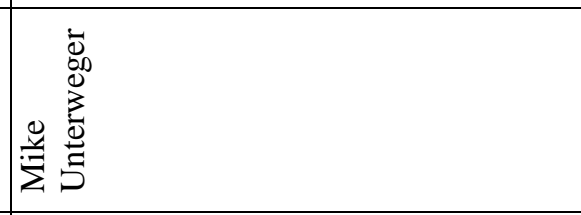 & 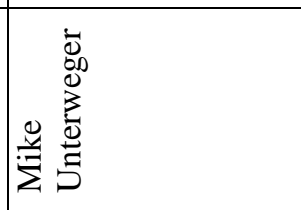 \\
\hline & 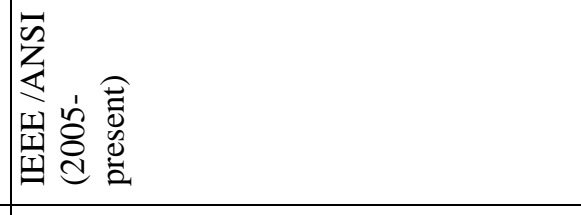 & 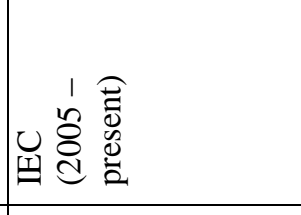 \\
\hline 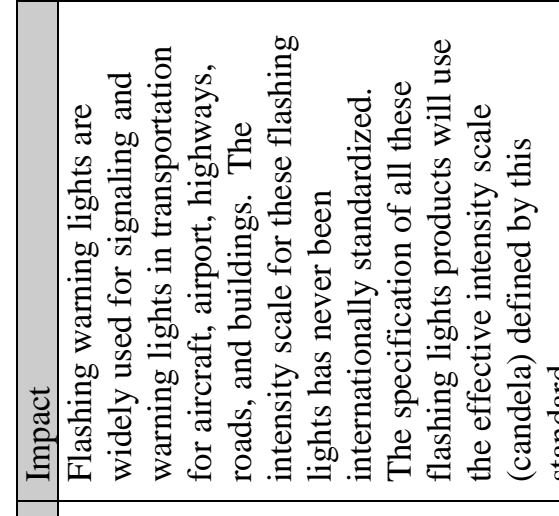 & 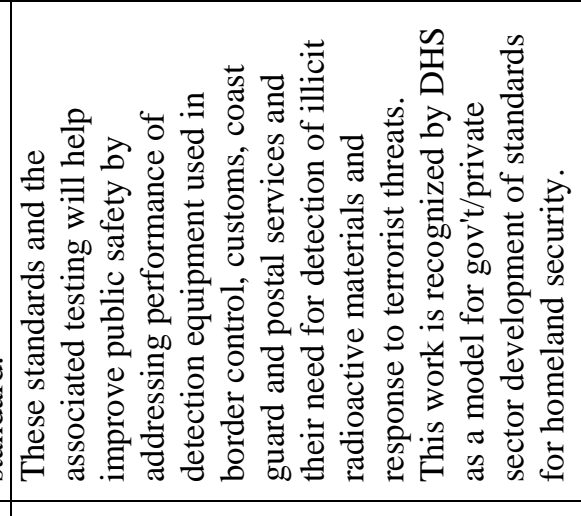 & 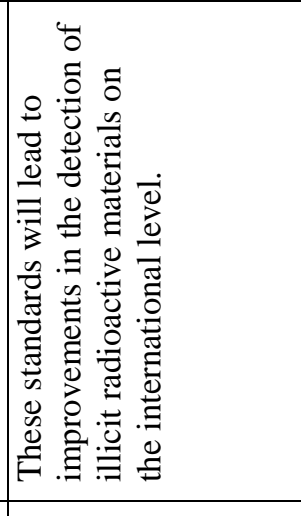 \\
\hline 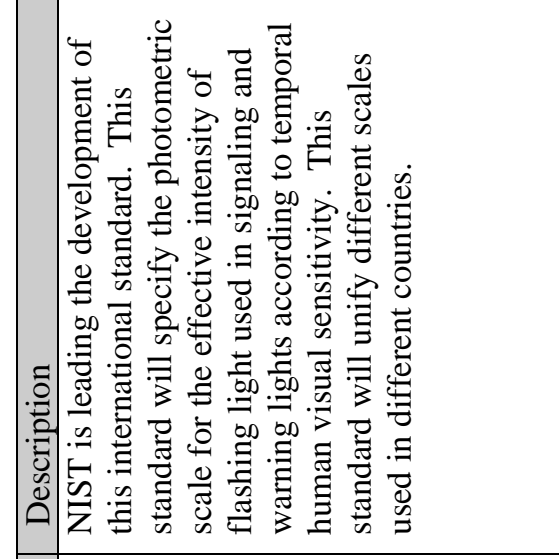 & 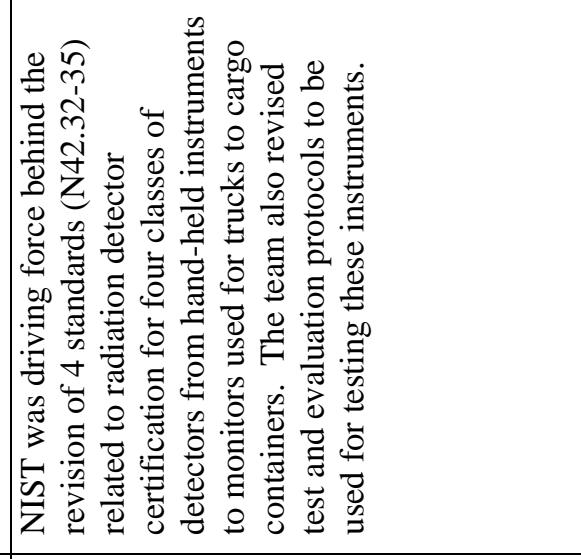 & 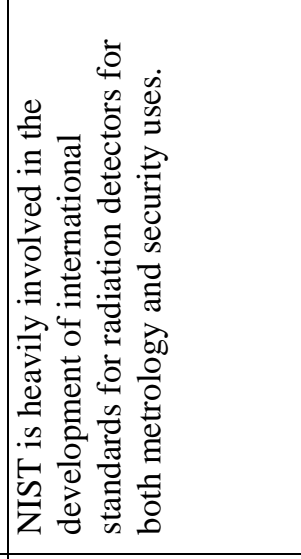 \\
\hline 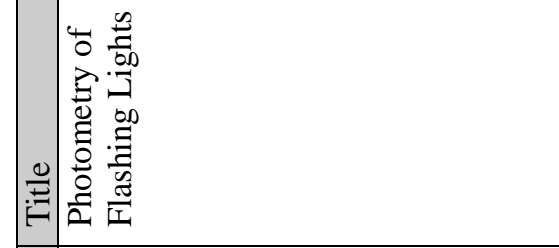 & 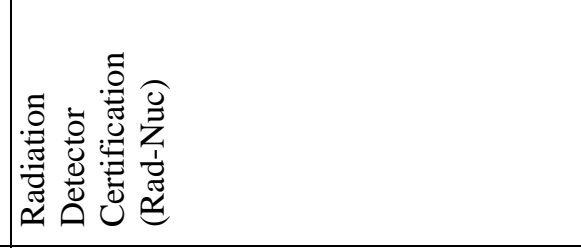 & 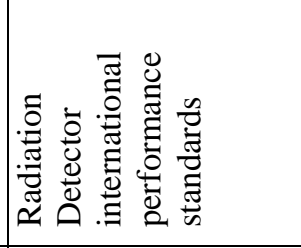 \\
\hline Эّ ఏ & $\vec{a}$ & $\vec{\partial}$ \\
\hline
\end{tabular}




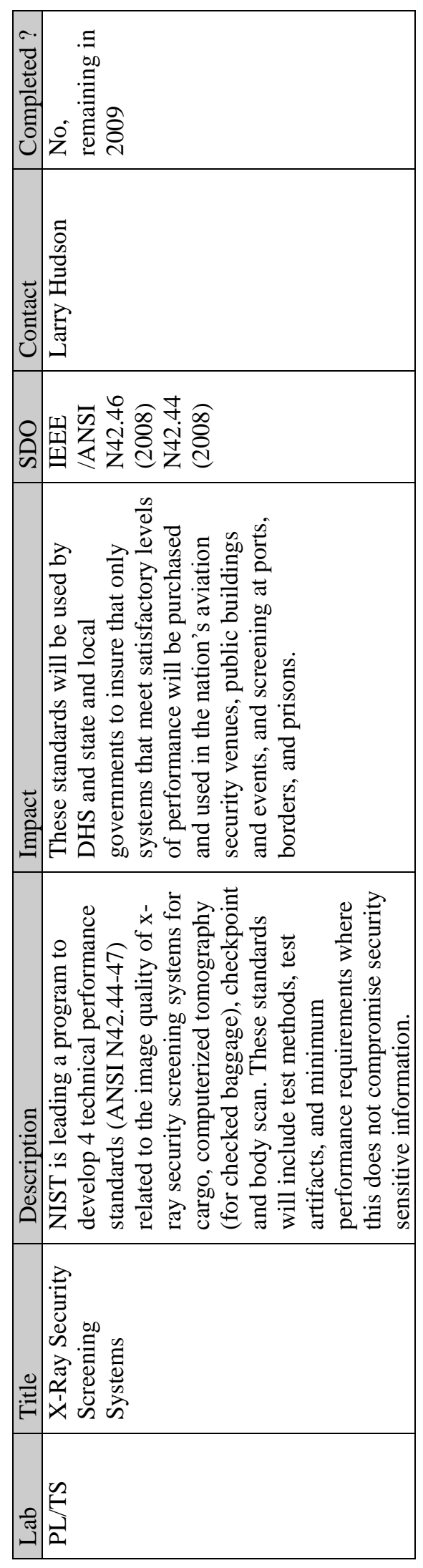




\section{ENDNOTES}

${ }^{1}$ It is possible that in some instances a narrower scope might actually serve the market better, but only 4 percent of the respondents indicated that NIST's involvement narrowed the scope of the standard.

${ }^{2}$ Link and Scott distinguish three different approaches to evaluating economic impact: the counterfactual approach, the Grilliches/Mansfield approach, and the spillover approach. The counterfactual approach appears more conservative, in the sense that it accounts for first-order net benefits that accrue to NIST's unique contributions. The availability of new products and services suggests second-order benefits and the application of the Grilliches/Mansfield approach to economic impact evaluation. See, A.N. Link and J.T. Scott, Evaluating Public Research Institutions, (Routledge) 2005, pp. 103-105.

${ }^{3}$ Gregory Tassey, The Technology Imperative, Edward Elgar 2007; The Roles and Economic Impacts of Technology Infrastructure (version 3), 2008; and "The disaggregated technology production function: A new model of university and corporate research," Research Policy, 34 (2005) 287-303.

${ }^{4}$ See, for example, Trade and the impact of innovations and standards: the case of Germany and the UK, Knut Blind and Andre Jungmittag, Applied Economics, 2005, vol. 37, issue 12, pages 1385-1398; Knut

Blind, The Economics of Standards: Theory, Evidence, Policy, (publisher)

${ }^{5}$ The ISO is undertaking a study to develop a general methodology for assessing the impact of documentary standards.

${ }^{6}$ David Leech is a Senior Analyst with the Industry \& Technology Evaluation Intelligence Group (TASC) of Northrop Grumman Corporation

${ }^{7}$ Joanne Henson was a Guest Researcher at NIST during 2008.

${ }^{8}$ Erik Puskar, Selected Impacts of Documentary Standards Supported by NIST, NISTIR 7398, March 2007.

${ }^{9}$ Our approach is adaptation of an approach to strategic assessment developed Clayton M. Christensen, Paul Carlile, and David Sundahl, The Process of Theory-Building, (Harvard Business School Working Paper 02-016), 2002; Clayton M.Christensen and Michael E. Raynor, "Why Hard-Nosed Executives Should Care About Management Theory," Harvard Business Review, September 2003, pp. 67- 74; and, Paul R. Carlile and Clayton M. Christensen, The Cycles of Theory Building in Management Research, (Harvard Business School Working Paper 05-057), 2005.

${ }^{10}$ For example, see, Tassey, op.cit., 2005; and the "U.S. Measurement System" framework described in, Dennis Swyt, An Assessment of the United States Measurement System, NIST Special Publication 1048, February, 2007. The United States Measurement System (USMS) is described as an essential infrastructure woven into the fabric of our economy by the organizing activities of private sector standards developing organizations (SDOs), supported by NIST's participation in these SDOs and its measurement science and technology development activities. From an economic perspective, these private and public activities mitigate the measurement risks and costs associated with product development, production, marketing, and use.

${ }^{11}$ In the context of the proposed strategic assessment development process, case studies are understood not simply as stand-alone vignettes but rather as means of building towards the kind of rich analysis capability that allows the case study \& lessons learned step to transition the strategic assessment step. See, Robert Yin, Case Study Research Design, $4^{\text {th }}$ edition, Sage Publications, 2005 [CHECK CITATION]; and Christenson, et al, op. cit., 2002, 2003, 2005.

${ }^{12}$ See, "Essays in Honor of Edwin Mansfield," The Journal of Technology Transfer, Vol. 30, Nos. 1/2, January 2005; Cite a compilation of ATP economic assessments; Tassey, op. cit., 2008.

${ }^{13}$ See, John T. Scott, "Financing and Leveraging Public/Private Partnerships: The Hurdle-Lowering Auction," STI Review, No. 23, 1998, pp.67-84.

${ }^{14}$ See, Ruegg, Rosalie and Irwin Feller, "A Toolkit for Evaluating Public R\&D Investment", NIST, July 2003, p. 34

${ }^{15}$ Nanotechnology (environment, health and safety measures); Biosciences; Leap-ahead security technologies; Optical communications and computing; Neutron research expansion; Quantum science, Enabling nanotechnology; Climate change science program; Measurement science; Earthquake hazards reduction; Disaster resilient structures; Hydrogen as fuel; Biometrics; Supply chain integration.

${ }^{16}$ The fraction of value added from new products or services depends on the gap in the timing or scope of the standards that can be attributed to NIST's participation.

${ }^{17}$ It is possible that in some instances a narrower scope might actually serve the market better, but only 4 percent of the respondents indicated that NIST's involvement narrowed the scope of the standard.

${ }^{18}$ As with the other intermediate indicators, we are only claiming that evidence of industry group or consortium involvement is suggestive of significant benefits. Significant economic impact is a much stronger claim requiring significant net benefits.

${ }^{19}$ Link and Scott distinguish three different approaches to evaluating economic impact: the counterfactual approach, the Grilliches/Mansfield approach, and the spillover approach. The counterfactual approach 
appears more conservative, in the sense that it accounts for first-order net benefits that accrue to NIST's unique contributions. The availability of new products and services suggests second-order benefits and the application of the Grilliches/Mansfield approach to economic impact evaluation. See, A.N. Link and J.T. Scott, Evaluating Public Research Institutions, (Routledge) 2005, pp. 103-105.

${ }^{20}$ Methods for Assessing the Economic Impacts of Government R\&D (Planning Report 03-1), NIST, September 2003 